Erster Beratungsgegenstand:

\title{
Das Gesetz als Norm und Maßnahme
}

\author{
1. Bericht von Professor Dr. Christian-Friedrich Menger, \\ Speyer.
}

I.

Der heutige Beratungsgegenstand stellt - wenn ich das Thema richtig interpretiere - den Berichterstatter vor zwei Aufgaben: Eine Bestandsaufnahme dessen zu geben, was dem Staatsbürger im Gewande des Gesetzes, Gehorsam erheischend, gegenübertritt; und eine kritische Würdigung der Art und Weise vorzunehmen, wie das Gesetz zum Mittel staatlicher Willensbetätigung gemacht wird. Allein es wäre ein vergebliches Bemühen, in einer kurzen Stunde den ganzen Bereich der Gesetzgebung abschreiten zu wollen. Erlauben Sie mir daher bitte, meine tberlegungen auf den atypischen Fall, die sog. Maßnahmegesetzgebung, zu konzentrieren und erst von daher jeweils auf den Normalfall zurückzuschließen.

Zunächst ist davon auszugehen, daß es weder einen auch nur für die ganze Neuzeit geltenden einheitlichen Gesetzesbegriff gibt, noch eine einheitliche Vorstellung von den Aufgaben der Gesetzgebung. Beide sind zeitbedingt, und es ist gefährlich, die Ansichten der deutschen spätkonstitutionellen Staatslehre ohne weiteres in andere Zeiten hineinzuprojizieren ${ }^{1}$ ).

Es wäre unter diesen Umständen eine reizvolle Aufgabe, die Untersuchung auf die verschiedenen Verfassungssysteme mindestens des modernen kontinentaleuropäischen Staates auszudehnen und dabei die langsame Wandlung des rechtsfindenden "Jurisdiktionsstaates" zum gestaltenden "Gesetzgebungsstaat" zu verfolgen. Die zur Verfügung stehende Zeit gebietet jedoch eine Beschränkung auf das hic et nunc Wesentliche. Ich werde mich daher ausschließlich mit der Rechtslage in der Bundes-

1) Vgl. dazu z. B. Hermann H e ll e r : Der Begriff des Gesetzes in der Reichsverfassung, VVDStRL 4 (1928), S. 98 ff. (101 ff.), Ulrich Scheuner: Ausländische Erfahrungen zum Problem der Ubertragung rechtsetzenider Gewalt (Die Ubertragung rechtsetzender Gewalt im Rechtsstaat, 1952, S. 118 ff.) S. 135, und De n s. : Der Bereich der Regierung (Rechtsprobleme in Staat und Kirche, Festgabe für Rudolf Smend, 1:952, S. 251 ff.), S. 262: 
republik Deutschland beschäftigen und nur insoweit zeitlich und räumlich darüber hinausgreifen, als es zum Verständnis der derzeitigen Situation erforderlich ist.

Als erstes möchte ich - gleichsam als Arbeitshypothesen kurze Umschreibungen der Begriffe "Gesetz", "Norm" und "Maßnahme“ geben, die zu verifizieren dann Aufgabe der weiteren Untersuchung sein wird.

Die Bezeichnungen Gesetz, Norm und Rechtssatz werden in der Rechtswissenschaft häufig synonym gebraucht, zuweilen aber auch scharf geschieden; eine einheitliche Terminologie gibt es nicht ${ }^{2}$ ).

Für diesen Bericht soll als $G$ e s e $t z$ jeder Rechtssatz gelten, der in der verfassungsmäßig für Gesetze vorgeschriebenen Art und Weise zustande gekommen ist; Norm und Maßnahme sollen als theoretisch mögliche Inhalte eines solchen Rechtssatzes Gegenstand der Untersuchung sein $\left.{ }^{3}\right)$.

Im Begriff der Norm, der dem Thema entsprechend auf die Rechtsnorm verengt werden darf $f^{4}$ ), begegnen sich die beiden Elemente des Verhaltensgebotes und des Beurteilungsbzw. Bewertungsmaßstabes ${ }^{5}$ ). Vom Standpunkte eines extremen Rechtspositivismus' aus könnte die nach den Vorschriften der Verfassung ordnungsgemäß gesatzte Rechtsnorm ihrem Adressaten jedes beliebige Verhalten gebieten $\left.{ }^{6}\right)$. Nach

2) Vgl. dazu z. B. H ell e r, VVDStRL 4 S. 99 f, 130, und Karl Friedrichs: Der Allgemeine Teil des Rechts, 1927, S. 24 f. mit eingehenden Angaben aus dem Schrifttum.

3) Schon daraus erhellt, daß der Begriff der Maßnahme i. S. d. $\S 64$ des Gesetzes über das Bundesverfassungsgericht vom 12. März 1951 (BGBl. I S. 243) mit dem Gegenstande dieses Berichts nichts zu tun hat.

4) Dabei sei die große Schwierigkeit einer klaren Abgrenzung der Rechtsnormen von den Religions-, Moral- und Konventionalnormen hier nur angemerkt; vgl. dazu das bei Ilmar T a m $\mathrm{m} \mathrm{lo}$ : Untersuchungen zum Wesen der Rechtsnorm, 1947, S. 55 ff., zusammengestellte Schrifttum.

5) Zur Formalstruktur der Rechtsnorm, die in unserem Zusarmmenhange nicht von Belang ist, vgl. z. B. Walter G. B e c k e r : Die Realität des Rechts, ARSP XL (1952/53), S. $216 \mathrm{ff.}, 375 \mathrm{ff}$., $534 \mathrm{ff}$. (395 ff.), Hans Kels e n: General Theorie of Law and State, 1949, p. 161, und Tamme I o : Rechtsnorm S. $41 \mathrm{f}$.

-) So ausdrüicklich Paul L a ba nid: Das Staatsrecht des Deutschen Reiches, 5. Aufl., 1911-1914, Bd. II S. 63. - Sehr bezeichnend ist auch die Polemik Richard $\mathrm{T}$ h o m a's : Rechtsstaatsidee und Verwaltungsrechtswissenschaft, JböffR IV (1910) S. 196 ff. (200 Anim. 1) gegen die These von $H . M$ a u r u s : Der moderne Verfassungsstaat als Rechtsstaat, 1878, S. 109 f.: „Der Staat, in welchem auch das Unrecht gesetzlich besteht oder bestehen kann, ist nicht Rechtsstaat"; T h o ma rügt, diese Ansicht widerspreche der herrschenden Auffassung. Ganz anders dagegen 2 Jahrzehnte später, wo Th $0 \mathrm{~m}$ a 
den Erfahrungen mit einem Regime, das uns lehren wollte, Recht sei, was dem Volke nützt ${ }^{7}$ ), teilt das Grundgesetz diesen Standpunkt nicht. Für die in der Bundesrepublik geltende Rechtsordnung ist davon auszugehen, daß die Rechtsnorm den Bewertungsmaßstab für den durch sie geordneten Lebensbereich stets der im Gewissen des abendländischen Menschen lebendigen Gerechtigkeitsidee entnimmt $t^{8}$ ). Dabei darf allerdings nicht jede isolierte Einzelvorschrift als Rechtsnorm verstanden werden. Die Rechtsnorm erschließt sich vielmehr erst aus der Betrachtung zusammengehöriger Bestimmungen des materiellen und des Verfahrensrechts, also einem Inbegriff von Sollenssätzen, die in ihrer Gesamtheit einen Lebensbereich ordnen?).

In diesem Sinne möchte ich unter der Rechts norm verstehen das a us einer festgef ügten, am $M$ a $B s t a b e$ der Gerechtigkeit orientierten Ordnung flieBende Verhaltensgebot.

Eine $\mathrm{Ma} \beta \mathrm{n}$ ahme ist nach der Umgangssprache eine im Hinblick auf die Erreichung eines bestimmten Zweckes geplante menschliche Handlung. Das Wort geht zurück auf das MaßNehmen, impliziert also das In-Beziehung-Setzen eines Verhaltens zu einem bestimmten konkreten Sachverhalt. Im $\mathrm{Zu}-$ sammenhang mit der dem Reichspräsidenten durch Art. 48 Abs. 2 der Reichsverfassung vom 11. August 1919 (RGBl. S. 1383) eingeräumten Diktaturgewalt ist der Begriff Gegenstand eingehender Untersuchungen der deutschen Staatsrechtslehre gewesen. Wir müssen zwar im Auge behalten, daß die damaligen Forschungen ausgehen vom Institut des Ausnahmezustandes und deshalb einen ganz bestimmten Akzent trage $\left.{ }^{10}\right)$. Gleichwohl ist die damals herausgearbeitete $\mathrm{Be}-$ griffsbestimmung auch über die Interpretation des Art. 48

den Gesetzgeber dem "Imperativ der Rechtsordnung“ unterstellt, „sich bei seinen Entschlüissen leiten zu lassen von Erwägungen der Gerechtigkeit und des Gemeinwohls" (HDStR II, 1932, S. 108 ff., 140).

7) Vgl. dazu auch Fritz von Hippel: Die Perversion von Rechtsordnungen, 1955, passim.

8) Auf die Frage, ob damit etwas für jede Rechtsordnung Gültiges ausgesagt ist, kann hier nicht eingegangen werden. Sie ist seit $\mathrm{K}$ a n t (Transzendentale Methodenlehre, I. Hpt.-Stück, 1. Abschn., Akademieausg., Bd. III, S.479) die Kernfrage der Rechtswissenschaft. Von modernen Autoren vgl. dazu etwa Erich F e chner: Rechtsphilosophie, 1956, S. 9 ff., 17 f. (mit besonders klarer Formulierung der verschiedenen Aspekte des Problems), T a m me lo: Rechtsnorm S. 74 f. (bejahend) und Hans $\mathrm{N}$ a w i a s $\mathrm{k} \mathrm{y}$ : Allgemeine Rechtslehre, 1948, S. 24 f. (verneinend).

9) Ebenso Na wias ky: Allgem. Rechtslehre S. 10 f., 54 f., 125 f.

10) Vgl. dazu Carl S ch $\mathrm{m}$ it t: Die Diktatur des Reichspräsidenten, VVDStRL 1 (1924) S. 63 ff., $87 \mathrm{f}$. 
WRV hinaus bedeutsam; und wir können hier um so weniger an ihr vorübergehen, als - wie Forsth of $f$ hervorhebt jedenfalls nach damals herrschender Lehre „in Art. 48 Abs. 2 WRV der Begriff der Maßnahme in einer logischen Relation zum Gesetzesbegriff steht" ${ }^{11}$ ).

Nach der Kommentierung von Anschütz kommen als Maßnahme gemäß Art. 48 Abs. 2 und 4 WRV zunächst „Vorkehrungen und Eingriffe tatsächlicher Art" in Betracht, die für unser Thema ohne Belang sind. Ferner fallen unter den Begriff „Rechtshandlungen: rechtlich bestimmbare, auf Erzielung gewollter Rechtswirkungen berechnete Staatsakte mannigfaltiger Art“; diese Akte können sich „auf einen Einzelfall beziehen und ihre Kraft an diesem Einzelfall erschöpfen", sie können aber auch "abstrakte Vorschriften enthalten" 12).

Nicht alle rechtlich bedeutsamen Akte sind jedoch Maßnahmen. Am Gegensatz zum Rechtsprechungsakt, der nach rechtsstaatlichen Vorstellungen allein von der Rechtsidee beherrscht sein soll'13), hat Carl Schmitt als wesentliches Kennzeichen der Maßnahme herausgearbeitet, daß sie inhaltlich "durch eine konkret gegebene Sachlage beherrscht" ist; ihre "Eigenart ... besteht in ihrer Zweckabhängigkeit von der konkreten Sachlage" 14). Für die in Form des Rechtssatzes getroffene Maßnahme folgt daraus, daß auch hier jene Zweckabhängigkeit das Entscheidende ist, und daß Rechtssätze, die „wesentlich ein Rechtsprinzip zum Ausdruck bringen, d.h. vor allem gerecht, von der Rechtsidee beherrscht" sein wollen, niemals bloße Maßnahmen sind ${ }^{15}$ ).

11) Ernst Forsth off: Uber Maßnahme-Gesetze (Forschungen und Berichte aus dem öffentlichen Recht, Gedächtnisschrift für Walter Jellinek, 1955, S. 221 ff.) S. 224.

12) Gerhand A n s c h üt z : Die Verfassung des Deutschen Reiches, 14. Aufl., 1933, S. 283.

13) Manche "Urteile" des Volksgerichtshofes, vor allem aus der letzten Zeit des nationalsozialistischen Unrechtsstaates, waren allerdings rein zweckabhängig und hatten mit Gerechtigkeit nichts mehr zu tun; diese Maßnahmen in der äußeren Form des Gerichtsurteils verdienen allerdings die Bezeichnung Rechtsprechungsakt nicht.

14) S c h m it t, VVDStRL 1 S. 97.

15) S ch mitt, VVDStRL 1 S. 97; zustimmend Erwin J a c obi, ebenda S. 108 ff., 129, ähnlich auch Georg D a h m : Deutsches Recht, 1951, S. 46 f., und F o rst h of $f$ : Maßnahme-Gesetze S. 226. - Die insbes. zwischen Carl S $\mathrm{ch}$ mitt und Richard G r a u, HDStR II, S. 274 ff., 279, bestehenden Kontroverse über die inhaltliche Begrenzung der Maßnahmen des Reichspräsidenten kann hier dahingestellt bleiben, weil sie nicht den Begriff der Maßnahme als solchen, sondern die Grenzen der präsidialen Diktaturgewalt betrifft; vgl. dazu auch Ludwig G e b h a rd: Die Verfassung des Deutschen Reiches, 1932, S. $254 \mathrm{f}$. 
Damit scheint mir das ausschlaggebende Kriterium angedeutet: nach allgemeinem Sprachgebrauch wie nach den Erkenntnissen unserer Wissenschaft ist die Maßnahme zweckabhängig; wer eine Maßnahme trifft, gewinnt den Maßstab seines Handelns nicht aus der Gerechtigkeitsvorstellung, sondern handelt nach der sachlichen Notwendigkeit oder gar nur Nützlichkeit. Als Grundlage für die weiteren Erörterungen kann daher die Maßnahme im Rechtssinne bezeichnet werden als rechtlich bestimmbarer, a uf Erzielung gewollter Rechtswirkungen berechneter (Staats-) Akt, der auf eine konkret gegebene Sachlage zweckbestimmt reagiert.

Zum Abschluß dieser begrifflich-terminologischen Einleitung soll noch versucht werden, eine $D$ efinition des $M$ a Bnahmegesetzes zu geben - unbeschadet der Frage, ob und wie sich ein solches Gesetz in unsere gegenwärtige deutsche Rechtsordnung einordnen würde.

Das Beherrschtsein durch eine konkret gegebene Sachlage, das die Maßnahme kennzeichnet, prägt sich im Maßnahmegesetz in einem verhältnismäßig geringen Abstande seiner Tatbestandsseite von den ihr zugrunde liegenden Sachverhalten aus; $d$. h. der Kreis von Lebenssachverhalten, den der Tatbestand generalisierend und typisierend erfaßt ${ }^{16}$ ), ist zeitlich und/oder zahlenmäßig relativ eng begrenzt, was logisch aus dem Wesen der konkreten Situation folgt. Aus dem engen Auf-einander-Bezogensein von Zweck und Mittel, das gleichfalls zum Wesen der Maßnahme gehört, ergibt sich zum anderen eine ganz spezifische Abhängigkeit der Rechtsfolge vom Tatbestand: sie ist allein an dessen sachimmanenten Gegebenheiten orientiert. Während nämlich bei der Rechtsnorm die Rechtsfolgeseite eine gerechte Lösung des in der Tatbestandsseite normierten Interessenkonflikts gebietet, den Regelungsmaßstab also der Rechtsidee entnimmt, soll die Rechtsfolge des Maßnahmegesetzes lediglich eine zweckmäßige, "technisch saubere" Lösung finden. Den von Anschütz mit Recht betonten Willensakt möchte ich unter diesen Umständen weniger in der Festlegung der Rechtsfolge erblicken, die durch den Tatbestand bei richtiger Erfassung der in ihm ruhenden Probleme mit einer gewissen Zwangsläufigkeit vorgezeichnet wird, als vielmehr in der Auswahl und Umgrenzung der im Tatbestand zusammengefaßten Sachverhalte, die einer "gezielten" Regelung - wie der bezeichnende terminus technicus lautet - unterworfen werden sollen.

16) Vgl. dazu Hans J. Wolff: Typen im Recht und in der Rechtswissenschaft, Studium Generale 5 (1952) S. $195 \mathrm{ff}$. 
Das Maßnahmegesetz ist also ein Rechtssatz, in welchem der Gesetzgeber einen zeitlich und /oder zahlenmäBig begrenzten Kreis von Lebenssachverhalten in einem Tatbestande mit der Absicht zusammenfaßt, ihn einer rein zweckmäBigen Rechtsfolge zu unterwerfen.

\section{II.}

Vom Standpunkte vieler moderner Rechtstheoretiker aus ist das Element des Wollens bei der Bildung des Rechtssatzbegriffes nichts besonderes ${ }^{17}$ ). Mit Recht weist jedoch Hermann J a hrreis $s$ darauf hin, daß der Mensch erst sehr spät und zögernd daran gegangen ist, aus seinem Willen heraus geborene Gesetze zu geben und so „mit Menschenschicksalen zu experimentieren" ${ }^{18}$ ).

Der antiken und der mittelalterlichen Welt ist eine derartige Vorstellung im wesentlichen fremd. Vorsichtig tastende Versuche, wenigstens die lex positiva auf den menschlichen Willen zurückzuführen, finden sich allerdings schon bei Thom as von Aquin ${ }^{19}$ ); aber sie sind angesichts des Dominierens der lex divina und der lex naturalis von um so geringerer Bedeutung, als Thom as sich bemühte, den Bereich der lex positiva bewußt eng zu umgrenzen. Für das Rechtsbewußtsein des Volkes spielte diese Möglichkeit vollends keine Rolle: in seiner Vorstellung bestand göttliches, natürliches und positives Recht in ungebrochener Einheit als „das Recht" schlechthin, welches Ausdruck der göttlichen Gerechtigkeit ist ${ }^{20}$ ).

Die eigentliche Wendung vom erkennenden Erfassen von etwas Vorgegebenem zum bewußten Gestalten aus eigener Machtvollkommenheit heraus, auf das allein es für unser Thema ankommt, erfolgt erst später, und zwar - wenn wir recht sehen - bei Francis B a c on.

B a c on s Begriff des Rechtsgesetzes steht in unmittelbarem Zusammenhange mit seiner Naturauffassung. Natur ist für ihn Macht, welche den Menschen zunächst zwingt, ihr zu dienen. Wenn der Mensch aber durch kluge Beobachtung der

1i) Vgl. dazu z. B. das bei Alf $R$ os $s$ : Theorie der Rechtsquellen, 1929, S. 178, insbes. Anm. 22, und S. 435, d) $\beta$ ), zusammengestellte Schrifttum.

18) Hermann $\mathrm{J}$ ahr reis $\mathrm{S}$ : Größe und Not der Gesetzgebung, Schriften der Wittheit zu Bremen, Reihe D Bd. 20, 1953, S. 32.

19) Thomas von A qu ino: Summa theologiae II, II, q. 57, a. 2.

20) Vgl. Fritz Kern: Recht und Verfassung im Mittelalter, Neudr. 1952, S. 17. 
Natur sich deren Kräfte untertan macht, dann wird er zu ihrem Herren. Freiheit im Sinne B a cons ist Macht über die Natur, und da auch der Mensch von ihm rein als Naturwesen begriffen wird, ist auch der (andere) Mensch Objekt jener Macht. „Ist die Natur Macht, Freiheit aber Herrschaft über die Natur, so wird auch der Inhalt des Rechtsgesetzes entsprechend zur Organisation der Macht'(21). Die Rechtsordnung wird so zum Machtgebot. In B a cons Gesetzesbegriff ist alles eliminiert, was als Bindung an göttliche Gebote oder die Vernunft im Sinne mittelalterlichen Denkens verstanden werden kann. Sein Gesetz ist nur noch die lex positiva, welche ihren alleinigen Geltungsgrund findet im Willen des herrschenden Menschen ${ }^{22}$ ). Schon vor $\mathrm{H}$ o b b e s' berühmter Formulierung: "autoritas non veritas facit legem" ${ }^{23}$ ) hat also $\mathrm{B}$ a c on den ebenso zukunftsträchtigen wie gefährlichen Gedanken vom Gesetz als Befehl ausgesprochen.

Mit der fortschreitenden Anerkennung der auf Bacon aufbauenden Gesetzesvorstellung im neuzeitlichen Vernunftrecht wandelt sich auch die Funktion der Gesetzgebung in entscheidender Weise. Bisher war es jedenfalls theoretisch allein ihre Aufgabe gewesen, das "gute alte Recht" aufzuzeichnen; Rechtsänderung und -erneuerung erschien nur möglich als wirkliche oder vorgebliche Wiederherstellung des wahren Rechts $\left.{ }^{24}\right)$. Und so hatte etwa noch der Freiherr Johann von $S \mathrm{chwarzenberg}$ seine Aufgabe bei der Schaffung der „Bambergensis“ aufgefaßt ${ }^{25}$ ). Von nun an wird das Gesetz - theoretisch und zunehmend auch praktisch zum Mittel, den zweckbestimmten Willen des seit Bodin souverän und seit $\mathrm{Hob}$ bes absolut gedachten Herrschers zu verwirklichen ${ }^{2 \theta}$ ).

Die seitdem bestehende Situation hat Scheuner mit folgenden Worten charakterisiert: „In allen Staaten ist, seit dem Ubergang vom mittelalterlichen Jurisdiktionsstaate zu einem regierenden, das soziale Geschehen aktiv gestaltenden

21) Ernst vo n H i p pel: Rechtsgesetz und Naturgesetz, 2. Aufl., 1949, S. 39.

22) Hippe 1: Rechtsgesetz S. 40; vgl. zu B a con's Rechtslehre auch Erik W o 1 : : Das Problem des Naturrechts, 1955, S. 96 ff.

23) Thomas $\mathrm{H}$ ob b e $\mathrm{s}$ : Leviathan, cap. 19.

24) Vgl. K e r $n$ : Recht S. $38 \mathrm{ff}$., insbes. $39 \mathrm{f}$.

25) Vgl. dazu Erik Wolf: Große Rechtsdenker der deutschen Geistesgeschichte, 3. Aufl. 1951, S. 112 ff., 114.

26) Vigl. in diesem Zusammenhang die Umdeutung des Begriffes des "Gemeinen Besten" im frühneuzeitlichen Territorialstaat und dazu Walter M e r k: Der Gedanke des gemeinen Besten in der deutschen Staats- und Rechtsentwicklung (Festschrift für Alfred Schultze, 1934, S. 451 ff.) S. 499 ff. 
Staate, das Gesetz, als Gebot des Herrschers und heute als Beschluß der Volksvertretung, zugleich die Form der Rechtsfeststellung und Rechtsfortbildung, wie auch das Mittel der politischen Lenkung und Formung des Soziallebens durch den Staat"(27).

Von nun an sind auch Maßnahmegesetze möglich. Es wäre allerdings eine "schreckliche Vereinfachung", wenn man das Gesetz als Gestaltungsmittel mit dem Maßnahmegesetz identifizieren wollte; denn das Maßnahmegesetz ist lediglich ein extremer Sonderfall innerhalb dieser Kategorie von Gesetzen. In der Regel sind im konkreten Gesetz beide Elemente vereinigt: die Verwirklichung des souveränen zweckgerichteten Willens und die Setzung von auf die Gerechtigkeitsidee ausgerichtetem Recht. Es ist aber nicht zu verkennen, daß es heute Gesetze gibt, die „der rechtlichen Substanz mehr oder weniger entbehren und nur noch den Charakter politischer, wirtschaftlicher und sozialer Maßnahmen haben" ${ }^{28}$ ).

III.

Für unsere Untersuchung kommt es nun darauf an, Unterscheidungsmerkmale zu finden, welche es ermöglichen, in der Gruppe der menschlicher Willensverwirklichung dienenden - also nicht nur der Aufzeichnung bestehenden Rechts geltenden - Gesetze die Maßnahmegesetze sicherer, als auf Grund der bisher entwickelten allgemeinen Kriterien zu erkennen. Ein gangbarer Weg dafür könnte die Prüfung einiger Grenzfälle sein. Dabei gilt es einmal festzustellen, was zwar Maßnahme ist, aber trotz der Bezeichnung als Gesetz nicht als Rechtssatz anerkannt werden kann. Zweitens muß eine Grenzlinie gesucht werden zwischen der echten Rechtsnorm

27) S c heu ner : Bereich der Regierung S. $253 \mathrm{ff.}$. 258; vgl. dazu auch Georg Cohn : Existenzialismus und Rechtswissenschaft, 1955, S. 71 f., und D a h m : Deutsches Recht, S. 46 f., der zwischen „Rechtsbewahrungsgesetzen" und "Zweckgesetzen" unterscheidet.

28) Da hm: Deutsches Recht S. 47; denselben Sachverhalt kennzeichnet Werner Kä g i : Die Verfassung als rechtliche Grundordnung des Staates; Untersuchungen über die Entwicklungstendenzen im modernen Verfassungsrecht, 1945, S. 30 ff., als Vendrängung des normativ-rechtsstaatlichen Gesetzesbegriff's durch einen politischdezisionistischen und spricht unter Hinweis auf Parallelerscheinungen in zahlreichen modernen Staaten von einer "Krise des Gesetzes". Dabei duirfen wir allendings nicht die Augen davor verschließen, daß es derartige Maßnahmegesetze auch im 19. Jahrhundert gegeben hat; vgl. z. B. das pr. Gesetz über die Bestrafung von Studentenverbindungen vom 7. Januar 1838 (GS S.13); auch das pr. Gesetz betr. die Indemnität in bezug auf die Führung des Staatshaushaltes vom Jahre 1862 ab ... vom 14. September 1866 (GS S. 563) ist in diesem Zusammenhange zu nennen. 
und dem Maßnahmegesetz. Mit anderen Worten: Maßnahme und Rechtssatz könnten als zwei Kreise dargestellt werden, die sich schneiden; die von beiden bedeckte Fläche umschreibt den Fall des Maßnahmegesetzes, während auf beiden Seiten die Rechtsnorm einerseits und die sonstige Maßnahme andererseits einzuzeichnen wäre.

In ihrer Kritik der "Lex Schörner" führt Hildegard $\mathrm{Kr}$ üger als Beispiele für Maßnahmegesetze die Ratifikationsermächtigung, den Haushaltsplan und die Kreditermächtigung an, also nach der Terminologie der herrschenden Lehre sogenannterein formelle Gesetze ${ }^{29}$ ). Das steht in Widerspruch $\mathrm{zu}$ unseren eingangs entwickelten Begriffen, denn rein formelle Gesetze sind Beschlüsse des Legislativorgans, die nicht auf Schaffung von Rechtssätzen gerichtet sind ${ }^{30}{ }^{31}$ ). Es fragt sich, ob hier eine lediglich terminologische Frage vorliegt, oder ob sich hinter der unterschiedlichen Terminologie eine sachliche Differenz verbirgt.

Frau Krüger nennt zuerst die Ermächtigung, welche die Gesetzgebungsorgane gemä $\beta$ Art. 59 Abs. 2 GG dem Staatsoberhaupt zur Ausübung seines Rechts der Ratifikation eines völkerrechtlichen Vertrages erteilen - und die begrifflich

29) Hildegand Kr üger: Die Verfassungswidrigkeit der Lex Schörner, DVBl. 1955, S. 758 ff., 791 ff. (761).

30) Das räumt auch Hildegand K r üg e $\mathrm{r}$ ein, v.gl. DVBl. 1955, S. 762.

s1) Bekanntlich hat Hermann $\mathrm{H}$ ell e $\mathrm{r}$ die Möglichkeit, daß Gesetzgebungsorgane A'kte ohne Rechtssatzeigenschaft beschließen könnten, überhaupt verneint; er gib't lediglich den Fall eines MiBbrauchs der verfassungsmäßig vorgesehenen Prozedur zu ( $\mathrm{H} \mathrm{e} \mathrm{I-}$ l e r, VVDStRL 4 S. 112 ff.). Soweit $\mathrm{H}$ eller dabei von Gesetzen mit sogen. "unverbindlichem Gesetzesinhalt" (E is e le, AcP 69 6. 279) spricht, möchte ich ihm zustimmen, daß es sich dabei entweder um als Legaldefinitionen oder -interpretationen praktisch notwendige Mittel der Gesetzgebungstechnik handelt oder um - entbehrliche - Proklamationen innerhalb eines "normativen Gesetzes" oder aber schließlich um Mißbräuche des "Gesetzeskostüms für Kundgebungen irgendwelcher Art" $\mathrm{H} \mathrm{ell} \mathrm{e} \mathrm{r}$, aaO. S. 113). Im übrigen vermag ich jedach seiner Ansicht, alle anderen sogen. rein formellen Gesetze seien in Wahrheit Rechtssätze, nicht zu folgen. H e l ler stützt seine These auf das Fehlen einer klaren Unterscheidbarkeit der Staatsfunktionen (S. 114 ff.). Auf diese Frage wind noch zurückzukommen sein (S. U. IV). Bei genauer Prüfung ergibt sich aber, daß Hellers Theorie, die auch den Befehl des Unteroffiziers zum Rechtssatz erhebt (S. 118 f.), auf seiner egalitärdemokratischen Staatsauffassung beruht, aus welcher er folgerichtig einen rein dezisionistischen Gesetzesbegriff herleitet (S. 123). Dieser Gesetzesbegriffi ist jedenfalls für das Grundgesetz nicht verbindlich, das nach den jüngsten Erfahrungen mit der "sittlichen Vernunftautonomie des Volkswillens" allen Grund hatte, der Volkssouveränität Zügel anzulegen. 
klarer, als sie es tut, von dem Gesetz unterschieden werden muß, in welchem der Inhalt des Vertrages entweder in innerstaatliches Recht transponiert oder dessen Eigenschaft als Bestandteil des innerstaatlichen Rechts festgestellt wird ${ }^{32}$ ). Diese Ermächtigung ist kein Rechtssatz, sondern die Wiederherstellung von, verfassungsrechtlich hinsichtlich ihrer Ausübung eingeschränkten, Rechten des Bundespräsidenten ${ }^{93}$ ) für den Einzelfall; sie stellt sich juristisch als Anwendung von Verfassungsrechtssätzen durch die Legislativorgane für jenen Einzelfall dar und ist inhaltlich eine staatsleitende Maßnahme.

Entsprechendes gilt für den Haushaltsplan und die Kreditermächtigung.

Bereits $\mathrm{Heckel}$ hat überzeugend nachgewiesen, daß der Haushaltsplan zwar nicht, wie $L$ ab and annahm ${ }^{34}$ ), Verwaltungsakt ist, aber auch nicht Gesetz im materiellen Sinne. Das Budgetgesetz ist vielmehr als Gesamtprogramm für die staatliche Wirtschaftsführung eines Etatjahres ein „staatsleitender Akt" ${ }^{35}$ ), eine „wirtschaftsgestaltende Maßnahme" so). Die Mitwirkung der Volksvertretung ist auch hier nicht Rechtsetzung, sondern politische Aktion besonderer Art, „Mitwirkung an der Staatsleitung" ${ }^{87}$ ). Art. 66 Abs. 2 der Verfassung der Freien und Hansestadt Hamburg vom 6. Juni 1952 (GVBl. S. 117) verlangt daher für die Verabschiedung

32) Vgl. zu dieser nicht unbestrittenen Frage BVerfGE 1 S. $396 \mathrm{ff}$. (410), die Referate von Wilhelm Grewe und Eberhand M e nze l: Die Auswärtige Gewalt der Bundesrepublik, VVDStRL 12 (1954), S. 129 ff., 179 ff., Erich $\mathrm{K}$ a u f m a n $\mathrm{n}$ : Normenkontrollverfahren und völkerrech'tliche Verträge (Jellinek-Gedächtnisschrift $\mathbf{S} .445 \mathrm{ff}$.) und Hans F. Z a c h e r: Ratifizierungsgesetz und Normenkontrolle, DVBl. 1955, S. 649 ff., 696 f. (651).

33) Jene Rechte sind mit dem Ubergang der Staatsgewalt auf das Volk diesem zugewachsen und müßten theoretisch von der Volksvertretung ausgeübt werden; da aber der internationale Verkehr - schon aus praktischen Gründen - eine Einzelperson oder ein kleines Kollegium (Direktorialverfassung) als Vertretungsberechtigten erfordert und voraussetzt, liegt die Vertretungsmacht im völkerrechtlichen Außenverhältnis nach wie vor beim Staatsoberhaupt, das aber im staatsrechtlichen Innenverhältnis für die Ausübung dieser Vertretungsmacht in der unmitteibaren Demokratie der Ermächtigung des Inhabers der Staatsgewalt, in der repräsentativen Demokratie derjenigen der Volksvertretung bèdarf.

34) L a b a nd : Staatsrecht, Bd. IV, S. 587.

35) Johannes $\mathrm{Heckel}$ : Einrichtung und rechtliche Gestaltung des Reichshaushaltsgesetzes, HDStR II S. 374 ff., 386 ff. (390).

s6) S c h e u n e r, Ubertragung $S .140$.

37) Scheuner, aaO.; ebenso Hecke1, HDStR II S. 389, der von einem "staatsrechtlichen Gesamtakt" spricht. 
des Haushaltsplanes mit Recht kein Gesetz, sondern läßt den Beschluß der Bürgerschaft genügen.

Ganz ähnlich ist auch das Gesetz gemäß Art.115 GG zu qualifizieren. Wie schon Art. 87 WRV verbietet diese Verfassungsvorschrift der Regierung Kreditaufnahmen zugunsten sowie Kreditgewährungen und Sicherheitsleistungen zu Lasten des Bundes, verknüpft das Verbot aber mit einem Erlaubnisvorbehalt und berechtigt die Gesetzgebungsorgane, die Erlaubnis zu erteilen ${ }^{38}$ ). Das Kreditermächtigungsgesetz ist also die Offnung einer verfassungsrechtlichen Schranke für den Einzelfall und damit rechtsanwendender Staatsakt, der lediglich in der Form des Gesetzes erlassen wird.

Erlauben Sie mir zur Vervollständigung noch einen Blick auf die in Art.59 a Abs. 1 GG vorgesehene, dem Bundestage obliegende Feststellung, da 3 der Verteidigungsfall eingetreten ist. Auch sie ist mindestens dann eine Maßnahme, wenn nicht das Bundesgebiet angegriffen ist, sondern das Gebiet eines anderen Staates, den militärisch zu unterstützen die Bundesrepublik vertraglich verpflichtet ist. Hier schreibt das GG, anders als Art. 45 Abs. 2 WRV, richtigerweise die Gesetzesform nicht vor ${ }^{39}$ ) ${ }^{40}$ ), während sie in Art. 59 a Abs. 4 GG entsprechend Art.45 Abs. 2 WRV für den Friedensschluß verlangt wird ${ }^{41}$ ).

Gegen die hier vertretene Ansicht, daß derartige staatsleitende Handlungen zwar Maßnahme, aber nicht Rechtssatz seien, könnten ihre unbestreitbaren rechtlichen Wirkungen eingewandt werden ${ }^{42}$ ). Diese Wirkungen folgen aber nicht unmittelbar aus der betreffenden Maßnahme. Die Maßnahme setzt vielmehr ein Tatbestandsmerkmal für einen Rechtssatz,

38) Vgl. dazu Friedrich E. M. S a e $\mathrm{m}$ is $\mathrm{ch}$ : Das Staatsschuldenwesen, HDStR II S. $435 \mathrm{ff}$., 437.

39) Bereits die hilfsweise Zuständigkeit des Bundespräsidenten in Verbindung mit dem Bundeskanzler (Art. 59a Abs. 2 GG) für den Fall, daß dem Zusammentreffen des Bundestages unüberwindliche Hindernisse entgegenstehen, deutet darauf hin, daß es sich um einen. Akt der Regierungsgewalt und nicht um einen Legislativakt handelt.

40) Bei der Kriegserklärung handelt es sich um das älteste „rein formelle" Gesetz überhaupt, da schon das römische Recht dafür die Gesetzesform vorschrieb, vgl. Theodor Mo m m sen : Römisches Staatsrecht, 4. Aufl., Neudruck 1952, III. Bd., 1. Teil, S. 327 Anm. 1.

41) Wenn man Friedensschluß und Ratifikation des Friedensvertrages begrifflich trennt, was notwendig ist, weil der rechtliche Kriegszustand nach geltendem Völkerrecht auch auf andere Weise beendet werden kann als durch Vertrag (vgl. z. B. Alfred Verd ro s s : Völkerrecht, 2. Aufl., 1950, S. 343), dann stellt sich auch der Friedensschluß als Maßnahme ohne Rechtssatzcharakter dar.

42) So z. B. S ch e u ner : Bereich der Regierung, S. 258. 
und die rechtlichen Wirkungen ergeben sich aus dessen Rechtsfolgeseite ${ }^{\mathbf{t}}$ ).

Zusammenfassend können wir feststellen, daß die sogenannten rein formellen Gesetze zwar in vielen Fällen Maßnahmen darstellen, aber keine Rechtssätze sind $\left.{ }^{44}\right)$.

Bei dieser Gelegenheit möchte ich den Vorschlag machen, die Bezeichnung "Gesetz im formellen Sinne" für die nichtrechtsetzenden Akte der Legislativorgane in Zukunft als irreführend $z u$ vermeiden. Dieser Appell richtet sich allerdings nicht in erster Linie an die Staatsrechtswissenschaft, der richtige Adressat ist vielmehr der Verfassungsgesetzgeber. Es ist $\mathrm{m}$. E. nicht einzusehen, warum Verfassungen für staatsleitende Akte der Volksvertretung zuweilen die Gesetzesform vorschreiben, wie etwa für die Kreditermächtigung oder den. Friedensschluß, in vielen anderen Fällen darauf verzichten, wie z. B. bei der Feststellung des Verteidigungsfalles, der Wahl des Bundeskanzlers, der Präsidentenanklage und der Einsetzung eines Untersuchungsausschusses, und in einzelnen Fällen verschiedene Wege gehen, wie beim Haushaltsplan ${ }^{45}$. Das sogenannte rein formelle Gesetz unter-

43) So resultiert die Zeugnispflicht der Staatsbürger gegenüber einem nach Art. 44 Abs. 1 GG vom Bundestag eingesetzten UntersuchungsausschuB, die $S \mathrm{c}$ h e $\mathrm{n}$ e $\mathrm{r}$ aaO. als Beispiel anfluhrt, nicht aus der Einsetzung des Ausschusses, sondern aus den nach Art. 44 Abs. 2 GG sinngemäß anzuwendenden Vorschriften über den Strafprozeß.

44) Nur anmerkungsweise möchte ich noch die von der h.L. ebenfalls in die Gruppe der sogen. rein formellen Gesetze eingereihten Gesetze zur Anderung von Gebietsgrenzen streifen. Sie können, wenn es sich etwa um sogen. technische Grenzberichtigungen handelt, durchaus als Maßnahme bezeichnet werden. Aber sind sie Rechtssätze? Diese Qualifikation engibt sich jedenfalls nicht aus der Behauptung, daß jede Gebietsänderung Rechtsfolgen für die betroffenen Bürger habe; denn diese Rechtsfolgen treten ebenfalls nicht unmittelbar auf Grund der Gebietsänderung ein, sondern auf Grund von Rechtssätzen, die nach der Grenzänderung im abgetretenen Gebiet Geltung erlangen. Ihre Bezeichnung als rein formelles Gesetz erscheint mir aber aus einem anderen Grunde unzulässig. Die Umgrenzung des Staatsgebiets selbst, soweit sie überhaupt gesetzlich - z. B. in völkerrechtlichen Verträgen - fixiert ist, enthält gar keine Sollens-Sätze. Sie ist aber als eine Art Deflnitionsnorm ein "vor die Klammer gezogener" Bestandteil der staatlichen Rechtsordnung, deren Geltungsbereich sie festlegt. Gesetze zur Anderung des Staatsgebiets sind Berichtigungen jener Definitionsnorm. Sie lassen sich als nur technilsch verselbständigte, aber inhaltlich unselbständige Teile der Rechtsondnung in unser Thema nicht einordnen.

43) Die im Falle der 'Gesetzesform sichergestellte Mitwirkung anderer Verfassungsorgane, vor allem des Bundesrates, kann vom Verfassungsgeber auch auf andere Weise sichergetellt werden. Ich vermag ohnehin nicht einzuehen, warum der Bundesrat z. B. bei 
scheidet sich nicht genügend von anderen Maßnahmen der Volksvertretung, um eine Sonderbehandlung zu rechtfertigen. Die in der Verfassung für die Beschlußfassung darüber vorgeschriebene Gesetzesform, die Carl Schmit t zutreffend als "einfachen Kunstgriff sprachlicher Technik" kennzeichnet" ${ }^{48}$ ), sollte daher in Zukunft beseitigt werden.

Entfällt so die Notwendigkeit, ja die Berechtigung, am Begriff des rein formellen Gesetzes festzuhalten, so scheidet auch die Möglichkeit aus, die erwähnten Maßnahmen des Legislativorgans als Maßnahmegesetze zu bezeichnen. Die von Hildegard Krüger verwendete Terminologie muß vielmehr ebenfalls als irreführend abgelehnt werden.

Die früher herrschende Lehre rechnete auch die Organisationsgesetze zu den nur formellen Gesetzen, weil sie nach der bekannten Definition Georg Jellineks ihr materielles Gesetz als Abgrenzung der gegenseitigen Rechtsmacht von Personen auffaßte ${ }^{47}$ ). Jene Lehre ist in mehrfacher Hinsicht unrichtig.

Zunächst muß die Errichtung einer Behördenorganisation von der Regelung der Zuständigkeiten unterschieden werden; beides wird zwar häufig zusammentreffen, muß es aber nicht notwendig ${ }^{48}$.

Ein Gesetz, das lediglich eine Behörde schafft, die Festlegung von deren Zuständigkeiten aber anderweitiger Regelung überläBt, ist $\mathrm{m}$. $\mathrm{E}$. ein Organisationsakt; es ist eine hier nicht zu erörternde Frage, ob man diese Maßnahme als Ausfluß einer eigenständigen Organisationsgewalt der Regierung allein überläßt, ob man der Volksvertretung ein Mit-

der Feststellung des Verteidigungsfalles durch den Bundestag ganz ausgeschaltet ist, bei der hilfsweisen Zuständigkeit des Bundespräsidenten und des Bundeskanzlers wenigstens durch seinen Präsidenten neben dem Bundestagspräsidenten beteiligt ist, beim Friedensschluß aber volle Mitwirkungsrechte besitzt. - Die Gründlichkeit der Beratung läBt sich, wie Art.66 Abs. 2 Satz 2 hambVerf. zeigt, mühelos sicherstellen. Die ohnehin fragwürdige Publizität durch Verkündung in der amtlichen Gesetz-Sammlung schließlich könnte ohne weiteres beibehalten werden, steht dieses Verkündungsorgan doch auch heute schon anderen Staatsorganen offen und ist keineswegs auf die Veröffentlichung von Legislativakten beschränkt.

46) Carl Sch m it t : Verfassungslehre, 1928, S. 144.

47) Georg Jellinek: Gesetz und Verordnung, 1887, S. 240, vgl. auch L a ba nd: Staatsrecht II S. 181 und die Nachweise bei H eller, VVDStRL 4 S. $123 \mathrm{f}$.

(8) Vgl. dazu neuerdings' F e I l n er : Zur Rechtsnatur der bayerischen Organisationsakte, bayerVBl. 1955, S. 229 ff., S c h w e i g e r : Erwiderung gleichen Titels, bayerVBl. 1956, S. 72 ff., und das dort angeführte Schrifttum. 
wirkungsrecht gibt oder ob man eine alleinige Zuständigkeit der Volksvertretung bestimmt ${ }^{40}$ ). Wenn, wie es Art. 77 Abs. 1 Satz 1 der Verfassung des Freistaates Bayern vom 2. Dezember 1946 (GVBI. S. 333) vorschreibt, die Volksvertretung die Organisation der Behörden durch Gesetz vorzunehmen hat, dann handelt es sich in der Tat um eine Maßnahme in Form eines Gesetzes, die nicht Rechtssatz ist. Es gilt dann das zuvor zum sogen. rein formellen Gesetz Gesagte.

Soweit ein Organisationsgesetz aber Zuständigkeiten begründet, ist es Rechtssatz. Schon $\mathrm{H}$ a e n e ${ }^{50}$ ) und Triepe $1^{51}$ ) haben die mißliche Konsequenz der herrschenden Lehre gerügt, daß danach folgerichtig auch der organisatorische Teil der Verfassung nur Gesetz im formellen Sinne sein dürfte ${ }^{52}$ ). Dieses fatale Ergebnis läßt sich vermeiden, wenn man anerkennt, daB Zurechnungs- und Zuordnungssubjekte von Rechtssätzen nicht nur natürliche und juristische Personen sein

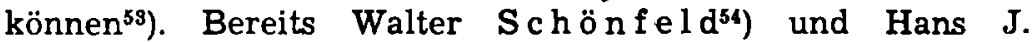
$\mathrm{W}$ olf $\mathrm{f}^{55}$ ) haben auf die Notwendigkeit hingewiesen, zwischen Person und Rechtssubjekt zu unterscheiden. Grade im öffentlichen Recht, das berufen ist, die Rechtsverhältnisse innerhalb „des Staates“ zu ordnen, genügt es nicht, nur mit der juristischen Person "Staat" zu operieren. Der Staat selbst besitzt zwar nur eine einheitliche Rechtsfähigkeit, ist nur eine einheitliche juristische Person. Die Fähigkeit, Subjekt eines Rechtssatzes zu sein, also die Rechtssubjektivität, kommt jedoch, wie in jedem Organisationsrecht nicht nur dem Staate als solchem $\mathrm{zu}$, sondern auch seinen Organen, ohne daB diese Rechtspersönlichkeit $\mathrm{zu}$ besitzen brauchen. Das Zuständigkeiten regelnde Organisationsgesetz läßt sich daher auf folgendes Schema zurückführen:Wenn ein im Tatbestande dieses Rechtssatzes umschriebener konkreter Sachverhalt vorliegt,

40) Vgl. dazu grundlegend Lutz $R$ ichter: Die Organisationsgewalt (1926).

s0) Albert $\mathrm{H}$ a e n e 1: Das Gesetz im formellen und materiellen Sinne, Studien zum Deutschen Staatsrecht II, 1888, S. 225 ff., vgl. auch D e n s.: Deutsches Staatsrecht, 1892, Bd. I, S. 122.

B1) Heinrich Trie p e I: Die Reichsaufsicht, 1917, S. 126, 585.

52) So mit Recht auch $\mathrm{H}$ e 1 l e $\mathrm{r}$ : VVDStRL $4 \mathrm{~S}$. 123.

5s) Ich habe den nachstehenden Gedankengang bereits in meinem System des verwaltungsgerichtlichen Rechtsschutzes, 1954, S. $37 \mathrm{ff}$., entwickelt und beschränke mich hier darauf, die dort gefundenen Ergebnisse vorzutragen.

54) Walter S c h ö n f e ld : Rechtsperson und Rechtsgut im Lichte des Reichsgerichts, Festgabe der juristischen Fakultäten zum 50jährigen Bestehen des Reichsgerichts, 1929, Bd. II, S. 191 ff., 223 ff.

55) Hans J. W o l f $\mathrm{f}$ : Organschaft und juristische Person, Bd. I: Juristische Person und Staatsperson, 1933, §§7-11, Bd. II: Theorie der Vertretung, $1934 \S \S 8-14$. 
dann soll das hiermit für zuständig erklärte Staatsorgan die Rechtsfolge setzen.

Sind wir so zu dem Ergebnis gelangt, daß auch solche Vorschriften, die nur Rechte und Pflichten zwischen Staatsorganen erzeugen, materielles Recht darstellen, so liegt die Frage nahe, ob wir es hier nicht in vielen Fällen angesichts der überwiegenden Zweckorientiertheit des Organisationsrechts mit Maßnahmegesetzen zu tun haben. Mit der Gegenüberstellung von Rechtssatz und Verwaltungssatz hat Herbert $\mathrm{K} \mathbf{r} \ddot{\text { ug e } r}$ diese Frage bereits angerührt, ohne allerdings den Terminus Maßnahmegesetz zu verwenden ${ }^{50}$ ).

In seiner Kritik der bisher herrschenden Lehre kommt er zu dem Ergebnis, daß der Rechtssatz nach dem Maßstabe der Gerechtigkeit der Friedensordnung zu dienen bestimmt ist, der Verwaltungssatz aber nach dem Maßstabe der Zweckmäßigkeit der Wohlfahrt. Organisationsgesetze sind nun sicher Verwaltungssätze im Sinne der K r üge r'schen Terminologie, wenn sie nicht, wie die Fundamentalsätze des organisatorischen Teils der Verfassung, ihre innere Begründung in der Aufrichtung und Erhaltung der freiheitlich-demokratischen Grundordnung besitzen und damit der Friedensordnung selbst dienen. Verwaltungssatz und Maßnahmegesetz sind jedoch nicht identisch. Der Gemeinsamkeit der Zweckabhängigkeit steht der Unterschied gegenüber, daß das Maßnahmegesetz in bestimmter Relation zu einer konkreten Situation steht, während das normale Organisationsgesetz als Dauergesetz für eine generell und abstrakt bestimmte Vielzahl von Fällen gilt. Innerhalb des Organisationsrechts kann man zwar z. B. ein Gesetz als Maßnahmegesetz bezeichnen, das für eine bestimmte befristete Aufgabe - etwa eine Messe - einen Staatskommissar einsetzt. Die Bezeichnung der normalen Organisationsgesetze als Maßnahmegesetz würde ich aber für eine Uberdehnung dieses Begriffs ansehen.

Auch für Grenzziehung zwischen Maßnahmegesetzen und Rechtsnormen müssen wir von der Feststellung ausgehen, daß keineswegs jedes Gesetz ein Maßnahmegesetz ist, das einen gewollten $Z$ weck verfolgt ${ }^{57}$ ). Es wäre wirklichkeitsfremd, den

s6) Herbert $\mathrm{K}$ r ü ger : Rechtsverordnung und Verwaltungsanweisung (Smend-Festgabe S. 211 ff.) S. $229 f$.

37) Mit Recht legt Forsthoff an den Beispielen der Reichsgewerbeordnung und der Reichsversicherungsondnung dar, daß damit Gesetze geschaffen wurden, die zwar auch bestimmten konkreten Zwecken dienen, die aber dariber hinaus am Maßstabe der Gerechtigkeit orientierte Ordnungen eigenen Wertes errichten (F o r th off: Maßnahme-Gesetze S. 225). Mit anderen Worten: die Rechtsfolgen in diesen Gesetzen sind nicht derart tatbestands- 
heutigen Gesetzgeber auf die Aufstellung genereller Normen beschränken und das zweckgerichtete Handeln allein der Exekutive - „a u f G r u n d" der Gesetze ${ }^{\text {B }}$ ) - erlauben zu wollen.

Eine solche Aufgabenverteilung war - in der Theorie! möglich in einem Staate, dessen Verfassungsordnung auf der Trennung von Staat und Gesellschaft aufbaute. Wie Forst h of f mit Recht hervorhebt, setzt sie zweierlei voraus: einmal, daB die Gesellschaft autonom gedacht wird, und die staatliche Rechtsordnung demgemä $\beta$ die Gesellschafts- und Sozialordnung als Faktum hinnimmt; und zum anderen, daß die Rechtsordnung jener von der autonomen Gesellschaft geschaffenen Ordnung prinzipiell zubilligt, im Einklange mit den Grundsätzen der Gerechtigkeit zu stehen ${ }^{58}$ ). Diese Voraussetzungen sind in Deutschland seit dem ersten Weltkriege entfallen. Die gründlich durch Krieg und Kriegsfolgen, insbesondere den Zusammenbruch der Währung, zerrüttete Sozialordnung liegt seither - auch theoretisch - nicht mehr jenseits der Zugriffsmöglichkeit der staatlichen Gesetzgebung, sondern wird zum, sogar bevorzugten, Objekt planender staatlicher Gestaltung. Es liegt auf der Hand, daß damit Zweckgesichtspunkte in der Gesetzgebung eine ungleich größere Rolle spielen, als bis dahin. Wo ist nun angesichts dieser Lage die Grenze zu ziehen $z$ wischen Normsetzung und MaBnahmegesetzgebung?

Zur Beantwortung dieser Frage möchte ich - entsprechend der eingangs aufgestellten Definition des Maßnahmegesetzes ausgehen von den bereits von Richard $\mathrm{Th}$ o $\mathrm{m}$ a herausgestellten drei Arten inhaltlich atypischer ${ }^{00}$ ) Gesetze, die sämtlich an konkrete Sachverhalte anknüpfen $\left.{ }^{81}\right)$ :

a) der Tatbestand des Gesetzes betrifft nur eine einzelne Person oder einen klar umgrenzten Personenkreis;

abhängig, daß sie lediglich „sachgemäße, nach Lage der Fälle getroffene Vorkehrungen" darstellen (Carl Sch m itt, VVDStRL 1 S. 97), sondern sie sind bestimmt, einem rechtlich geordneten $\mathrm{Zu}$ sammenleben der Bürger zu dienen.

58) Vgl. zu der Bedeutung dieser Formel Carl S c h mitt: Verfassungslehre, S. $152 \mathrm{f}$.

50) Forst h of : Maßnahme-Gesetze S. 222 f., vgl. auch Dens.: Verwaltungsrecht, I. Bd., 6. Aufl. 1956, S. $58 \mathrm{ff}$.

60) Zum typischen Gesetzesinhalt vgl. Carl Schmith: Die geistesgeschichtliche Lage des heutigen Parlamentarismus, 2. Aufl. 1926, S. $52 \mathrm{ff}$., und D e n s.: Verfassungslehre, S. $151 \mathrm{ff}$. Daß dieser typische Inhalt aber nicht der einzig mögliche ist, weist $\mathbf{R}$ os $\mathbf{5}$ : Rechtsquellen, insbes. S. $378 \mathrm{ff}$., überzeugend nach.

11) Richand Thoma: Der Polizeibefehl im badischen Recht, Bd. I, 1906, S. $60 \mathrm{f}$; vgl. dazu auch Hildegard $\mathrm{Kr}$ üg er: DVBl. 1955, S. 761 . 
b) er betrifft nur einen einzelnen Fall oder einen klar abgegrenzten Kreis von Fällen;

c) er erfaßt nur Fälle eines bestimmten, nach Daten festgelegten Zeitraumes.

Ich möchte die erste Art abgekürzt "Einzelpersonengesetz", die zweite "Einzelfallgesetz" und die dritte „Zeitgesetz" nennen und dabei den von Forsth of $f$ als "generelles aber konkretes Gesetz" bezeichneten Sachverhalt ${ }^{62}$ ) wegen des von vornherein feststehenden, wenn auch vielleicht nicht immer kleinen Kreises von betroffenen Fällen unter die "Einzelfallgesetze“ rubrizieren ${ }^{\text {(3) }}$.

Ehe wir uns den Einzelperson- und den Einzelfallgesetzen speziell zuwenden, darf festgestellt werden, daß es nicht darauf ankommt, ob solche Gesetze ihren Individualcharakter offen zeigen, oder ob sie ihn hinter einer generellen und abstrakten Fassung verstecken. Mit Recht weist Forsthof $f$ auf das Gesetz über den Ausgleich bürgerlichrechtlicher Ansprüche vom 13. Dezember 1934 (RGBl. I S. 1235) hin, das zwar abstrakt und generell formuliert war, in Wirklichkeit aber geschaffen wurde, um einen bestimmten Rechtsstreit dem Gericht zu entziehen ${ }^{64}$ ). Auch "getarnte“ Individualgesetze ${ }^{65}$ ) müssen nach ihrem wahren Inhalt beurteilt werden, nicht nach ihrer - bewußt oder unbewußt - falschen Selbstqualifikation.

Diese Tarnung ist auch nicht durch die typische konditionale Formalstruktur des Rechtssatzes ${ }^{66}$ ) gerechtfertigt. Denn es wäre sinnlos, den Gesetzgeber auch dann zu einer generellen und abstrakten Formulierung zwingen zu wollen, wenn ein Gesetz seinen Tatbestand nur auf einen oder wenige bereits feststehende Sachverhalte gründet. In solchen Fällen ist vielmehr das Abweichen von der üblichen Form ein Gebot der Ehrlichkeit. Wo der Gesetzgeber diese Ehrlichkeit vermissen läßt, muß er sich als Ausnahme von der allgemeinen deutschen Auslegungsregel für Gesetze auch bei scheinbar eindeutigem

62) Forsth of : Maßnahme-Gesetze S. 224.

63) Ebenso Hildegard Kr ü g e r, DVBl. 1955 S. 761.

64) Forsth of if: Maßnahme-Gesetze S. 223.

B5) Hildegard $\mathrm{K}$ r ü g e r, DVBl. $1955 \mathrm{~S} .761$, die daneben auch den m. E. weniger zutreffenden Ausdruck „abstrakte“ Individualgesetze verwendet.

66) „Wenn durch ein Zurechnungssubjekt oder ein Ereignis ein Tatbestand verwirklicht ist, dann soll ein Zuondnungssubjekt, d. h. darf ein Rechtssubjekt oder soll ein Pflichtsubjekt, eine Rechtsfolge setzen"; vgl. Hans J. W o l f $f$ : Der Unterschied zwischen öffentlichem und privatem Recht, AöR 76 (1950) S. 205 ff. (208); ähnlich Hans Kels e n: Allgemeine Staatslehre, 1925, S. 49, der jedoch die Rechtsfolge mit dem Zwangsakt identifiziert. 
Wortlaut eine gründliche Prüfung seiner Motive gefallen lassen.

Bei der Forderung, Individualgesetze nicht hinter generellen und abstrakten Fassungen zu verstecken, müssen wir allerdings dem Einwand begegnen, wie ein solches Gesetz, das doch gleichwohl Rechtssatz sein soll, sich unterscheidet vom staatsleitenden Akt des Legislativorgans, dem wir den Rechtssatzcharakter nicht zuerkennen konnten. Der Unterschied liegt darin, da $B$ der staatsleitende Akt vorhandene Verfassungsrechtssätze auf einen konkreten Sachverhalt des Verfassungslebens anwendet, während das Individualgesetz für den konkreten Fall anwendbares positives Recht schafft.

Vielzitierte Beispiele für deutsche Einzelpersonengesetze sind das preußische Dotationsgesetz vom 28. Dezember 1866 (GS 1867 S. 25) und das Gesetz über die Befreiung des Reichspräsidenten von Hindenburg von Reichs- und Landessteuern für das Rittergut Neudeck vom 27. August 1933 (RGBI. I S. 595). Ihr Maßnahmecharakter liegt auf der Hand. Im übrigen sind offene Einzelpersonengesetze in Deutschland sehr selten. Häufiger kommen getarnte Einzelpersonengesetze vor. Ein neueres Beispiel bietet das Straffreiheitsgesetz vom 17. Juli 1954 (BGBl. I S. 203) in seinem ominösen § 8. Während die übrigen Bestimmungen dieses Gesetzes, ähnlich wie schon das Straffreiheitsgesetz vom 31. Dezember 1949 (BGBl. S. 37), bestrebt sind, einen Strich unter eine in vieler Hinsicht verworrene und oft rechtlose Zeit $\mathrm{zu}$ ziehen, und damit der Wiederherstellung der gestörten Rechtsordnung dienen ${ }^{67}$ ), bezweckt $\S 8$ des Straffreiheitsgesetzes 1954 einen bestimmten, relativ kleinen Personenkreis, der in die sogen. Platow-Affaire verwickelt war, der Strafverfolgung zu entziehen. Mit Recht stellt Forsth off auf Grund der Vorgeschichte dieser Bestimmung fest, daß hier nicht eine „am Gerechtigkeitsgedanken orientierte Intention des Gesetzgebers" verwirklicht wurde, sondern bloße Zweckmäßigkeitserwägungen zum Zuge kamen ${ }^{69}$ ). Wir haben es also bei dieser Bestimmung mit einer Maßnahme zu tun, die sich in doppelter Weise tarnt; einmal ist sie in einem Gesetz versteckt, das im übrigen keinen Maßnahmecharakter hat; und zum anderen versucht sie, den unbefangenen Leser durch eine generelle und abstrakte Formulierung zu täuschen.

87) Vgl. BVerfGE 2 S. 213 ff., 219, und F or s th of $f$ : MaßnahmeGesetze S. 227 Anm. 10. - Auf die Streitfrage, ob die Amnestie generelle Begnadigung ist oder Korrektur des Rechts, kann hier nicht eingegangen werden; vgl. dazu BVerfG, aaO., und das dort zit. Schrifttum.

68) Forsth of : Maßnahme-Gesetze S. 227. 
Die meisten Individualgesetze sind Einzelfallgesetze. Beispiele sind in fast jedem Bande des Bundesgesetzblattes zu finden. Ich darf aus diesem Jahr anführen das Gesetz zur Förderung der deutschen Eierwirtschaft vom 31. März 1956 (BGBl. I S. 239), auf Grund dessen den Hühnerhaltern zum Ausgleich für die über dem Weltmarktniveau festgehaltenen deutschen Futtermittelpreise für jedes in den Verkehr gebrachte Hühnerei ein Ausgleichsbetrag gezahlt wird; ferner auch das Gesetz über die Handwerkszählung vom 12. Juni 1956 (BGBl. I S. 495). Zwei besonders instruktive Beispiele finden sich in der dänischen Gesetzgebung dieses Jahres. Das Gesetz Nr. 86 vom 6. April 1956 (Lovtidende A 1956 Nr. XII, S. 174) gebietet den Arbeitern der Transportgesellschaften und einiger namentlich aufgezählter Mineralölbetriebe den von ihrer Gewerkschaft angeordneten Streik sofort abzubrechen und ihn frühestens am Ende des neunten Tages wiederaufzunehmen. Das Gesetz Nr. 93 vom 13. April 1956 (Lovt. A 1956 Nr. XV S. 227) reagiert auf die Tatsache, $\mathrm{da} \beta$ in der mit dem vorigen Gesetz erzwungenen Streikpause eine Einigung der Tarifpartner nicht zustande kam, der Streik vielmehr in anderen Wirtschaftszweigen fortgesetzt worden war, indem es den Tarifvertrag des staatlichen Schlichters für verbindlich und für die Dauer von zwei Jahren alle Streiks für gesetzwidrig erklärt.

Der Maßnahmecharakter auch dieser Gesetze ist unverkennbar. Gleichwohl wäre der Schluß voreilig, daß Individualgesetze notwendig Maßnahmegesetze sein müßten. Es spricht allerdings eine gewisse Vermutung dafür. Denn in vielen Fällen wird schon die Tatsache, daß es sich um ein individuelles Rechtsverhältnis handelt, den Gesetzgeber in die Richtung einer rein zweckhaften Regelung drängen. Auch ein Individualgesetz kann aber primär dem Ziele dienen, einen einmaligen Sachverhalt nach gerechten Maßstäben $\mathrm{zu}$ ordnen. Ich möchte hier neben dem von Forsth of $f$ erwähnten Fall des früheren Reichfilmvermögens ${ }^{69}$ ) vor allem an die Notstandsgesetzgebung zu Gunsten Berlins denken.

Als letztes in der Gruppe der inhaltlich atypischen Gesetze ist das $\mathrm{Z}$ eitgeset $\mathrm{z}$ auf seinen Maßnahmecharakter zu prüfen. Dabei ist jedoch anzumerken, da $B$ dieser systematischen Unterscheidung keine strenge Trennung in der Rechtswirklichkeit entspricht; vor allem Einzelfallgesetze sind häufig zugleich Zeitgesetze; unsere Beispiele versuchen unter diesen Umständen nur, ein Uberwiegen des einen oder anderen Moments zu berücksichtigen.

69) Forsth off: Maßnahme-Gesetze S. 226. 
In einem Zeitschriftenaufsatz bezeichnet Otto $\mathrm{H}$ a ussleiter Zeitgesetze schlechthin als Maßnahmerecht ${ }^{70}$ ). Wenn auch die Begrenzung der Geltungsdauer ein gewichtiges Indiz für das Vorliegen eines Maßnahmegesetzes sein kann, möchte ich $\mathrm{H}$ a u s $\mathrm{l}$ e i t e $\mathbf{r}$ in dieser Allgemeinheit doch nicht zustimmen. Es wäre sinnlos, z. B. ein zur Bekämpfung bestimmter Kriegsfolgen ergehendes Gesetz dann als Dauergesetz zu verabschieden, wenn die erstrebte Wiederherstellung eines nach dem Maßstabe der Gerechtigkeit geordneten Zusammenlebens der Bürger zu einem bestimmten, voraussehbaren Zeitpunkt erreicht sein kann und soll. Die Kriegsfolgegesetzgebung verschiedener Länder bietet gute Beispiele für von der Rechtsidee beherrschte Zeitgesetze.

Oft allerdings werden Gesetze, die einer zeitbedingten Situation zu begegnen suchen, jene enge Verknüpfung von Zweck und Mittel aufweisen, welche das Maßnahmegesetz kennzeichnet. Beispiele aus jüngerer Zeit sind das Gesetz über Preise für Getreide inländischer Erzeugung für das Getreidewirtschaftsjahr 1951/52 vom 21. Juli 1951 (BGBl. I S. 451) oder das Gesetz über eine zeitweilige besondere Regelung der Prüfung der Jahresabschlüsse von Eisenbahnaktiengesellschaften des öffentlichen Verkehrs vom 25. Dezember 1955 (BGBl. I S. 868).

Eine gegenüber der These $\mathrm{H}$ ausleiters umgekehrte Feststellung läßt sich jedoch treffen: Wenn das Maßnahmegesetz nicht bereits als Individualgesetz auf einen klar umgrenzten Kreis von Personen oder Fällen zugeschnitten ist, dann muß es seine Geltungsdauer zeitlich beschränken. Denn eine konkrete Situation kann logisch nicht unbegrenzt andauern.

Mit der Erkenntnis, daß Maßnahmegesetze stets entweder Individualgesetze oder Zeitgesetze sind, ist die Grenzziehung gegenüber den normalen Gesetzen noch nicht abgeschlossen. Es ist vielmehr noch ein Unsicherheitsfaktor zu berücksichtigen, den ich wiederum an einem Grenzfall deutlich machen möchte, nämlich an dem Gesetz über die Investitionshilfe der gewerblichen Wirtschaft vom 7. Januar 1952 (BGBl. I S. 7). Es wäre nach meiner Terminologie unter die Einzelfallgesetze $z u$ rechnen und wird meist als typisches Beispiel für ein Maßnahmegesetz angeführt ${ }^{71}$ ).

70) Otto H a ussleiter: Maßnahmerecht und Dauerrecht auf dem Gebiet der wirtschaftspolitischen Verondnungs- und Gesetzgebung, DöV $1956 \mathrm{~S} .143 \mathrm{ff}$.

71) Vgl. For st h off: Maßnahme-Gesetze S. 226 f. und Hildegand $\mathrm{K}$ r ü ger, DVBl. 1955 S. 761 . 
Forsthoff meint, der Maßnahmecharakter dieses Gesetzes sei deutlich geworden, „als infolge der wirtschaftlichen Entwicklung während seiner Durchführung die Erwägungen hinfällig wurden, die das Gesetz veranlaßt hatten"72). Grade diese - durchaus zutreffende - Feststellung gibt Anlaß zu Zweifeln, ob jene Qualifikation des Investitionshilfegesetzes so unproblematisch ist. Ich glaube nämlich, daß diesem Gesetz bei aller unbestreitbaren Zweckhaftigkeit ursprünglich auch der Gedanke zugrunde lag, im Wege der Vorteilsausgleichung eine ungerechte Benachteiligung der Grundstoffindustrien wettzumachen, deren wirtschaftliche Entwicklung vor allem durch die besatzungsrechtlichen Entflechtungsvorschriften gehemmt worden war. Ob dieser am Maßstabe der Gerechtigkeit orientierte Gesetzeszweck den rein wirtschaftlichen überwog oder doch wenigstens so stark ins Gewicht fiel, daß der Maßnahmecharakter des Investitionshilfegesetzes zum Zeitpunkte seiner Entstehung verneint werden kann, mag hier dahingestellt bleiben ${ }^{73}$ ). Bei diesem Beispiel kommt es mir nur darauf an, zu zeigen, daß bei solchen Gesetzen die Clausula rebus sic stantibus eine gewichtige Rolle spielt. Schon Carl $\mathrm{Schmitt}$ hat auf ihre Bedeutung im Zusammenhange mit dem Maßnahme-Begriff hingewiesen ${ }^{74}$ ). Ich möchte seine These dahin erweitern, daß Maßnahmegesetze nicht nur hinsichtlich ihrer Anwendbarkeit der Clausula unterliegen, sondern daß diese für die Eingruppierung eines Gesetzes als Norm oder als Maßnahme selbst von Bedeutung sein kann. Es gibt Ge se t z e zunächst unbestimmten $\mathrm{Ch}$ arakters, bei denen erst der Lauf der allgemeinen Entwicklung eine Bestimmung nach der einen oder anderen Seite herbeizuführen vermag. Die wirtschaftliche Entwicklung in der Bundesrepublik hatte im Falle des Investitionshilfegesetzes die ursprünglich ungerechte Situation ausgeglichen, ohne daß es dazu der vollen Durchführung des Gesetzes bedurft hätte. Spätestens von diesem Zeitpunkte ab wurde das zuvor unbestimmte Gesetz als Maßnahmegesetz fixiert, mit all' den Folgen, von denen noch zu sprechen sein wird. Es ist aber auch der umgekehrte Fall denkbar, daß eine Verschlechterung der allgemeinen Lage tragbare Ungleichheiten derart $\mathrm{zu}$ Ungerechtigkeiten verschärft, daß in einem bis dahin unbestimmten Gesetz der Gerechtigkeitsgehalt die in ihm zunächst überwiegende $Z$ weckhaftigkeit ganz zurückdrängt ${ }^{75}$ ).

72) Forsth off aaO.

73) Vgl. dazu BVerfGE 4 S. 7 ff., 18.

74) Carl S c h m it t, VVDStRL 1 S. 97.

73) Ohne näher darauf einzugehen, erwähnt Herbert K r üg e r, Rechtsverondnung S. 230 ff., 235, diese Möglichkeit als "Merkposten“. 
Damit haben wir das Feld abgeschritten und können als Ergebnis unserer Bestandsafnahme festhalten:

Maßnahmegesetze sind stets entweder auf einen von vornherein feststehenden Kreis persönlicher oder sachlicher Lebenssachverhalte gerichtet oder auf eine zeitlich begrenzte konkrete Situation.

Der Umkehrschluß, daß jedes solche Gesetz ein Maßnahmegesetz sei, ist unzulässig; es besteht lediglich eine widerlegliche Vermutung dafür.

Es gibt Gesetze, in denen neben ihrer primären Zweckgerichtetheit ein entwicklungsfähiger Keim für die Aufrichtung einer gerechten Ordnung schlummert; dieser Keim kann auf Grund der allgemeinen Entwicklung absterben, dann ist das Gesetz unbestimmten Inhalts als Maßnahmegesetz fixiert; er kann sich aber auch so kräftig entwickeln, daß dahinter die Zweckhaftigkeit zurücktritt; dann kann von einem Maßnahmegesetz nicht mehr gesprochen werden.

IV.

Bei der bisherigen Bestandsaufnahme habe ich mich bewußt jeder Wertung enthalten, um zunächst einmal den vorliegenden Tatbestand zu registrieren. Das bedeutet natürlich nicht, daß ich zur Maßnahmegesetzgebung als solcher und zu jedem einzelnen ihrer Produkte uneingeschränkt Ja sage. Mit Recht hebt Forsth off hervor, daß auch abgesehen von den Einschränkungen in Art. 19 Abs. 1 und 79 GG die Gesetzgebungskompetenz des Bundestages in Art. 77 Abs. 1 Satz 1 GG nicht als "Ermächtigung zu beliebigem Tun" verstanden werden darf. Denn das Maßnahmegesetz stelle jedenfalls einen $\mathrm{E}$ in bruch in die von der Gewaltentrennung vora usgesetzte Eigenständigkeit der Exekutive dar. Er fügt allerdings einschränkend hinzu, daB die in Art. 20 Abs. 2 in Verbindung mit Art. 79 Abs. 3 GG zum unabänderlichen Bestandteil der Verfassung erhobene Gewaltentrennung im Grundgesetz ,auf eine durchaus individuelle, von herkömmlichen Vorstellungen vielfach abweichende Weise verwirklicht" worden sei $^{76}$ ).

Hier müssen wir etwas weiter ausholen. Es ist zwar schon rein zeitlich nicht möglich, an dieser Stelle die Lehre von der Trennung und Balance der Gewalten in ihrer historischen Entwicklung nachzuzeichnen. Einige wenige Gedanken möchte ich

70) Forsth off: Maßnahme-Gesetze S. 227; vgl. auch Hans Peters: Die Gewaltentrennung in moderner Sicht (Arbeitsgemeinschaft für Forschung des Landes Nordrhein-Westfalen, Geisteswissenschaften Heft 25, 1954) S. $10 \mathrm{ff}$. 
aber doch andeuten, die mir für unser Thema wichtig erscheinen.

In bewußter Vereinfachung könnte man sagen, daß die Unterscheidung der Gewalten und der Versuch, sie in ein ausgewogenes Gleichgewicht zu bringen, bei Locke die $\mathrm{Be}$ schreibung eines politischen Zustandes ist, um dessen Verwirklichung im England seiner Zeit nicht ohne Erfolg gerungen wird; und daß Montes qui u diesen Gedanken - neben anderen ${ }^{77}$ ) - aufgreift als politisches Reformprogramm für das absolutistische Frankreich unter dem Roi Soleil. Beiden sind die "Gewalten" echte politische Potenzen, welche in den Funktionszusammenhang des Staates eingebaut sind oder eingebaut werden sollen, um die Ubermacht oder gar Allmacht einer politischen Kraft $\mathrm{zu}$ verhindern und die damit notwendig entstehende Gefahr für die Freiheit der Bürger zu bannen.

Den Politiker Mon tesquieu interessiert die Unterscheidung der Staatsfunktionen in Wahrheit ziemlich wenig; seine recht grobschlächtige Einteilung in Gesetzgebung, Rechtsprechung und Vollziehung der auswärtigen Politik dient ihm nur als Mittel, die vorhandenen politischen Kräfte - Krone, Adel, Volk - die er "Gewalten" nennt, in die notwendige Gleichgewichtslage zu bringen. Und es erscheint gradezu als Beweis für den politischen Charakter dieser Gewaltentrennungslehre, daß bei der Verteilung der Funktionen auf die "Gewalten" die dritte, richterliche Gewalt wieder verschwindet: Sie ist „en quelque façon nulle“"78), weil das politische Gewicht der „noblesse du robe“ gegenüber demjenigen der anderen, am Staatsgeschehen beteiligten Kräfte bis zur Bedeutungslosigkeit zurücktritt.

In England ist die Gewaltentrennung auch weiterhin als politisches Prinzip des Ausgleichs und der Mäßigung der Staatsgewalt verstanden worden; deshalb konnte es dort, wie J e nn in g s überzeugend nachweist ${ }^{79}$ ), zu einer klaren Funktionentrennung nicht kommen. Deutliches Beispiel dafür ist das für deutsches Rechtsdenken fast anstößige Institut der private bills.

77) Daß die Gewaltentrennung in Montes quie us Werk nicht die zentrale Bedeutung besitzt, welche frühere Generationen ihr zuschreiben zu können glaubten, weist Forsth of f in seiner Einleitung zum „Esprit des Lois“ überzeugend nach; vgl. M o n te s quieu : Vom Geist der Gesetze, eingeleitet und herausgegeben von E. Forsth off, 1951, Bd. I S. XXVff.; vgl. ferner Peters : Gewaltentrennung, S. 7 ff.

78) Montesquieu : Vom Geist der Gesetze, Bd. I S. 220.

79) Sir Ivor J e $\mathrm{n} n$ in $\mathrm{gs}$ : The law and the constitution, 3. Aufl., 5. Neudr., 1948, S. 261; vgl. auch $S$ c h e u n e r : Ubertragung rechtsetzender Gewalt S. $134 \mathrm{f}$. 
Ganz anders dagegen verlief die Entwicklung in Deutschland. Die Aktivbürgerschaft als Repräsentant der dem Staate gegenüberstehenden "Gesellschaft" errang dort zunächst ein Mitspracherecht und mit dem Ende des deutschen konstitutionellen Staates das Monopol auf dem Gebiete der Gesetzgebung; in der Verwaltung blieb es bei den Ansätzen der mit den Namen Frhr. vom $S t$ e in und $G n$ e is $t$ verknüpften sogen. politischen Selbstverwaltung; und in der Rechtsprechung kam es nur zu der wenig bedeutsamen Einschaltung des Laienelements in die Straf- und Verwaltungsgerichtsbarkeit. Wichtig für unseren Zusammenhang ist aber, daß damit der liberale Gedanke der politischen Gewaltentrennung im Kerne aufgegeben wurde zugunsten des, egalitär-demokratischen Forderungen entsprechenden, Versuchs, den ganzen Staat gleichmäßig zu durchdringen $\left.{ }^{80}\right)$.

Das hat zwei Konsequenzen:

Einmal werden nun nicht mehr gewachsene politische Kräfte einander gegenübergestellt, balanciert und in das staatliche Verfassungssystem eingefügt; denn diese Kräfte sind im Zuge derselben Entwicklung bereits politisch und zunehmend auch sozial in die bürgerliche "Gesellschaft" eingeschmolzen worden. Das um der Erhaltung der Freiheit willen notwendige potentielle Gleichgewicht politischer Kräfte verlagert sich aus dem in der Verfassung vorgezeichneten Raum in die - nach

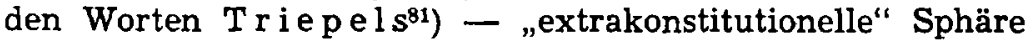
der politischen Parteien. Hier, im Wechselspiel von Regierungsmehrheit und Opposition, lebt der politische Gleichgewichtsgedanke Montesquieus fort ${ }^{82}$ ).

Was in den Verfassungen als "Gewaltentrennung" angesehen wird - und damit kommen wir zur zweiten Konsequenz dieser Entwicklung - ist zu einer bloßen Funktionenunterscheidung verblaßt, also zu einem technischen Mittel der Verfassungsorganisation ${ }^{83}$ ).

Das Grundgesetz rezipiert mit seinem Bekenntnis zum Mehrparteienstaat und zum parlamentarischen System die Gleichgewichtsfunktion der politischen Parteien; ja es macht

80) Vgl. dazu auch $H$ e c ke l, HDStR II S. 388 f.

81) Heinrich Triepel, Die Staatsverfassung und die politischen Parteien, 2. Aufl. 1930, S. 29 f.

82) Vgl. dazu auch Werner We be r: Spannungen und Kräfte im westdeutschen Verfassungssystem, 1951, S. $25 \mathrm{f}$.

83) Auf die Notwendigkeit einer Unterscheidung dessen, das hier als "Gewalt" und „Funktion" einander gegenübergestellt wird, weist auch hin Hermann Jah rre is s : Die Wesensverschiedenheit der Akte des Herrschens und das Problem der Gewaltenteilung (Vom Bonner Grundgesetz zur gesamtdeutschen Verfassung, Festschrift für Hans Nawiasky, 1956, S. 119 ff.), S. 121. 
in seinem Art. 21 sogar den Versuch, sie verfassungsrechtlich zu "incorporieren" ${ }^{\text {"84) }}$, und folgt damit dem Vorbilde $\mathrm{M}$ ontesquieus, der ja auch vorhandenen politischen Kräften ihren festen Platz innerhalb der Verfassung zuweisen wollte ${ }^{85}$ ).

Zum anderen verlangt es zwischen der Rechtsprechung und den übrigen Staatsfunktionen eine klare Unterscheidung, weil es die Rechtsprechungsfunktionen ${ }^{88}$ ) in Art. 92 GG den Richtern anvertraut, also voraussetzt, daß diese Funktion eindeutig umgrenzbar und umgrenzt ist ${ }^{87}$ ).

Das Grundgesetz geht aber noch einen Schritt weiter. Indem es die Richter zu Hütern des Rechts auch gegenüber den mit der Wahrnehmung der anderen Staatsfunktionen Betrauten bestellt und diese ihrerseits an Recht und Gesetz bindet, verwandelt es die Funktionentrennung in eine wirkliche Gewaltentrennung zurück: Während alle anderen Staatsorgane ihren Auftrag letztlich auf die Volkssouveränität zurückführen, finden die Rechtsprechungsorgane die Legitimation ihres Tuns in der „Souveränität“ des Rechts. Das Grundgesetz weist also insofern "dualistische" Züge auf, als es dem demokratischen Prinzip der Volkssouveränität das materiell-rechtsstaatliche Prinzip der "Souveränität" des Rechts gegenüberstellt ${ }^{83}$ ).

Dagegen ist dem Grundgesetz eine klare Funktionentrennung zwischen Gesetzgebung, Regierung und Verwaltung fremd. Wohl ist es möglich, zwischen Rechtssatz und Staatsakt zu unterscheiden; das haben unsere Untersuchungen zum sogen. rein formellen Gesetz gezeigt, das ein Staatsakt des Legislativorgans ist. Ferner ergibt Art. 80 Abs. 1 Satz 1 GG, daß die Rechtsetzungskompetenz bei den Legislativorganen liegt, und die Exekutive zur Rechtsetzung deren Ermächtigung bedarf. Es ist aber nicht möglich, dem Grundgesetz ein allgemeines Verbot zu entnehmen, demzufolge die Legislativorgane nicht

84) Triepe 1 : Staatsverfasoung S. 12.

85) Vgl. dazu P e t e r s : Gewaltentrennung S. $24 \mathrm{ff}$., $31 \mathrm{ff}$., der mit Recht auch die Funktion eines föderativen Staatsaufbaus im Sinne einer politischen Gewaltentrennung deutet, Friedrich August Frhr. von der $\mathrm{H}$ e y d t e : Freiheit der Parteien, Die Grundrechte, herausgegeben von Franz L. N e u m a n n, Hans Carl N i p per d e y und Ulrich. S c h e u n e r, Bd. II, 1954, S. $457 \mathrm{ff}$., und meinen Aufsatz: Zur verfassungsrechtlichen Stellung der deutschen politischen Parteien, AöR 78 (1952) S. $149 \mathrm{ff}$

80) Die Bezeichnung "rechtsprechende Gewalt" in Art.92 GG ist - wie noch darzulegen sein wird - gleichwohl richtig.

87) Zum Begriff der Rechtsprechung vgl. mein System des verwaltungsgerichtlichen Rechtsschutzes, S. 36-50, und das dort angegebene Schrifttum.

88) Es überschneiden sich also im GG zwei Formen von Gewaltentrennung. 
konkrete Sachverhalte auch über die in der Verfassung genannten Fälle hinaus nach Zweckgesichtspunkten regeln, also gestaltende Regierung und Verwaltung ausüben dürften ${ }^{89}$ ). Das folgt m. E. zwingend aus der Tatsache, daß die Volksvertretung heute Repräsentant des Souveräns ist, und daß ihr daher - soweit die geschriebene oder ungeschriebene Verfassung nichts anderes bestimmt - dessen Prärogative zugewachsen ist.

Diese Antwort könnte anders lauten, wenn das Grundgesetz dem Umstande Rechnung getragen hätte, daß der heutige Staat nun einmal zuweilen genötigt ist, Maßnahmen mit Gesetzeskraft zu treffen. Wenn unsere Verfassung ein Staatsorgan oder mehrere gemeinsam mit der Kompetenz ausgestattet hätte, in sinnvoller Fortentwicklung des Art. 48 WRV, also gelöst vom "klassischen" Institut des Ausnahmezustandes, konkreten Sonder- und vor allem Notsituationen politischer, sozialer oder wirtschaftlicher Art mit der gesetzesvertretenden Verordnung zu begegnen, dann könnte eine klare Trennungslinie zwischen Legislativ- und Exekutivfunktionen gezogen werden ${ }^{00}$ ). Dadurch würde nicht nur die rechtsstaatliche Formtypik wiederhergestellt, welche die Gefahr eines Parlamentsabsolutismus hintanhalten könnte ${ }^{01}$ ) ${ }^{92}$ ); die Schaffung einer derartigen

89) $\mathrm{Zu}$ diesen Begriffen vgl. mein System des verwaltungsgerichtlichen Rechtsschutzes S. 28, $30 \mathrm{f}$.

00) Ebenso Forsth off: Maßnahme-Gesetze S. 228. - Diese Trennung zwischen Legislativakten (Gesetzen) und Verondnungen des Reichspräsidenten auf Grund des Art. 48 Abs. 2 WRV, die inhaltlich Maßnahmen sind, hält Carl S ch m it t noch klar aufrecht, wenn er trotz praktisch oft übereinstimmender Wirkung zwischen der verfassungsrechtlich formalisierten Gesetzgebung und der aus Art. 48 Abs. 2 WRV fließenden Befugnis, Maßnahmen zu treffen, scharf unterscheidet und hinzufügt, der Reichspräsident sei kein Gesetzgeber. Wenn Sch mitt so allen Akten den Maßnahmecharakter abspricht, die „durch verfassungsmäßige Bindung an ein bestimmtes Verfahren eine solche Rechtsförmigkeit erhalten haben, daß sie aufhören, ausschließlich durch die Lage der Verhältnisse bestimmt zu werden", so wird deutlich, daß er den Maßnahmebegriff weniger inhaltlich bestimmt wissen will, als vielmehr situationsbedingt; vgl. S c h m itt, VVDStRL 1 S. $99 \mathrm{f}$.

01) Ebenso F orsth of : Maßnahme-Gesetze S. 228.

02) Es würde damit auch eine sehr sinnvolle Unterscheidung der Staatstheorie aus der ensten Hälfte des 19. Jahrhunderts wieder aufgenommen, welche im Gesetz inhaltlich das allgemein Grundlegende, Ondnungen Schaffende erblickte, während stie besondere, auch lokale und temporäre Fragen der Regelung durch Maßnahmen im Verordnungswege vorbehielt; vgl. dazu etwa He g e 1: Grundlinien der Philosophie des Rechts \$211 (Hegels Schriften zur Gesellschaftsphilosophie, Teil I, herausgeg. von Alfred $B$ a e u m le r, 1927, S. $744 \mathrm{ff}$.), Carl von R ott e $\mathrm{ck}$ : Lehrbuch des Vernunftsrechts, 2. Aufl. 1840, Bd. II S. 326 ff., Friedrich Julius $S$ t a h 1 : Die 
Kompetenz würde vor allem mit einer klaren Regelung der Voraussetzungen für ihre Ausübung mißbräuchliche Maßnahmegesetzgebung erschweren und ihre verfassungsgerichtliche Kontrolle erleichtern ${ }^{93}$ ).

Solange aber eine solche Kompetenz nicht besteht, sind die Schranken für eine Maßnahmegesetzgebung nicht dem Funktionentrennungsschema zu entnehmen, sondern finden sich in der materiell-rechtsstatichen Struktur des Grundgesetzes, welche nicht nur alle Staatsorgane an die Formen der Verfassung bindet, sondern sie alle - auch den Gesetzgeber - dem Recht unterwirft und damit die alte Unterscheidung von lex und jus wiederaufnimmt, die der Positivismus des 19. Jahrhunderts zu unserem Unheil nicht mehr sehen wollte.

Daraus ergeben sich folgende Konsequenzen, die ich nur noch thesenartig vortragen möchte.

Eingriffe in die grundrechtlich gesicherte Freiheitssphäre sind schon wegen Art. 1 und 2 Abs. 1 GG nur unter gerechter Abwägung der Interessen von Allgemeinheit und Betroffenen zulässig; Maßnahmegesetze in diesem Bereich sind verfassungswidrig, da für grundrechtseinschränkende Gesetze der Gerechtigkeitsmaßstab unverzichtbar ist, also eine bloß zweckmäßige Lösung nicht genügt. Das gilt nicht nur für die nach Art. 19 Abs. $1 \mathrm{GG}^{94}$ ) verbotenen Individualgesetze einschließlich ihrer Tarnformen, sondern auch für legitimerweise abstrakt und generell formulierte Zeitgesetze, wenn sie nicht, wie die Beispiele in Art. 13 Abs. 3 GG deutlich machen, der

Philosophie des Rechts, 2. Aufl. 1846, II, 2, §55, Lorenz von S te in : Verwaltungslehre, 1865 , Bd. I S. $78 \mathrm{f}$., D e n s.: Handbuch der Verwaltungslehre, 3. Aufl. 1888, Bd. I, S. $100 \mathrm{ff}$., Karl Salomon Z a c h a r i a e: Vierzig Bücher vom Staate, 1820, 21. Buch, S. 11, 13 f., Heinrich $\mathrm{Z}$ oe $\mathrm{p} \mathrm{fl:}$ : Grundsätze des gemeinen deutschen Staatsrechts, Teil II, 5. Aufl. 1863, $\S 4338 \mathrm{f}$. - Einschnänkend allendings Carl Theodor Wel cke r, Staatslexikon Bd. 6, 1838, S. $41 \mathrm{f}$.

93) Ein solcher Schritt des Verfassungsgebers erschiene mir wirkungsvoller als der von $\mathrm{Ha}$ a us le it e r, DöV $1956 \mathrm{~S}$. $143 \mathrm{ff}$., vorgeschlagene Weg des befristeten Richtliniengesetzes; für die gegenwärtige Situation allerdings verdienen Haussleiters Anregungen durchraus Beachtung, zumal dafür auch auf österreichische Erfahrungen zurückgegriffen werden kann; vgl. dazu Theo $M$ a y e $\mathrm{r}-\mathrm{M}$ a $1 \mathrm{y}$ : Das Verhältnis zwischen Gesetz und Verondnung in der Rechtsgeschichte, AöR 80 (1955) S. $157 \mathrm{ff}$., $169 \mathrm{f}$.

94) In Art. 19 Abs. 1 GG wird der von der Stalatslehre des Spätkonstitutionalismus sogen. "materielle Gesetzesbegriff“ wieder aufgenommen, der mit der "Freiheit- und Eigentum-Formel“ umschrieben wird; vgl. dazu z. B. A n s chütz, WBStVwR II S. 215. Mit Recht hebt Carl S ch m it : Verfassungslehre, S. 148 f, den politischen Charakter dieses Gesetzesbegriffes hervor. 
Erhaltung eines der Grundrechtsordnung entsprechenden $\mathrm{Zu}-$ sammenlebens der Bürger gegenüber einer vorübergehenden Bedrohung dienen.

Die rechtsprechende Gewalt ist unabhängig von allen Organen, die ihre Kompetenz auf die Volkssouveränität zurückführen; sie ist allein dem Recht verpflichtet. Daher sind Maßnahmegesetze stets verfassungswidrig, wenn sie die Zuständigkeit des "gesetzlichen Richters" antasten. Ich halte deshalb $\$ 8$ des Straffreiheitsgesetzes 1954 aus den oben erörterten Gründen für verfassungswidrig. Für die nach Art. $101 \mathrm{Abs}$. 2 GG zulässigen Gesetze, durch die Gerichte für besondere Sachgebiete errichtet werden können, sind Abstraktheit, Generalität und zeitliche Unbegrenztheit erforderlich, d. h. sie müssen die Gerichtsverfassung weiter ausbauen, dürfen sie aber nicht für einen bestimmten Kreis von Fällen oder Personen oder für eine bestimmte Zeit durchbrechen.

Maßnahmegesetze sind - wie ich bereits andeutete - Fälle gestaltender Regierung und Verwaltung. Ich darf jetzt hinzufügen: $n u r$ in diesem Bereich können sie zulässig sein. Aus dem Gegensatz von gestaltender und rechtsvollziehender Regierung bzw. Verwaltung ergibt sich, daB die Regelung einer konkreten Situation durch Maßnahmegesetz stets dann unzulässig ist, wenn die positive Rechtsordnung bereits Organe eingesetzt hat, die für jene Regelung zuständig sind, und bereits materiell-rechtliche Vorschriften bereitgestellt hat, die objektiv geeignet sind, die erforderliche Regelung im Wege der Rechtsanwendung herbeizuführen. D. h. der Gesetzgeber darf durch Maßnahmegesetz nicht bestehende Kompetenzen an sich ziehen. Er darf das vorhandene materielle und Organisationsrecht auch nicht durch Maßnahmegesetz ändern. Denn die Rechtsnorm, die nach dem Gerechtigkeitsmaßstab eine Ordnung eigenen Wertes aufrichtet, hat höheren Rang, als das nur zweckorientierte Maßnahmegesetz. Jenes - so könnte man vielleicht sagen - erlangt Rechtsgültigkeito5), dieses nur positivrechtliche Geltung ${ }^{\text {p)}}$ ).

o5) $\mathrm{Zu}$ dem Problem, wie gesatztes Recht sich „einbürgert“, vgl. J a hrre is s: Gesetzgebung $\$$. 33 ff., und Gerhard $S$ t a m mler, ARSP XXXVII S. $211 \mathrm{ff}$.

06) Von dieser Feststellung aus läßt sich vielleicht auch ein neuer Aspekt zur Betantwortung der Frage gewinnen, ob Gesetze kraft ihres in der Uberzeugung der Rechtsgenossen wurzelnden Rechtsgehalts gelten oder nur auf Grund der Möglichkeit staatlicher Zwangsdurchsetzung; vgl. dazu etwa Rudolph von I hering: Der Zweck im Recht, 1893, I S. $320 \mathrm{ff}$., Hans K e ls e $n$ : Allgemeine Staatslehre, 1925, S. 17 f., N a wi a s ky : Allgemeine Rechtslehre, S. $9 \mathrm{ff}$., Wilhelm S a uer: System der Rechts- und Sozialphilosophie, 2. Aufl. 1949 S. 191, Rudolf S t a m m le r: Lehrbuch der 
Auch inhaltlich muß das Maßnahmegesetz besonders strengen Anforderungen genügen. Wie jede Exekutivhandlung ist es dem Grundsatz der Verhältnismäßigkeit von Zweck und Mittel unterworfen. Während es sinnlos wäre, etwa die Institutionen des Bürgerlichen Gesetzbuches an diesem Grundsatze messen zu wollen, gibt er bei Gesetzen, die durch ein besonders Aufeinander-Bezogensein von Zweck und Mittel begrifflich bestimmt sind, eine brauchbare Handhabe für die Kontrolle ihrer Rechtmäßigkeit. Mit Recht hat daher das Bundesverfassungsgericht dieses zunächst verwaltungsrechtliche Prinzip $^{97}$ ) bei der Prüfung eines Maßnahmegesetzes mit herangezogen ${ }^{98}$ ). Denn hier kann wirklich von einem Ermessen des Gesetzgebers gesprochen werden, es sind also auch Ermessensfehler denkbar, Begriffe, die dem Legislativbereich sonst wenig adäquat $\operatorname{sind}^{90}$ ).

Wie schon erwähnt unterliegt die Anwendbarkeit des Maßnahmegesetzes der Clausula rebus sic stantibus; sie entfällt also, sobald der Gesetzeszweck erreicht oder sonst gegenstandslos geworden ist ${ }^{100}$ ).

Eine Besonderheit ergibt sich schließlich für die Erzwingung der zur Durchführung eines Maßnahmegesetzes etwa erforderlichen Einzelakte. Ich halte es für rechtswidrig, dafür Kriminalstrafen, und für untunlich, dafür Ordnungsstrafen anzudrohen; denn bestraft werden sollten nur Verstöße gegen ein Gesetz, dessen Inhalt auf die Rechtsidee zurückgeführt werden kann. Die Behinderung einer nur zweckorientierten Maßnahme ist kein Unrecht; gegen sie sollten daher nur Beugemittel an-

Rechtsphilosophie, 3. Aufl. 1928, S. 148; - Hermann Hell e r : Staatslehre, 1934, S. 188, Georg J ell in ek: Allgemeine Staatslehre, 3. Aufl., 3. Neudr. 1921, S. $334 \mathrm{ff}$., Ludwig W a lde cker: Allgemeine Staatslehre, 1927, S. 160 Anm. 1. Weiteres Schrifttum bei Walter G. B e cke r, ARSP XL, S. $410 \mathrm{ff}$. Soweit ein Rechtssatz Konkretisierung des Rechts ist, die lex also auf das jus zurückgeführt wird, gilt er $\mathrm{m}$. E. ohne Rlicksicht auf die staatliche Zwangsordnung; soweit er aber, wie das Maßnahmegesetz, nur lex positiva ist, hängt seine Geltung von seiner Durchsetzbarkeit ab.

97) $\mathrm{Da}$ es darüber hinaus auch in anderen Rechtsgebieten, etwa im Völkerrecht oder im Arbeitsrecht, Bedeutung besitzt, hebt Herbert $K r$ üger: Rechtsverordnung S. 235, hervor.

98) BVerfGE 3 S. 384 ff., 399; das BVerfG erblickt allendings offenbar in den Wahlrechtsvonschriften gegen Splitterparteien, um die es in der Entscheidung geht, kein Maßnahmerecht, wie aus seinen Ausführungen S. 401 hervorgeht; es verwendet den Begriff also in einem engeren Sinne, als er hier gebraucht wind.

09) Ebenso Forsthoff: Maßnahme-Gesetze S. 233 f, und Scheuner: Regierung S. $281 \cdot f$.

100) Vgl. dazu die von $S \mathrm{c}$ h e u ner: Ubertragung rechtsetzender Gewalt, S. $133 \mathrm{f}$., zitierte amerikanische Entscheidung Duncan v. Kahanamoku $(1946 ; 327$ US 304). 
gewandt werden dürfen, deren Vollstreckung mit dem Aufhören der Behinderung einzustellen ist.

Damit bin ich - da die verfassungsgerichtliche Kontrolle im Korreferat behandelt werden soll - am Ende meines Berichts. Lassen Sie mich zum Schluß noch eines sagen: Wir haben gesehen, daß die Maßnahmegesetzgebung in der Bundesrepublik ihre Schranken findet in der materiell-rechtsstaatlichen Struktur des Grundgesetzes. Wegen der Verbindung der dem Gesetz immer noch anhaftenden Autorität mit einer vom Gerechtigkeitsdenken unbeeinflußten Zweckhaftigkeit birgt auch jede zulässige Maßnahmegesetzgebung Gefahren für den Rechtsstaat in sich. Den Rechtsstaat auch gegenüber dem Gesetzgeber zu verteidigen, ist Aufgabe der "Dritten Gewalt". Es scheint mir die Aufgabe unserer heutigen Arbeitstagung zu sein, den Richtern dafür die Wege zu ebnen. 


\section{Leitsātze des Berichterstatters über: Das Gesetz als Norm und MaBnahme}

I.

Dem Bericht wird folgende Terminologie zugrunde gelegt:

1. Als Gesetz soll jeder Rechtssatz gelten, der in der verfassungsmäßig für Gesetze vorgeschriebenen Art und Weise zustande gekommen ist;

Norm und Maßnahme sollen als - theoretisch - mögliche Inhalte eines solchen Rechtssatzes Gegenstand der Untersuchung sein.

2. Rechtsnorm ist das aus einer festgefügten, am Maßstabe der Gerechtigkeit orientierten Ordnung fließende Verhaltensgebot.

3. Maßnahme ist der rechtlich bestimmbare, auf Erzielung gewollter Rechtswirkungen berechnete (Staats-) Akt, der auf eine konkret gegebene Sachlage zweckbestimmt reagiert.

4. Maßnahmegesetz ist ein Rechtssatz, in welchem der Gesetzgeber einen zeitlich und/oder zahlenmäßig begrenzten Kreis von Sachverhalten in einem Tatbestande mit der Absicht zusammenfaßt, ihn einer rein zweckmäßigen Rechtsfolge zu unterwerfen.

II.

1. Staatsleitende Akte des Legislativorgangs (sogen. rein formelle Gesetze) sind keine Maßnahmegesetze, weil ihnen die Rechtssatzeigenschaft fehlt.

2. Weil Maßnahmegesetze auf eine konkrete Situation zweckhaft reagieren, sind sie stets entweder auf einen von vornherein feststehenden Kreis persönlicher oder sachlicher Lebenssachverhalte gerichtet oder auf einen zeitlich begrenzten Bereich; beide Voraussetzungen treffen häufig zusammen.

Der Umkehrschluß, daß jedes solche Gesetz ein Maßnahmegesetz sei, ist unzulässig; es besteht lediglich eine widerlegliche Vermutung dafïi: 
3. Es gibt Gesetze, in denen neben ihrer primären Zweckgerichtetheit ein entwicklungsfähiger Keim für die Aufrichtung einer gerechten Ordnung schlummert; dieser Keim kann auf Grund der allgemeinen Entwicklung absterben, dann ist das Gesetz unbestimmten Inhalts als Maßnahmegesetz fixiert; er kann sich aber auch so kräftig entwickeln, daß dahinter die Zweckhaftigkeit zurücktritt; dann kann von einem Maßnahmegesetz nicht mehr gesprochen werden.

III.

1. Die Schrānken für eine Maßnahmegesetzgebung sind nicht dem Funktionentrennungsschema zu entnehmen, sondern finden sich in der materiell-rechtsstaatlichen Struktur des Grundgesetzes.

2. Maßnahmegesetze sind unzulässig, wenn sie Eingriffe in die grundrechtlich gesicherte Freiheitssphäre oder in die Kompetenz des "gesetzlichen Richters" enthalten.

Sie können nur als Fälle gestaltender Regierung und Verwaltung zulässig sein.

3. Durch Maßnahmegesetz darf der Gesetzgeber weder bestehendes Recht ändern noch nach diesem Recht bestehende Kompetenzen anderer Staatsorgane an sich ziehen.

4. Maßnahmegesetze müssen dem Grundsatz der Verhältnismäßigkeit von Zweck und Mittel genügen.

5. Ihre Anwendbarkeit unterliegt der Clausula rebus sic stantibus; für ihre Durchsetzung sollten keine Strafen, sondern nur Beugemittel angedroht werden. 


\section{Das Gesetz als Norm und Maßnahme}

\section{Mitbericht von Dozent Dr. Herbert We $\mathrm{hrh}$ a h $\mathrm{n}$, Tübingen}

Meine sehr verehrten Herren, lassen Sie mich vorweg bemerken, da $\beta$ in dem folgenden Korreferat das rein formelle Gesetz unerörtert bleiben soll, daß demgemäß die Worte "Gesetz" und "Norm" hier stets in dem Sinne von genereller oder abstrakter Norm verwendet werden.

Das letztere gilt auch für den Begriff des Maßnahmegesetzes, der den Hauptgegenstand auch dieses Korreferats bilden wird. Ich beschränke mich also darauf, einwandfrei abstrakte Maßnahmegesetze, wie sie etwa in den Gesetzen zum Art. 131 GG oder zum Lastenausgleich vor uns stehen, zu erörtern.

Vorbehalte gegen das Maßnahmegesetz als Rechtsbegriff kann ich erst gegen Schluß des Referats erläutern. Bis dahin verwende ich den Begriff in dem Verständnis, das er durch die bisherigen Äußerungen ${ }^{1}$ ) erhalten hat; zur Abwehr von Mißverständnissen fixiere ich dieses Verständnis in vier Punkten:

(1) hinsichtlich des Begriffes: Maßnahmegesetze lassen sich von sonstigen Gesetzen, wenn überhaupt, nur unter dem Zweckgesichtspunkt sondern, etwa als temporären und damit überschaubaren Zwecken derart dienende Gesetze, daß diese $Z$ wecke die Priorität vor den darin normierten, als Verwirklichungsmittel gedachten Rechtsfolgen haben;

(2) hinsichtlich der Ursachen: Maßnahmegesetze werden in ihrer bedrohlichen Häufung ermöglicht durch das Fehlen einer von der Legislative unabhängigen Exekutivspitze und durch Assimilierung der verschiedenen Willensbildungsorgane in Bund und Ländern im Zeichen der Parteiendemokratie und des Parteienbundesstaates;

(3) hinsichtlich der praktischen Folgen: Die Häufung von Maßnahmegesetzen führt zu Störungen im Ablauf der rechtsanwendenden Staatsfunktionen, und sie erweitert und verfestigt die Ausfallerscheinun-

1) i.s.: E. Forsthoff, Uber Maßnahmegesetze; Gedächtnisschrift für Walter Jellinek (1955), S. 221 ff.; de r s. : Lehrbuch des Verwaltungsrechts I (Allg. Teil), 6. Aufl. (München 1956), S. 9, 139, 286; C. F. M e n ger in dem vorstehenden Erstbericht. Zur Herkunft dieses terminus vgl. Carl S $\mathrm{ch} \mathrm{m}$ i $t$, Legalität und Legitimität (München und Leipzig 1932), S. 70 ff. 
gen im rechtsstaatlichen Kontroll- und Balancegefüge, auf denen sie beruht;

(4) hinsichtlich der Kontroll- und Korrekturmöglichkeiten: Im Vordergrund steht die Frage nach solchen Möglichkeiten $d u r c h$ die R e cht s p r e chung als der einzigen Gewalt, die an der Entstehung dieses $P$ hänomens unbeteiligt ist.

\section{Erster Abschnitt}

Unter der Voraussetzung, da $B$ dieses komplexe Phänomen der von uns übereinstimmend gesichtete Gegenstand ist, wenn wir von Maßnahmegesetzgebung sprechen, bitte ich, von der Feststellung ausgehen zu dürfen, daB unsere $B$ e gr if $f l i c h$ $k$ it $z$. Z. noch hinter dieser unserer Einsicht zurückbleibt.

A.

Die Bemühungen, auf die wir zurücksehen, sind von drei Basen ausgegangen.

Voran steht die Gesetzeslehre der konstitutionellen Staatsrechtslehre, unter deren Nachwirkung sich sozusagen das pathologische Symptom der Maßnahmegesetzgebung hat entwickeln können, ohne eine zureichende Diagnose $\mathrm{zu}$ finden, die Unterscheidung von materiellem und rein formellem Gesetz. Unser heutiges Begriffspaar "Gesetz als Norm" und "Gesetz als Maßnahme" deckt sich mit ihr in keinem seiner Teile. Wir meinen mit "Norm" die abstrakte Norm schlechtweg und nicht nur die in Freiheit und Eigentum eingreifende; und wir erblicken eine "Maßnahme" nicht nur im Individualgesetz, sondern auch in einwandfrei abstrakten Normen des Gesetzgebers.

Zwangsläufig wurde die Staatsrechtslehre durch diesen Wandel der Fragestellung genötigt, der Normentheorie der allgemeinen Rechtslehre ihre Begriffe zu entlehnen. Dies gelang aber nur für den Begriff der Norm²), und selbst mit diesem erhielt die Staatsrechtslehre nur einen Stein statt eines Brotes: sie mußte erfahren, $d a ß$ es lediglich eine Standortfrage sei, ob man das moderne positive Gesetz norma-

2) Diesen Schritt tut für die allgemeine Staatslehre G. J e llin e k, Allg. Staatslehre (3. Aufl., 4. Neudruck von 1922), S. 333, für die Staatsrechtslehre Hans $\mathrm{K}$ els e $\mathrm{n}$, Hauptprobleme der Staatsrechtslehre (1911), S. $291 \mathrm{ff}$., auch 226 f. u. ö. Vgl. G. A n s chü tz, Art. "Gesetz" im WB des dt. Staats- und VerwR, 2. Aufl., 2. Bd. (1913), S. 212: „Das Gesetz im materiellen Sinne ist ein Begriff nicht eigentlich des Staatsrechts, sondern der allgemeinen Rechtslehre." 
tivistisch als Norm oder dezisionistisch als Maßnahme des Gesetzgebers verstehe $\left.{ }^{3}\right)$. Einen Versuch, dieses Unvermögen zur Unterscheidung zwischen Norm und Maßnahme $z u$ überwinden, machte Carl Schmitt'), indem er auf den darin liegenden Methodensynkretismus hinwies. Das war, für sich genommen, zutreffend, konnte sich aber nicht durchsetzen; der ererbte Methodensynkretismus war stärker und kennzeichnet unser Rechtsdenken noch heute.

Der Umweg über die allgemeine Rechtstheorie hatte indessen den Wert zu zeigen, daß dem Begriffspaar „Norm“ und „Malsnahme" mit grammatikalischen Deduktionen kein Unterscheidungskriterium abzugewinnen war. Während er noch begangen wurde, setzte der erste nicht ausschließlich formale und wenigstens zu einem gewissen Erfolg führende Versuch ein, das Wesen des Maßnahmegesetzes im Zusammenhang mit der Funktion der Regierung zu bestimmen, getragen und gefördert vor allem von Rudolf Smend und Ulrich Scheuner, aber auch von Carl Schmitt.

$\mathrm{DaB}$ auch dieser Versuch nicht $\mathrm{zu}$ einem durchschlagenden Erfolg führte, liegt an den bekannten Schwierigkeiten, von denen die Frage einer exakten Bestimmung der Regierungsfunktionen umwittert ist, und von denen zwei zugleich entscheidende Schwierigkeiten auch unseres Fragenkreises sind.

Die eine Schwierigkeit ist der bleibende Idealcharakter der Rechtsstaatslehre. Sieht man zunächst von dem Postulat der Grundrechte $a b$, so setzt der traditionelle $e^{5}$ ) Ausgangssatz, daß Freiheit dort ist, wo Gesetze herrschen, eine Ruhelage des Gemeinwesens derart voraus, daß es weder von außen noch

3) Vgl. etwa U. S c h e u n e r, Gesetz und Einzelanordnung; Festgabe für Rudolf Hübner (Jena 1935), S. 195, $215 \mathrm{f}$.

4) Carl S c h m it t, Uber die drei Arten des rechtswissenschaftlichen Denkens (Schrift der Akademie für dt. Recht, Hamburg 1934), S. $35-40$.

s) Cicero, Pro Cluentio, § 53: Omnes legum servi sumus, ut liberi esse possimus; John L o c k e, The second Treatise of Civil Government (benutzte Ausgabe: Thomas I. Cook, New York, 1947), sect. 57: where there is no law, there is no freedom. Montes$q u$ i e $u$, De l'Esprit des Lois (benutzte Ausgabe: Oeuvres complètes de Montesquieu avec des notes de Dupin, Crevier, Voltaire, Mably, Servan, La Harpe, etc. etc.; éd.: Parelle, Paris 1885), XI 3: „Dans un état, c'est à dire dans une société où il y a des lois, la liberté ne peut consister qu'à pouvoir faire ce que l'on doit vouloir, et à n'être point contraint de faire ce que l'on ne doit pas vouloir."

$\mathrm{DaB}$ die obige These Gemeingut der deutschen Rechtsstaatstheorie seit ihren Anfängen war, bedarf keiner Darlegung, vgl. I. Kant, Idee zu einer allgemeinen Geschichte der Menschheit in welbbürgerlicher Absicht, 6. Satz; Carl S c h m it t, Verfassungslehre (Neudruck 1954), S. $125 \mathrm{ff}$. 
von innen genötigt wird, seine eigenen Gesetze zu suspendieren. Die juristischen ${ }^{\theta}$ ) Theoretiker des Rechtsstaates haben zwar mit dieser Notwendigkeit stets gerechnet, mit dem Ergebnis, daß der rechtsstaatlich entworfene Staat nur mit einer offenen Flanke gesehen wurde, in der "der Staat" schlechtweg, der jeweilige historische Staat, seine einstige unbeschränkte und unbeschränkbare Wirksamkeit entfalten konnte - bei Montesquieu der Monarch mit seinen erhalten gebliebenen Prärogativbefugnissen ${ }^{7}$, bei Georg Jellinek der im Staatsnotstand seine Rechtsstaatlichkeit abstreifende Staat $\left.{ }^{8}\right)$.

Mit dem Wegfall des Monarchen als des Stabilitätsfaktors mußte sich das Schicksal eines reinen Rechtsstaates so darstellen, daß er ein kurzes Glück, aber auch ein sicheres und frühes Ende bedeute, ein Ende entweder infolge äußerer Wehrlosigkeit oder infolge der notwendigen Heraufkunft einer staatserhaltenden Diktatur. Die im Angesicht dieser Alternative einsetzenden Versuche, einen „Bereich der Regierung" aus der herkömmlichen rechtsstaatlichen Funktionentrias auszuklammern, gehen in ihrer ersten Phase dahin, der Staatsleitung einen gesetzes f reien Handlungsspielraum ${ }^{9}$ ), später dahin, ihr daneben das Instrument des Gesetzgebungsbeschlusses zur Verfügung zu stellen ${ }^{10}$ ). Damit war dem Be-

B) Anders I. Ka n t mit seinem Vertrauen auf die teleologisch zum Endresultat eines "großen Völkerbundes" hinarbeitende menschliche Natur - aaO. 7. Satz.

7) aaO., XI 6 al. 19; für die Republik: XII 19. Vgl. unten Anm. 10.

8) Vgl. G. Je 11 i ne k, aaO. S. $610 \mathrm{f}$.: „Neben diesen normalen Funktionen gibt es aber noch außerordentliche Staatstätigkeiten, die in keine der drei Kategorien passen. Das ist in erster Linie der Krieg . . . Im Kriege steht des Staates Dasein auf dem Spiele, in der Verwaltung bewährt er sich als unenschüitterliche Macht." \#... Alle Verwaltung setzt die unbestrittene Herrschaft des Staates, ... das sichere Funktionieren seiner Rechtsordnung voraus."

9) G. Jelline k, aaO. S. 616 ff.; R. Smend, Die politische Gewalt im Verfassungsstaat und das Problem der Staatsform; Festgabe der Berliner Juristischen Fakultät für Wilhelm Kahl (Tübingen 1923), III, S. $15 \mathrm{ff}$. = Staatsrechtliche Abhandlungen S. 79 ff.; Franz M e y e r, Der Begriff der Regierung im Rechtsstaat (Zürich 1948), S. 119 ff. und 147 ff.

10) U. S c h e u n e r, Der Bereich der Regierung; „Rechtsprobleme in Staat und Kirche", Festgabe für Rudolf Smend (Göttingen 1952), S. $277 \mathrm{ff}$. - Nicht ohne Interesse ist, daß Montesquieu die zur Behebung eines Staatsnotstandes erfonderlichen Einzelakte in der Monarchie der Exekutivspitze, in der Republik aber der Legislative zuweist; vgl. i. E. XI 6 al. 19: . . . Si la puissance législative se croyait en danger ... elle pourrait, pour un temps court et limité, permettre à la puissance exécutrice de faire arrêter les citoyens suspects, qui ne perdraient leur liberté pour un temps que pour la conserver pour toujours - XII, 19: Il $\mathrm{y}$ a, dans les états, 
dürfnis nach einem Begriff der Maßnahmegesetzgebung in einer vorläufigen Weise Genüge geleistet - als Maßnahmegesetze konnte man nunmehr die zur Vorbeugung oder zur Behebung eines Staatsnotstandes ergehenden Gesetze umschreiben - aber die alte Frage stellte sich in der praktischen Gewandung wieder ein, wie man dem jetzt Rücken an Rücken mit der Exekutivspitze operierenden Gesetzgeber Grenzen setzen könne, welche Kontrollmöglichkeiten also gegenüber dem Gesetze verbleiben, das nunmehr der Exekutivspitze verfügbar geworden war ${ }^{11}$ ). In der herkömmlichen Vorstellungswelt der rechtsstaatlichen Lehrtradition ausgedrückt bedeutete dies, daß der Grundsatz, Legislative und Exekutive durch voneinander unabhängige Organe wahrnehmen zu lassen, durch diese Lage gefährdet, wenn nicht beseitigt war, und daß man folglich danach Umschau halten mußte, wie die hier aussetzende Gewaltenbalance an einer anderen Stelle des Verfassungsorganismus auszugleichen sei.

Nachdem dann die Funktionsweise der Parteiendemokratie in der Bundesrepublik und in den Ländern jene theoretische Besorgnis vollauf bestätigt hatte, richtete sich diese Umschau vor allem nach Ausgleichsmöglichkeiten seitens der $\mathrm{Ju}$ s ti z, stand also im Zeichen einer eventuell verstärkbaren Nachprüfbarkeit von Maßnahmegesetzen durch die Gerichte ${ }^{12}$ ). Damit

où l'on fait peu de cas de la liberté, des lois qui la violent contre un seul pour la garder à tous ... Mais, de quelque manière que le peuple les donne, Cicéron veut qu'on les abolisse, parce que la force de la loi ne consiste qu'en ce qu'elle statue sur tou't le monde. J'avoue pourtant, que l'usage des peuples les plus libres ... me fait croire, qu'il y a des cas où il faut mettre, pour un moment, un voile sur la liberté, comme l'on cachait les statues des dieux.

11) Hierzu Montesquie $u$ aaO. V 10: Le gouvernement monarchique a un grand avantage sur le républicain: les affaires étant menées par un seul, il y a plus de promptitude dans l'exécution. Mais comme cette promptitude pourrait dégénérer en rapidité, les lois y mettront une certaine lenteur. Elles ne doivent pas seulement favoriser la nature de chaque constitution, mais encore remédier aux abus qui pourraient résulter de cette même nature.

12) So U. S che u n e r aaO., S. $290 \mathrm{ff}$. - Der historischen wie grundsätzlichen Würdigung dieser Bestrebung dürfte der Hinweis dienlich sein, daß auch Montesquieu das Prinzip einer Uberprüfung der (königlichen) Gesetzgebungsakte durch die (damaligen französischen) obersten Gerichte befürwortet - V 10, al. 3, 4: Les corps qui ont le dépôt des lois (i.s. die Cours souveraines du royaume, voran die Parlamente, die Chambre des comptes und die Cours des aides) n'obéissent jamais mieux que quand ils vont à pas tardifs, et qu'ils apportent dans les affaires du prince cette réflexion qu'on ne peut guère attendre ... de la précipitation de ses conseils. Que serait devenue la plus belle monarchie du monde, si les magistrats, par leurs lenteurs ... n'avaient arrêté le cours des vertus mêmes de ses rois ...? 
stehen wir in der jüngsten Phase der Erörterung über das Maßnahmegesetz, die durch den bekannten Aufsatz Ernst Forsthoffs in der Jellinek-Gedächtnisschrift gekenzeichnet wird ${ }^{23}$ ); in ihm und seitdem ist die Frage nach einem justitiablen Kriterium des Maßnahmegesetzes gestellt.

B.

Die bisherigen Vorschläge gehen dahin, als Maßnahmegesetze solche Normen zu bezeichnen, die einem politischen ${ }^{14}$ ) oder technischen ${ }^{15}$ ) Zweck dienen, und von ihnen auszunehmen alle Normen, die dem sog. Rechts- oder Gerechtigkeitszweck ${ }^{16}$ ) dienen.

I.

Es bestehen zunächst gegen die begriffliche Eignung dieser Zweckbegriffe Bedenken, auf die ich ganz kurz eingehen möchte.

Uber den Dépôt des lois - sonst durchweg als Droit d'enregistrement bezeichnet - vgh. Actes du Parlement de Paris (Archives de l'Empire, Inventaires et Documents), t. Ier (Paris 1863), Préface p. VII, Notice p. CXI ss.; R. H ol tz m a n n, Französische Verfassungsgeschichte von der Mitte des' 9. Jahrhunderts bis zur Revolution (Handbuch der mittelalterlichen und neueren Geschichte, Abt. III, München und Berlin, 1910), S. 347 ff.

13) Vgl. Anm. 1.

14) So U. S c h eu ne r, aaO., S. 274: „Es gibt Gesetze, in denen die rechtsfeststellende Wirkung überwiegt - etwa bürgerlichrechtliche Normen - und andere - so die wirtschaftspolitischen Gesetze, Sozialisierungen, Regelungen der Mitbestimmung in Betrieben - in denen das politische Element vorherrscht." Ahnlich P. B o ckelma n n, Richter und Gesetz (Smend-Festschrift) S. 29.

15) So der Erstbericht; wohl auch E. F or sth of f, aaO., S. $225 \mathrm{f}$. und 233, insbesondere 226: „Das Maßnahmegesetz ist dahin zu kennzeichnen, daß es logisch vom Ziel und Zweck zum Mittel gelangt." - Vgl. auch Herbert $\mathrm{K}$ r ü. ge r s Kennzeichnung des "Verwaltungssatzes" (in: Rechtsverordnung und Verwaltungsanweisung, Festschrift für Rudolf Smend, S. 230): „Eine Norm, die die Wohlfahrt föndern soll und nach dem Maßstab der Zweckmäßigkeit gestaltet wunde." Ahnlich U. S c h e u ner, aaO., S. 277: ,... daß zur Verwaltung die laufende Tätigkeit ... gehört, erst recht das Technische, Lokale, das Besondere und Einzelne."

16) So der Erstbericht; U. S ch Anm. 14); E. Forsth off, aaO., S. 225: „Eine Rechtsnorm kann geschaffen werden, um einen Lebensbereich angemessen, $d . h$. zweckmäßig und in Ubereinstimmung mit den geltenden Vorstellungen von Gerechtigkeit zu ondnen. Ein solches Gesetz als Ganzes ist der Zweckhaftigkeit entzogen, denn es trägt seinen Wert in sich selbst." Vgl. Herbert K r ü g e r, aaO. (,Rechtssatz ist eine Norm, die dem Frieden zu dienen bestimmt und nach dem Maßstab der Gerechtigkeit gebildet ist", und ihm folgend, E. F orsth of $f$, Vw R I (6. Aufl.), S. 126. 
1. Faßt man Rechtszweck als Gerechtigkeitszweck auf, so steht man vor der mißlichen Einsicht, daß Normen sich an der umfassenden Idee der Gerechtigkeit nur selten messen lassen. Der Gerechtigkeitsbegriff hat in der philosophischen Ethik und in der Rechtsphilosophie, auf die hier vorzugsweise $\mathrm{zu}$ rekurrieren ist ${ }^{17}$ ), eine höchst kontroverse Beurteilung erfahren. Was ihn zur Charakterisierung eines seinem Begriff nach statischen und dauerhaften abstrakten Gesetzes untauglich macht, ist der aktuale und personale Charakter, der das Wesen der Gerechtigkeit in den Akt der Gerechtigkeitsverwirklichung verlager ${ }^{18}$ ), juristisch gesprochen also in die konkrete, sachlich wie persönlich individuell bestimmte Fallentscheidung. Das bedeutet, daB nach diesem Denken eine abstrakte Norm Gerechtigkeit zwar ermöglichen, nicht aber unmittelbar bereits verwirklichen kann. Summarisch gesprochen: die so verstandene aktuale und personale Gerechtigkeit läßt sich mit dem Medium einer abstrakten Norm zwar vereiteln, nicht aber verwirklichen, so daß man hiernach in einem exakten und verbindlichen Sinn zwar sehr wohl von einer ungerechten, nicht aber von einer gerechten Norm sprechen kann. - Dieses Gerechtigkeitsverständnis soll selbstverständlich nicht als das allein herrschende hingestellt werden ${ }^{19}$ ); aber es kennzeichnet die rechtsphilosophische

17) Aber auch in den ethischen Disziplinen der Theologie - s. folgende Anmerkung.

18) $\mathrm{Zu}$ verweisen ist hier

a) in enster Linie auf die seit Kant gelehrte und problematisierte Autonomie und (formale) Reinheit der sittlichen Entscheidung; ich stütze mich insoweit auf Th. Litt, Ethik der Neuzeit (Sonderausgalbe aus dem Handibuch der Philosophlie), München 1926; vgl. insbesondere die Formuliemunigen S. 103 .

b) sodann auf Entwicklungen innerhalb der theologischen Ethik des Protestantismus, für die ich Quellen und Literatur in „Kirchenrecht und Kirchengewalt" (Tübingen 1956), S. 99-120, auch S. 52-54, zusammengestellt habe.

19) Dies ist schon im Hinblick auf die gegenwärtige Rechtsprechung nicht möglich - vgl. etwa BVerfG vom 18.12.1953 (BVerfGE 3, $225 \mathrm{ff}$., hier insbes. S. 232 f.). Das Ergebnis dieser Entscheidung hätte sich mit der im vorstehenden Text vertretenen Auffassung müheloser und insbesondere ohne Utberforderung der Gerechtigkeitsidee gewinnen lassen. Bedenklich ist insbes. die Erwägung S. 233: Der Parlamentarische Rat war „bemüht, i m G G die Idee der Gerechtigkeit $z u$ verwirklichen. Ob und inwieweit dies gelungen ist, kann zwar nur (!) a us dem objektiven Ergebn is der Gesetzgebung ... abgelesen werden." Treffend demgegenüber derselbe Senat im Urteil vom 30. 4. 1952 (1, 265 ff., hier insbes. S. 276: Der Gleichheitssatz verpflichtet den Gesetzgeber nur dann, Ungleiches ungleich zu behandeln, wenn eine gleichbehandelnde Norm gerechte Einzelfallent- 
Entwicklung seit Hegels „Grundlinien der Philosophie

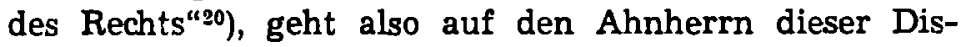
ziplin zurück und ist seitdem so gewichtig vertreten worden ${ }^{21}$ ), daß es nicht übergangen werden kann.

2. Für den politischen $\mathrm{Zweck}$ gilt etwas Ähnliches. Was ein politicum ist, bestimmt sich nach wechselnden Lagen und wechselnden Orientierungen; gerade diese Wandelbarkeit und Relativität der politisch zu qualifizierenden Lagen, Werte und Akte macht es ja so schwer, den „Bereich der Regierung“ zu definieren"2). Den bisher

ocheidungen vereiteln würde). - Wohin eine legalistische Kanonisierung der Gerechtigkeitsidee führen kann, illustriert unwiderleglich Günter D ürig, Grundrechte und Zivilrechtsprechung (,Vom Bonner Grundgesetz zur gesamtdeutschen Verfassung", Festschrift für Hans Nawiasky, München 1956, S. 157 ff.).

20) Die Terminologie Hegels setzt dem Nachweis dieser These die - hier besonders aufschlußreiche und keineswegs zufällige! Schwierigkeit entgegen, daß in ihr die Vokabel „Gerechtigkeit“ nur selten und ohne jeden prinzipiellen Wert gebraucht wird: in dem 2. Aibschnitt (,Die bürgerliche Gesellschaft") des dritten Teiles dürfte man sie vergeblich suchen, solange von dem die bürgerliche Gesellschaft kennzeichnenden „System der Bedürfnisse" und der Rechtspflege (\$\$ 209-229) die Rede ist; erst gegen Schluß taucht sie hier ( $\$ 229$, Zusatz) auf, und zwar als Programmwort für den folgenden, „Polizei und Korporation" überschriebenen Sozialstaatsentwurf.

Den Beleg für die These des Textes ergeben folgende Hinweise:

1. „Die Verwirklichung des Gesetzes im besonderen Falle“ (\$224), insbesondere die Subsumtion unter das Gesetz (\$ 228) gehört zu den "Rechten des subjektiven Bewusstseyns" ( $\$ 224)$, des "Selbstbewusstseyns der Parthei" ( $\$ 228)$.

2. Diese Rechte sind in der Fallentscheidung gewahrt, wenn

a) „das Gesetz bekannt und damit das Gesetz der Parthei selbst" geworden,

b) "der Rechtsgang öffentlich ist" und

c) "Zutrauen zu der Subjektivität des Entscheidenden" herrscht (\$ 228).

3. Der Begriff ,Subjektivität" ist zuvor ( $\$ \S 141-157$ ) seiner landläuflgen Bedeutung entkleidet und als ,die absolute Form und die existierende Wirklichkeit der Substanz" des Guten entwickelt worden: „Die Subjektivität ... ist im Sittlichen die ihm adäquate Existenz" (§ 152). Vgl. auch § 144, Zusatz: „Im Ganzen der Sittlichkeit ist sowohl das objektive als das subjektive Moment vorhanden: beide sind aber nur Formen derselben. Das Gute ist hier Substanz, das heißt Erfüllung des Objektiven mit der Subjektivität.“

(Benutzte Ausgabe: 3. Aufl., 7. Bd. der faksimilierten Jubiläumsausgabe der sämtlichen Werke, herausgegeben von $\mathrm{H}$. Glockner, Stuttgart 1952).

21) Vgl. meinen Literaturbericht in JZ 1954, S. 769.

22) Uber Versuche und Schwierigkeiten, „das politische Gesetz zu definieren", vgl. W. W en g l e r, Der Begriff des Politischen im internationalen Recht (Recht und Staat 189/90, Tübingen 1956), 
geschlossensten Versuch, diesem Wesenszug mit einem entsprechenden "Begriff des Politischen" gerecht zu werden, hat Carl Schmitt vorgelegt; dieser Versuch führte folgerichtig in die Grundfragen der philosophischen Anthropologie ${ }^{23}$ ) und hat von dort aus ernsteste Bestreitungen erfahren ${ }^{24}$ ). Schon dieser Umstrittenheit wegen kann er unseren juristischen Schlußfolgerungen nicht zugrunde gelegt werden. Dazu kommt aber - nicht weniger relevant - der Supremat einer occasionellen ${ }^{2 i}$ ) und damit we chselnden Feindorientierung, der hier ausdrücklich eingeschärft wird ${ }^{28}$ ), und der ihn aus den gleichen Gründen, wie sie soeben gegen das aktuale Gerechtigkeitsverständnis vorgetragen wurden, zur Qualifizierung statisch dauerhaft gedachter, abstrakter Normen untauglich macht ${ }^{27}$ ).

S. 7-9; über ,politische Rechtsetzung" und den sie bedingenden Habitus animae (im Gegensatz zur "Rechtsetzung aus rechtlicher Gesinnung") S. 44 ff. Für H. P. I p s e n, Politik und Justiz, Das Problem der justizlosen Hoheitsakte (Hamburg 1937), S. 169, ist ,das Politische kein Sachbereich, sondern objektlos, nicht kategorial beschränkt, sondern allumfassend, nicht restriktiv, sondern alles durchdringend, nicht Stoff, sondern Fänbung." Carl Sch m it t, Der Begriff des Politischen (Hamburg 1933), S. 21: ,... jede Angelegenheit potentiell politisch ..." Franz M e yer zitiert (aaO., S. 165) M. Le Courtois, Des actes de gouvernement (Thèse Poitiers 1899), p. 93: „La politique embrasse tout, elle peut tout transformer, elle est le contraire d'un critérium". Uber die seither erfolgte Preisgabe des Politischen als Kriterium des acte gouvernemental in der Rechtsprechung des Conseil d'Etat vgl. U. S c h e u n e r, aaO., S. $297 \mathrm{f}$.

23) Carl Schm it t, aaO., S. 8 f., 41 ff.

24) Martin Buber, Die Frage an den Einzelnen (Vortrag von 1933, als Buch erschienen 1936; hier zitiert nach: „Dialogisches Leben" - Gesammelte philosophische und pädagogische Schriften - Zürich 1947), S. 240 ff., aber auch vorher.

25) So treffend U. S c h e u ner, aaO., S. 272, Anm. 51.

26) Carl S ch mit t, aaO., S. 8: „... hier beruht selbst die bloße Möglichkeit richtigen Erkennens und Verstehens ... nur auf dem existenziellen Teilhaben und Teilnehmen ...; insbesondere kann jeder von ihnen nur selbst entscheiden, ob das Anderssein des Fremden im konkret vorliegenden Konfliktsfall die Negation der eigenen Art Existenz bedeutet ..." „Weder die Frage, ob der ,äußerste Fall' gegeben ist, noch die weitere Frage, was als ,äußerstes Mittel' notwendig wird, ... könnte ein Fremder entscheiden... Seine ,Objektivität' ist entweder nur eine politische Verschleierung oder a'ber die völlige, alles Wesentliche verfehlende Beziehungslosigkeit." Treffend hierzu Franz M e y e $r$, aaO., S. 163: „Der jeweilige Konflikt wird nur dann gelöst, wenn die je andere Existenz die je meine nicht mehr negiert."

27) Der Gedanke der Inlkommensurabilität der Feindorientierung mit ,genereller Normierung“ (vgl. S. 8, 9, 28 f., 47 ff.), ja, selbst mit geklärter Begrifflichkeit (13 f.) und allgemeinen Verstehensvoraus- 
II.

Dazu treten Schwierigkeiten der Abgrenzung dieser Begriffe untereinander und im Verhältnis zum technischen Zweck.

Aus dem, was ich über das aktuale Wesen der Gerechtigkeit im Verhältnis zur Norm sagte, folgt, daß die Grenzen zwischen dem Gerechtigkeitszweck und den technischen Zwecken fließend werden: in dem geschilderten aktualen und personalen Verständnis steht die Gerechtigkeit zur Form der abstrakten Norm nur in einem vermittelten, gebrochenen Verhältnis; und das Ergebnis ist, daß für diese Sicht durch eine nur an technischen Zwecken orientierte, diese Zwecke aber auch erfüllende Norm dem Gerechtigkeitszweck in grundsätzlich gleicher Weise gedient wird wie mit einer Norm, die ihm unmittelbar gewidmet sein soll. Mithin verläuft für dieses Denken zwischen technischen Normzwecken und dem Gerechtigkeitszweck keine aufweisbare Grenze.

Uberlagerungen ergeben sich auch sofort zwischen dem politischen Zweck und den übrigen Zwecken. Es ist einerseits nicht ausgemacht, da $\beta$ politischen Zwecken dienende Maßnahmegesetze dem Gerechtigkeitszweck widersprechen müssen; andererseits: sind sie ungerecht, so dient ihre Qualifikation als politische Maßnahme in der Regel gerade dazu, sie trotzdem zu rechtfertigen, dem politischen Zweck also den Vorrang vor dem Gerechtigkeitszweck zu geben.

$\mathrm{Zu}$ diesen begrifflichen Uberlagerungen und Abgrenzungsschwierigkeiten tritt nun auch hier das Element der Wandelbarkeit und Relativität hervor. Was heute ein politicum ist,

setzungen (S. 8 - s. o. Anm. 26) therrscht bei Carl Schmitt dunchgängig.

Die obige Abweisung beschränkt sich auf den hier erörterten Zusammenhang. Unter anderen Gesichtspunkten verlangt Schmitts Lehre von ,dem Politischen" die volle Aufmerksamkeit der Staatstheorie. Es handelt sich hier um einen alles umwertenden monistischen Totalaspekt, dessen therzeugungskraft in dem hier entworfenen Menschenbild wurzelt. Da für Deutschland die Aera des Rechtsstaats durch anthropologische Gegenentwürfe (Kants, Fichtes, Wilh. v. Humboldts u. a.) eingeleitet wunde (vgl. Fr. D a r m s t ädter, Die Grenzen der Wirksamkeit des Rechtsstaates Heidelberger Rechtswiss. Abh. 8 - Heidelberg 1930, S. 10-23), berührt das Wiederauftauchen einer Anthropologie von der archaischen Dïsternis der hier zitierten die Frage der Utberzeugungskraft des Rechtsstaatsgedankens; sie steht den lichteren, aber doch auch enthusiastischeren „Menschenbildern", die den Rechtsstaatsgedanken geschichtlich heraufgeführt haben, bis heute zwar abgelehnt (vgl. U. S cheuner, aaO, auch "Grundfragen des modernen Staates", Recht, Staat und Wirtschaft, III, S. 133; Fnanz M e y e r, aaO., S. 164 ff.; R. S m e n d, Staatsrechtliche Abh. S. 219, Anm. 113, auch $212 \mathrm{f}$ ), aber unwiderlegt gegenüber. Sine ira et studio gewürdigt, kann sie von beträchtlichem knitischen Nutzen sein. 
kann morgen einem anders orientierten Bewußtsein der Gesellschaft als gerechte Dauerlösung erscheinen; was einst, in gesicherten Zeiten, wertneutral und in diesem Sinne technisch erschien, kann heute zum Probierstein des Gerechtigkeitsdenkens werden. Vor allem kann die ihrer Natur nach wechselnde Qualifikation als "politisch" hier zur Aufhebung bzw. Relativierung auch aller übrigen Qualifikationen führen ${ }^{28}$ ).

C.

Innerhalb des öffentlichen Rechts sind diese drei Adjektive "politisch", "technisch“ und "gerechtigkeitsbezogen" zur Kennzeichnung spezifischer Hoheitsfunktionen verwandt worden. Für "das Politische" ergab sich bereits: es kennzeichnet die notstandsvorbeugende und -behebende Funktion der Regierung. "Technisch" und "gerechtigkeitsbezogen" sind die Elemente des Begriffspaares, mit dessen Hilfe die neue Verwaltungsrechtstheorie Verwaltungsverordnungen von Rechtsverordnungen, "Verwaltungssätze“ von „Rechtssätzen" unterscheidet ${ }^{29}$ ). Dieser konventionelle Sprachgebrauch unseres Faches kann zwar, wie sich zeigen wird, die angedeuteten Bedenken nicht zum Schweigen bringen; aber es deutet sich hier eine Möglichkeit an, die Materien der heutigen Gesetzgebung mit Hilfe einer Kombination von historischen und teleologischen Gesichtspunkten aufzuteilen.

\section{I.}

Es ergeben sich dann vorweg 1. die „klassischen Gesetze“s0) - mit Ausnahme auch hier der Einzelakt-Gesetze -, deren klassischer Charakter zwar, historisch genau betrachtet, nur darin besteht, daß sie in genereller Weise Eingriffe in „Freiheit und Eigentum" normieren; aber diese Eingriffsnormierungen genießen für diese Betrachtung die Vermutung, daß sie von dem Gerechtigkeitsgesichtspunkt bestimmt wurden. Innerhalb des verbleibenden Bereichs 2. der nichtklassischen Gesetze ergeben sich (a) die Rechtsverordnungen - einschließlich derjenigen Regelungen, die die Verwaltung für besondere Gewaltverhältnisse trifft, einschließlich auch der Satzungen öffentlich-

28) Carl Schmitt, aaO., S. 13 f.: „Alle politischen Begriffe, Vorstellungen und Werte ... sind an eine konkrete Situation gebunden ... und werden zu leeren ... Abstraktionen, wenn diese Situation entfällt ... Auch was ,Recht', ,Ordnung' und ,Frieden" bedeutet, ist konkret durch den Feind bestimmt."

29) Vgl. E. F o r s th of $f$, Lehrbuch des Verwaltungsrechts, Bd. I (6. Aufl., 1956), S. 126 f., und die oben, Anm. 14 bis 16, angeführten Außerungen H. Krügers.

so) Ausdruck von E. F orst h of $f$, aaO., z. B. S. 139. 
rechtlicher Körperschaften - , (b) die generelle Normen setzenden Regierungsakte, (c) die Verwaltungsverordnungen.

1. Diese drei Untergruppen werden in qualitativer Hinsicht aufgeteilt unter die oben behandelte Trias der Zweckbegriffe: Rechtsverordnung (a) ist diejenige von einer Exekutivinstanz gesetzte generelle Norm, die der Gerechtigkeit, Verwaltungsverordnung (c) diejenige, die einem technischen, Regierungsakt (b) diejenige, die einem politischen Zweck dient. - In funktiona ler Hinsicht - funktional, weil auf die in diesen Normen sich betätigende Staatsfunktion abstellend ergibt sich: In den Rechtsverordnungen (a) betätigt die Exekutive die ihr angestammte Befugnis zu gestaltendem Handeln; in den normsetzenden Regierungsakten (b) betätigt sich die sog. Praerogative; die Verwaltungsverordnungen (c) enthalten reine Vollziehungsmodalitäten. - Unter einem letzten, dem systematischen Gesichtspunkt schließlich ergibt sich: Die Rechtsverordnungen (a) gestalten das durch "das Gesetz" - das klassische Gesetz - determinierte Verwaltungsrechtsverhältnis; die Regierungsakte (b) bewegen sich darüber hinaus im Gesamtbereich des allgemeinen Gewaltverhältnisses; die Verwaltungsverordnungen (c) sind rein instruktioneller Natur.

2. Zieht man diese Gesichtspunkte heran, so lassen sich in dem Gesamtbereich der nichtklassischen Gesetze drei historische Materien unterscheiden, die sich in der vorgeführten dreifachen Weise - qualitativ, funktional und systematisch sondern lassen. Es ergeben sich dann

a) nichtklassische Gesetze, die das durch klassische Gesetze determinierte Verwaltungsrechtsverhältnis unter dem Gerechtigkeitsgesichtspunkt ausgestalten, also Materien der einstigen Rechtsverordnungskompetenz der Exekutive behandeln;

b) nichtklassische Gesetze, die dem „politischen Zweck“ der Notstandsvorbeugung und -behebung dienen, also Materien der Praerogative behandeln;

c) nichtklassische Gesetze, die, "technischen Zwecken" dienend, Vollziehungsmodalitäten und also Materien der "reinen Exekutive" regeln.

Diese Unterscheidung läßt sich aufstellen, und unzweifelhaft hat sie einen erheblichen erklärenden Wert: sie ermöglicht gleichsam eine genealogische Ubersicht über das Material, das sich in den nichtklassischen Gesetzen pausenlos vor uns auftürmt. Wie aber steht es mit ihrem normativen Wert -d.h.: sind diese Unterscheidungen geeignet, der Handhabung dieser nichtklassischen Gesetze durch die Gerichte in Auslegung und Normenkontrolle differenzierende Beurteilungs- 
gesichtspunkte $\mathrm{zu}$ bieten? - Hierzu muß der Hinweis eingeschaltet werden, daß sich der Bereich und der Begriff des nichtklassischen Gesetzes mit denen des Maßnahmegesetzes nicht deckt (vgl. unten III), und daß demzufolge dieser Frage in zwei Utberlegungen nachgegangen werden muß.

II.

Zunächst ist $\mathrm{zu}$ fragen, was von diesen Unterscheidungen bleibt, wenn diese nichtklassischen Gesetzesmaterien mit den klassischen Gesetzen zusammen in dem einheitlichen Gewande der gesetzgeberischen Norm auftreten. Wir haben unter dem GG nicht mehr den vom ordentlichen Gesetzgeber institutionell verschiedenen außerordentlichen Gesetzgeber der WV $\left.{ }^{31}\right)$. Damit haben wir die wichtige Möglichkeit verloren, für die Unterscheidung der nichtklassischen von den klassischen Gesetzen in ihrer Herkunft und Form wenigstens vermutungsweise Anhaltspunkte zu sehen; unser Gesetzesrecht ist nach Herkunft und Form "e inerlei Recht" geworden.

1. Für das Verhältnis der einst der Exekutive zur Regelung durch Rechtsverordnungen belassenen Materien zu denen der klassischen Gesetze fällt die oben (I, 2 a) aufgestellte Unterscheidung in sich zusammen. Der identische Gegenstand ist das Verwaltungsrechtsverhältnis; klassische Gesetze determinieren es, nichtklassische Gesetze gestalten es aus - wie aber soll innerhalb einer Fülle formal ununterscheidbarer und gleicherweise materielles Recht setzender Gesetzesnormen zwischen determinierenden und ausgestaltenden Gesetzen unterschieden werden? Jene sind an dem Gerechtigkeitsgesichtspunkt orientiert, diese gleichfalls. Nimmt man hinzu, daß die Kompetenz der Exekutive zum Erla $B$ von Rechtsverordnungen für die Sichtweise des parlamentarischen Gesetzgebungsstaates als delegierte Kompetenz anzusehen ist, so erweist sich ihre heutige Beanspruchung durch den Gesetzgeber als Widerruf der Delegation; und damit entfällt auch jede Berechtigung, nichtklassische Gesetze von klassischen Gesetzen in diesem Bereich unter dem historischen Gesichtspunkte zu unterscheiden.

2. Für die Besonderung der Praerogativmaterien der Notstandsvorbeugung und -behebung liegen die Voraussetzungen günstiger: In der Regel läßt sich dem Inhalt des Gesetzes entnehmen, ob es den Einsatz jener außerordentlichen Machtreserve der Regierung oder ein klassisches Gesetz darstellt. Wie aber soll sich dieser Unterschied auf seine Auslegung und Kontrolle durch die Gerichte auswirken? Anders formuliert:

s1) Vgl. Carl S c h m it t, Legalität und Legitimität (1932), S. $70 \mathrm{ff}$. 
Welches sind die rechtswissenschaftlichen Kategorien, in denen er faßbar werden könnte? - Von der Rechtsverordnung der Exekutive trennte den Regierungsakt zwar, daß dieser nicht lediglich Ausgestaltung des gesetzlich determinierten Verwaltungsrechtsverhältnisses war, sondern daß er, praeter oder contra legem, in dem Gesamtbereich des gesetzlich nicht determinierten allgemeinen Gewaltverhältnisses operierte; eben dieses aber hat er mit dem klassischen Gesetz gemeinsam. Von allen drei anderen Normengruppen unterscheidet den Regierungsakt zwar seine spezifische Zweckwidmung; aber dieser "politische Zweck" ist einmal, wie dargelegt, vom Gerechtigkeitszweck nicht abgrenzbar, sodann kann gerade er in diesen umschlagen, ohne da $\beta$ die Norm sich ändert ${ }^{32}$ ), wie oben (B II) gleichfalls dargelegt wurde. Hierzu kommt, daß die Entscheidung über die politische Notwendigkeit, ihre Fortdauer und ihr Aufhören den Regierungsorganen durch die Justiz nicht abgenommen werden kann.

Das Regierungsmaßnahmegesetz läßt sich hiernach zwar von reinen Vollzugsnormen abgrenzen (vgl. unten Ziff. 3). Es besteht auch je ein abstraktes Kriterium für seine Abgrenzung vom klassischen Gesetz und von der einstigen Rechtsverordnung; beide entziehen sich aber dem Versuch, sie am konkreten Gesetz nachzuweisen: das historische Kriterium versagt gegenüber dem klassischen Gesetz, der Zweckgesichtspunkt gegenüber beiden.

3. Beschränkt man das Kriterium "technischen Zwecken dienend" auf Vollzugs- und Durchführungsbestimmungen, so liefern sowohl der historische wie der Zweckgesichtspunkt ein generelles und konkretisierbares Kriterium gegenüber dem Regierungsmaßnahmegesetz.

Gegenüber den beiden anderen Gruppen des klassischen Gesetzes und der Rechtsverordnung, die ja nunmehr zu einer Gruppe zusammengeronnen sind (vgl. oben Ziff. 1), versagt der Zweckgesichtspunkt wegen der dargelegten Inkommensurabilität der Gesichtspunkte "gerecht" und "technisch": Vollzugsregelungen können gerecht wie ungerecht sein; technischen Zwecken dienen sie in diesem wie in jenem Falle ${ }^{33}$ ).

32) Beispiel: Die Fürsorgepflichtverordnung erging seinerzeit, wie die Delegationsnorm (2. Ermächtigungsgesetz v. 8. 12. 1923) ausweist, als „Maßnahme der Reichsregierung".

s3) An die unbestreitbare Feststellung, „daß im modernen Sozialstaat das Gesetz . . . in höherem oder geringerem Grade situationsbedingt" sei und "die früher der Verwaltung zur Regelung überwiesenen Modalitäten des Vollzugs vorwegnehme", knüpft E. Forsthoff die weittragende Folgerung, "daß ... das Gesetz seine festumrissene Struktur als abstrakte, "generelle Norm verloren" habe (Lehrbuch des Verwaltungsrechts, Bd. 1., 6. Aufl., Mümchen 1957, 
III.

Wie bereits oben (I a.E.) bemerkt, decken sich der Bereich und der Begriff des Maßnahmegesetzes nicht mit denen des nichtklassischen Gesetzes. Geht man, wie bisher, davon aus, daß ein solches Gesetz eine temporären Zwecken - der Notstandsvorbeugung und -behebung - gewidmete Regierungsmaßnahme ist, so gehören die beiden Gruppen der einstigen Rechtsverordnungen und die lediglich instruktionellen reinen Vollzugsregelungen nicht unter diesen Begriff.

Damit entfallen einige der vorgeführten Abgrenzungsschwierigkeiten; aber die entscheidenden bleiben bestehen: dem klassischen Gesetz wie dem Maßnahmegesetz ist gemeinsam, daß sie Rechts- und insbesondere Verwaltungsrechtsverhältnisse schaffen, ändern und aufheben können, ohne durch andere als Verfassungsnormen beschränkt zu sein; die in abstracto sich anbietende Unterscheidung nach Zweckkategorien ist in concreto unvollziehbar - jedenfalls solange und soweit, als eine solche Unterscheidung nicht Gegenstand eines verfassungsrechtlichen Gebotes ist. -

Der Versuch, mit Hilfe einer Kombination von historischer und teleologischer Betrachtung Kriterien für einen Begriff des Maßnahmegesetzes zu gewinnen, ist hiernach gleichfalls gescheitert.

S. 72; vgl. auch S. 57 u. S. 70). In erklärtem Gegensatz hierzu drängt nach W. Flume "die Entwicklung dazu, daß im Verhältnis von Staat und Individuum ... an die Stelle des Gewaltverhältnisses das Rechtsverhältnis tritt, indem nicht mehr nur Handlungsnormen für ein Handeln knaft eigenen Ermessens der Obrigkeit ergehen, sondern Sachentscheidungsnormen das Verhältnis bestimmen und die Entscheidung kraft Gewalt ausschließen" (Steuerwesen und Rechtsordinung, Festschrift für Rudolf Smend, S. 96). Sieht man von der verschiedenen Terminologie ab, die beide Autoren trennt, so behandeln doch beide die gleiche Entwicklung, aber eben mit entgegengesetztem Resultat: Hier eine ungeheure Inflation genereller Normen zur Bewältigung von Massenphaenomenen (Flume), dort Verwischung der „Unterscheidung von genereller Norm und individuellem Befehl, von Regel und Einzelgriff“ (so E. Forsthoff aaO., S. 70). Ich vermag hier Forsthoff nicht zu folgen: die Sachentscheidungsnormen Flumes sind eben diejenigen Normen, die "durch detaillierte Festlegung der Verfahren bis in die Einzelheiten hinein" die Modalitäten des Gesetzvollzugs "vorwegnehmen" (Forsthoff aaO., S. 57 mit 72). Detaillierte Verfahrensnormen verlieren ebensowenig wie kasuistische Regelungen des materiellen Rechts ihre Eigenart als generelle Normen; sie sind keine Einzelfall- oder Einzelpenson-Gesetze, sondern bleiben generelle, d. h. eine unbestimmte Vielzahl gleichartig normierter Tatbestände mit einheitlicher Rechtsfolge ausstattende Normen. Diese Entwicklung, die auf den verschiedensten Gebieten, zumal im Steuer- und Sozialversicherungswesen, mit Händen zu greifen ist (vgl z. B. die unten in Anm. 45 erwähnte Denkschrift), verwischt also jene Unterscheidung in Wahrheit nicht. 


\section{Zweiter Abschnitt}

Dieses negative Ergebnis macht weitere grundsätzliche Uberlegungen erforderlich. Es gilt, Gewißheit darüber zu erhalten, ob es lediglich die Eigenart der bisher betrachteten Zwecke war, die ein positives Ergebnis verhinderte, oder ob wir hier vor grundsätzlichen Hindernissen stehen.

Der Ubersichtlichkeit halber nehme ich das später sich ergebende Resultat vorweg. Es wird sich zeigen, daß es einige Möglichkeiten der Gesetzeszweckkontrolle durch die Rechtsprechung gibt, daß diese aber weit hinter den hierzu geäußerten Wünschen zurückbleiben; sie ergeben sich nur am Maßstabe einer verfassungsrechtlichen $Z$ weckdirektive und als Folge einer lediglich systematisch wichtigen Grenzerscheinung, nämlich des verhältnisbedingten Bedeutungswandels einer Norm.

\section{A.}

Diese Erweiterung des systematischen Gesichtspunktes wird dadurch notwendig, daB uns ein apriorischer Begriff des Maßnahmegesetzes nicht zur Verfügung steht.

I.

Die Ausgangsfeststellung Ernst Forsth of $\mathrm{s}, \mathrm{daB}$ das Maßnahmegesetz sich von normalen Gesetzen durch eine besondere $\mathrm{log}$ is $\mathrm{ch}$ e Struktur unterscheide, kann ich nicht teilen. Forst h of $f$ erblickt diese besondere logische Struktur darin, daß das konkrete Ziel, das der Gesetzgeber mit der Norm verfolgt, die „Priorität vor den im Gesetze getroffenen Maßnahmen"34) „die Priorität vor den zu seiner Verwirklichung eingesetzten Mitteln" ${ }^{\text {"35) }}$ habe. Zweifellos besteht diese Priorität; aber sie ist nicht eine logische, sondern eine teleologische und darum ohne apriorischen Charakter. Sie erlaubt darum auch nicht die Bildung eines form a le $n$ Begriffs vom Maßnahmegesetz, der die Rechtsprechung in den Stand versetzte, von ihm a usgehend "die Maßnahmegesetze" ex ante aus den übrigen Gesetzen auszusondern. Vielmehr läßt sich eine Priorität des Normenzweckes vor den eingesetzten Verwirklichungsmitteln, wie sie F o r s th of $f$ vorschwebt, nur ex post und also nur von Fall zu Fall feststellen. Die hierzu zur Verfügung stehenden allgemeinen Begriffe sind keine anderen als die sonst verwendeten, nämlich Gesetz und

34) aaO., S. 233.

35) aaO., S. 235. Vgl. auch E. F orsth off, VwR I (6. Aufl. 1956) S. 139: "Nach der Logik des Maßnahmegesetzes kann es eigentlich eine Unterscheidung von Vergangenheit und Zukunft nicht geben." 
gesetzliche Geltung, Zweck und Geltungsdauer des Gesetzes. Da der Zeitfaktor im Verhältnis zum Zwecke nur eine begleitende Rolle spielt, kommt er nur in Verbindung mit ihm in der Weise zur Erörterung, ob im Hinblick auf den Widmungszweck die Geltungsdauer des Gesetzes gegen die Verfassung verstoße. $\mathrm{Da}$ es aber in allen denkbaren Fällen stets und nur um die Frage der Geltung oder der Nichtgeltung der wegen ihrer Zwecke angegriffenen Norm geht, spielt der Zeitfaktor, abgesehen vom Zwecke, keine Rolle.

Das wird sich des näheren zeigen, wenn man in schulmäßiger Systematik zunächst nach Verfahren, Gegenstand und Maßstab fragt, die sich bei der richterlichen Prüfung eines als Maßnahme verdächtigten Gesetzes ergeben.

Es ergeben sich dann

(1) als Prüfungs verfahren die verschiedenen Normenkontrollverfahren, gegebenenfalls auch das Verfassungsbeschwerdeverfahren und der echte Verfassungsstreit zwischen Gesetzgebungsorganen, sei es des Bundes oder von Bund und Ländern;

(2) als Prüfungsma $\mathrm{B} s \mathrm{tab}$ stehen demzufolge nur Verfassungsrechtssätze einschließlich solcher Grundsätze und Grundwerte zur Verfügung, die als von der Verfassung rezipiert gelten können ${ }^{36}$ ); und schließlich kann

(3) als Prüfungs g e genst and nur eine Norm, in unserem Falle nur eine gesetzliche Norm, in Betracht kommen.

In dem so begrenzten Feld kann der Maßnahmecharakter einer gesetzlichen Norm, wie gesagt, nur Gegenstand, nicht Ausgangspunkt der Prüfung sein. Erblickt man, wie es bisher geschehen und anders nicht möglich ist, das Charakteristikum des Maßnahmegesetzes in seiner Widmung an temporäre Zwecke, so kann innerhalb dieser Verfahren nur die Frage Berücksichtigung finden, ob die Wahl, die der Gesetzgeber hinsichtlich des Zweckes und der Dauer seiner Norm getroffen hat, mit der Verfassung vereinbar ist.

Als der Gegenstand der hier anzustellenden Untersuchung erweisen sich hiernach $Z$ weck und Geltung eines Gesetzes, beide unter dem Gesichtspunkt, ob sie gegen die Verfassung verstoßen. Nur Zweck und Geltung bilden

36) Diese Formulierung meint sachlich das, was das BVerfG. im Urteil vom 1.7.1953 (2, 403) dahin formuliert hat, ,daß das Verfassungsrecht nicht nur aus den einzelnen Sätzen der geschriebenen Verfassung besteht, sondern auch aus gewissen sie verbindenden, innerlich zusammenhaltenden allgemeinen Grundsätzen und Leitideen, die der Verfassungsgesetzgeber, weil sie das vorverfassungsmäßige Gesamtbild geprägt haben, von dem er ausgegangen ist, nicht in einem besonderen Rechtssatz konkretisiert hat." 
diesen Gegenstand: auch wenn man mit Ernst For sth of $f$ einen justitiablen Verfassungssatz des Inhalts annimmt, daB die eingesetzten Mittel dem Zweck des Gesetzes entsprechen müssen, erweitert das den Prüfungs g e g en s t a nd nicht; dieser Satz gehört vielmehr auf die Seite der verfassungsrechtlichen Prüfungs $m$ a $B s t a ̈ b e$, und er ist, da er für alle Gesetze gelten soll, nicht spezifisch für unseren Fragenkreis.

II.

Wendet man sich der Frage nach dem Wesen der Geltung und dem Verhältnis von Zweck und Geltung zu, so erweist sich alsbald, daß man mit diesem Begriffspaar in das Zentrum eines Fragenkreises hineingeführt wird, von dem die grundsätzlichsten Folgerungen für unser Rechtsleben und -denken ausgehen, und der sich seit geraumer Zeit in lebhafter Bewegung befindet.

Was zunächst die Frage nach dem We se n angeht, so ist, um in möglichster Kürze möglichste Klarheit zu schaffen, an dieser Stelle eine kurze historisch-dogmatische Bemerkung unumgänglich. In den rechtspolitischen und rechtsphilosophischen Reflexionen, die das Rechtsdenken unseres Kulturkreises geprägt haben, sind sich seit je zwei Geltungsbegriffe gegenübergestanden, die Geltung kraft Setzung und die Geltung kraft Wertteilhabe. Der letztere und ältere Geltungsbegriff kraft Wertteilhabe läuft darauf hinaus, die Geltung einer Rechtsregel danach $\mathrm{zu}$ bestimmen, ob und inwieweit sie Anteil an der Hierarchie der Werte hat, in der der Idealismus platonischer Herkunft den Kosmos gefügt sah. Der erste und jüngere Geltungsbegriff kraft Setzung entspringt dem Verzicht auf eine solche Einsehbarkeit des Wert- und Weltgefüges; er leitet die Würde und Autorität des Setzungsaktes, geschichtlich betrachtet, aus Analogieschlüssen zu den gesetzten Offenbarungsgeboten, insbesondere zum Jus divinum positivum, ab.

Uber die praktische Durchsetzung dieser beiden kontrastierenden Geltungsbegriffe darf hier soviel gesagt werden, daß zumindest seit der Herrschaft des Christentums der Geltungsbegriff kraft Wertteilhabe nicht mehr einseitig geherrscht hat. Das hohe Mittelalter vertritt z. B. für das weltliche Recht in Thomas von Aquin $^{37}$ ) ein Kompromiß aus Wertteilhabe und Setzung, während sich im Kirchenrecht der Vorrang der Setzungsgeltung anbahnt. Von hier, aus dem mittelalterlichen Kirchenrecht, übernehmen sie die weithin nominalistisch

37) Mit seiner bekannten Gesetzesdeflnition S. th. 1.2. q. 90 Art. 4: Lex est ordinatio rationis ad bonum commune (- einerseits), $a b$ eo, qui curam habet communitatis, promulgata (- andererseits). 
denkenden Juristen des Spätmittelalters und mit ihnen die neuzeitliche Staatstheorie. Ihr gegenüber wird Geltung kraft Wertteilhabe zum Gewande der modernen kritischen Gegenpositionen gegen den Staatsabsolutismus, insbesondere der Volkssouveränitäts- und der Menschenrechtslehren.

Das Verhä $1 \mathrm{t} n$ is beider ist seitdem ein Verhältnis der Spannung geblieben. Der Absolutismus bedeutet unter diesem Gesichtspunkt die völlige Verwerfung einer rechtlichen Geltung kraft Wertteilhabe; die abstrakte Norm ist für ihn zunächst das gegebene Mittel zur Verwirklichung des fürstlichen Zentralismus und kann daher in ihrer Geltung nur von der Setzung abhängen.

Die gegenwärtige Lage wird man bestimmt sehen müssen, einmal durch die noch andauernde Herrschaft des Rechtspositivismus, der von der Setzungsgeltung seinen Namen hat, und zum anderen durch die Herrschaft des Rechtsstaatsgedankens, der ein neues Kompromiß geschaffen hat. Er gebietet für den Bereich der Grundrechte und ihrer Verwirklichung durch den Gesetzgeber einerseits, von einer Geltung kraft Wertteilhabe auszugehen; für den gesamten übrigen $\mathrm{Be}-$ reich des Rechtslebens und dort, wo die Grundrechte garantiert sind, auch und gerade für den Bereich ihrer Verwirklichung hält er im Interesse der Sicherheit und Berechenbarkeit an dem Begriff der Setzungsgeltung fest.

Diese Lage ist auch bestimmend für das wechselseitige Verhältnis von $Z$ weck und Geltung. Denn es zeigt sich nun, daß, wer den Zweck eines Gesetzes gegen seine Geltung ausspielt, von dem Begriff der Setzungsgeltung zu dem der Setzung kraft Wertteilhabe hinüberwechselt. Die Frage, wieweit das zulässig ist, muß sich zunächst der Vorfrage zuwenden, welchem von ihnen beiden heute der Primat zukommt; dies ist nach dem Gesagten der Begriff der Geltung kraft Setzung. Es ist dann weiter zu fragen, ob etwa dieses Hinüberwechseln freigegeben ist durch eines jener Wert- und Zweckwahrungsgebote der Verfassung. Deren Kreis ist für uns heute erheblich größer als in den individualistischen Anfängen des Rechtsstaatsgedankens, wie Sozialstaatlichkeit, Familien- und Jugendschutz, Direktiven für das Bildungswesen u. a. zeigen; aber sie bilden aus historischen und systematischen Gründen nach wie vor die Ausnahme von der Regel. Praktisch bedeutet dies, daß die Geltung eines Gesetzes aus Uberlegungen, die sich auf seinen einstigen oder gegenwärtigen Zweck stützen, nur dann verneint oder beendigt werden kann, wenn sich diese Uberlegungen als Vollzug eines verfassungsrechtlichen Zweckwahrungsgebots ausweisen können. 
B.

Für unsere engere Frage steht bisher als Ausgangsbasis nur der Satz zur Verfügung, daß an die Ungültigerklärung gesetzlicher Normen durch die Rechtsprechung wegen unzulässiger oder unzulässig gewordener Zwecke nur zu denken ist, soweit diese Zwecke gegen ein verfassungsrechtliches $\mathrm{Zweckwahrungsgebot} \mathrm{verstoBen.}$

Vorschriften der Verfassung über die Zwecke von einfachen Gesetzen sind in denjenigen materiellen Weisungen zu finden, die Ernst Fors th off als Funktionsnormen bezeichnet hat ${ }^{28}$ ); Nachweisungen erübrigen sich daher. Es erscheint dienlich, sie für unseren Zusammenhang als Zweckwahrungsgebote zu bezeichnen; daß ein großer Teil von ihnen nicht nur den Gesetzgeber, sondern auch die gesetzesgebundenen Gewalten bindet (vgl. Art. 1 Abs. 3, Art. 19 Abs. 3 GG), ist für unseren Zusammenhang unerheblich. Unerheblich ist auch die Form, in der sie ergehen.

Der Form nach kennt die Verfassung positive und negative, bedingte und unbedingte $Z$ weckwahrungsgebote: Bald gebietet die Verfassung die Wahrung, bald verbietet sie die Vereitelung von Zwecken. Der Sache $\mathrm{nach}$ bedeuten sie als Zweckdirektiven an den (einfachen) Gesetzgeber beides: das Ver bot etwa, Grundrechte und institutionelle Garantien in ihrem Wesensgehalt anzutasten, ist gleichbedeutend mit dem Ge bot, diesen Wesensgehalt $\mathrm{zu}$ wahren. Lediglich für die Auswirkung dieser beiden Seiten läßt sich ein Unterschied feststellen: a ls $\mathrm{Z}$ w e ckvere i t el ung s verbote binden sie den (einfachen) Gesetzgeber unbedingt, als Zweckverwirklichungsgebote im Regelfalle bedingt - bedingt für den Fall, daß er ein den geschützten Zweck berührendes Gesetz erläßt, unbedingt indessen, wo die Verfassung mit einem Zweckwahrungsgebot ein Gesetzgebungsgebot verbindet. Diese Besonderheit bewegt sich lediglich im Bereiche der Verwirklichung: ist bei den allgemeinen Zweckwahrungsgeboten die Verwirklichung nur bedingt - für den Fall eines Gesetzesbeschlusses - geboten, so schreibt hier der Gesetzgeber die Erfüllung der Bedingung zusätzlich vor. Allen gemeinsam ist, daß sie die Wahrung von Zwecken gebieten, sei es durch gesetzgeberisches Tun, sei es durch gesetzgeberisches Unterlassen, und dies rechtfertigt die

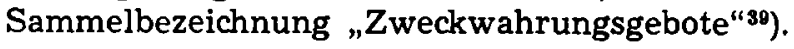

38) Jellinek-Gedächtnis-Schrift S. 233.

so) Da nicht daran gedacht ist, einen neuen Begriff einzuführen, darf darauf verzichtet werden, diese Sammelbezeichnung ou an- 
I.

Wichtiger ist der Hinweis, daß ein Teil von ihnen dazu verurteilt ist, eine lex imperfecta zu bleiben. Theorie und Rechtsprechung haben das Außerste getan, um in ihnen aufzufangen, was von allgemeinen Wertideen verwertbar und notwendig ist, um das Funktionieren von Verfassung und Rechtsordnung $\mathrm{zu}$ sichern ${ }^{40}$ ). Indessen stößt man auch hier auf Grenzen. Da an eine erschöpfende Utbersicht nicht zu denken ist, erwähne ich nur die Gewaltenteilungsmaxime.

Das Grundgesetz setzt Gewaltenteilung einerseits - in Art. 1 - voraus und gebietet andererseits ihre Wahrung, indem sie der Bundesrepublik Deutschland die "Gewährleistung“ einer rechtsstaatlichen verfassungsmäßigen Ordnung in den Ländern zur Pflicht macht - Art. 28 Abs. III mit Abs. I. Daß das Gewaltenteilungsgebot den Gesetzgeber bindet, steht außer Erörterung ${ }^{41}$ ). Aber eine andere Frage ist, wieweit der Gesetzgeber durch die Rechtsprechung zu seiner Beachtung angehalten und darin überwacht werden kann. Sicherlich dann, wenn er expressis verbis die Gewaltenteilung schlechtweg aufheben oder etwa die Gesetzgebungsbefugnisse auf die Exekutivspitze oder hergebrachte Rechtsprechungsfunktionen auf weisungsgebundene Verwaltungsbehörden überführen würde; in diesen Fällen wäre eine Einzelnorm unvereinbar mit der Verfassung, und ihrer Ungültigerklärung im Normenkontrollverfahren stünde nichts im Wege. Das uns

deren Klassifizierungen der Verfassungsnormen in Beziehung zu setzen. Es genügt hervorzuheben:

a) potentiell kommt jeder objektiven Verfassungsnorm - eingeschlossen die ,elementaren Verfassungsgrundsätze und Grundentscheidungen" des Verfassungsgebers (im Verständnis des BVerfG, Urteil vom 23.10.1951 - Bd. 1, S. 32 f.), ausgeschlassen lediglich ,bloße Programmsätze" - die Bedeutung eines Zweckwahrungsgebotes zu;

b) darüber hinaus liegt in den Gewährleistungs- und Vorbehaltsschranken der Grundrechtsbestimmungen (hierzu Friedr. K le in, aaO., S. 120 ff.) eine Fülle verfassungsrechtlicher Zweckwahrungsgebote der einen oder anderen Art vor.

40) Vgl. die Ubersicht Friedrich $K I$ e i $n s$ in v. Mangoldt-Klein, Das Bonner Grundgesetz, 2. Aufl., S. $78 \mathrm{ff}$., auch S. $9 \mathrm{ff}$. - Wegen des Verhältnisses von "Wert" und "Zweck" sei auf Nicolai Ha r t mann, Teleologisches Denken (Berlin 1951), S. $112 \mathrm{ff}$. und E. F o rst h off, VwR I (6. Aufl. 1956) S. 144 f, verwiesen; „daB die Gerechtigkeit kein Zweck" sei, ist allerdings keine „Selbstverständlichkeit" (so Forsthoff aaO., S. 145).

41) Ebenso, daß das Gewaltenteilungsprinzip der verschiedensten Ausgestaltung fähig ist - vgl. Werner $K$ ä $g$ i , Zur Entstehung, Wandlung und Problematik des Gewaltenteilungsprinzips (Zürich 1937) und die dort behandelte Literatur; auch B.VerfG vom 18.12. $1953(3,225$ ff.), S. 247 f. 
vorliegende Problem sind dagegen solche Gesetze und Normen, die für sich allein weder das Gewaltenteilungsgebot noch eine sonstige Verfassungsbestimmung verletzen, sondern die lediglich insgesamt, mit ihrer Häufung, das Gewaltenteilungsgefüge durchbrechen und bedrohen. Da die Rechtsprechung die Waffe der Ungültigerklärung nur gegenüber einzelnen Normen, nicht aber gegenüber einem solchen geschichtlichen Häufungsphänomen besitzt, erweist sich das Gewaltenteilungsgebot der Maßnahmegesetzgebung gegenüber als eine lex imperfecta - in der Sprache Ernst Forsthoffs: als eine Funktionsnorm, der eine Kontrollnorm mit entsprechendem Anwendungsbereich nicht zur Seite steht.

II.

Nur kurz sei die Frage nach der Erkenntnisquelle der gesetzgeberischen Zweckwidmung berührt: Ist es die subjektive Motivierung des Gesetzgebers, die occasio legis? Ist es die ohne Rücksicht hierauf aus dem Gesetz selber und seiner Stellung in der gesamten Rechtsordnung zu entnehmenden Zweckwidmung, die ratio legis? Oder soll die erst ex post erkennbare praktische Funktion der Norm, der usus legis, entscheidend sein? - Es wird sich empfehlen, von einseitigen Festlegungen für diesen Zusammenhang abzusehen und das Prinzip der verfassungskonformen Auslegung, das Bestreben also, eine Gesetzesnorm solange zu halten, als die ihr zur Seite stehende Vermutung ihrer Vereinbarkeit mit der Verfassung nicht widerlegt wird, walten zu lassen.

\section{III.}

Die Zweckwidmung kann entweder von vornherein oder erst nachträglich gegen ein verfassungsrechtliches Zweckwahrungsgebot verstoßen. Im ersten Fall ist eine Norm ex tunc, im zweiten erst vom Eintritt der Kollision mit dem Zweckwahrungsgebot der Verfassung ab nichtig. Der erste Fall gehört in den Bereich der Gebundenheit des Gesetzgebers und scheidet daher aus unserem jetzigen Zusammenhang gleichfalls aus. Der zweite Fall dagegen wirft die für unser Problem kardinale Frage auf: Welche Voraussetzungen müssen gegeben sein, um der Rechtsprechung die Ungültigerklärung einer Norm wegennachträglicher Verfehlung ihres Widmungszeckes im Normenkontrollverfahren $z$ e rlauben? Und ich füge hinzu: allein unter dieser Fragestellung kann die Rechtsprechung gegen Maßnahmegesetze vorgehen. 
1. Die Verhältnisse müssen sich gewandelt haben. Und zwar kommen nur a u B e r n orm a ti ve, d. h. solche Verhältnisse in Betracht, die in den Tatbestandsvoraussetzungen der Norm selbst keine Erwähnung gefunden haben. Der Grund für diese Beschränkung auf außernormative Verhältnisse liegt auf der Hand: Tatbestandsmäßige Verhältnisse sind für den Richter nur nach zweierlei Seiten bedeutsam: liegen sie vor, so wendet er die Norm an, liegen sie nicht vor, so lehnt er die Anwendung ab; nie berührt das Vorliegen oder Nichtvorliegen tatbestands$m$ ä B i g e r Voraussetzungen die Geltung der Normen.

Weiter muß dieser Wandel außernormativer Verhältnisse dahin geführt haben, daß die Anwendung der Norm nach ihrem ursprünglichen Wortlaut und Inhalt allgemein gegen ein verfassungsrechtliches $Z$ weckwahrungsgebot verstoßen würde. Das Gewicht dieser Erfordernisse im einzelnen liegt auf der Hand: Die Außergeltungsetzung einer Norm kann nur in Betracht kommen, wenn ihre Anwendung stets, nicht nur in einem Einzelfall, ihren verfassungsrechtlich zugelassenen $Z$ weck verfehlt; und sie kann ebenso nur in Betracht kommen, wenn sie nunmehr gegen ein verfassungsrechtliches $Z$ weckwahrungsverbot verstößt, nicht schon dann, wenn sie ohne einen solchen Versto $B$ lediglich ihren seinerzeitigen Ursprungszweck nicht mehr erfüllt.

Schließlich muß dieser verhältnisbedingte Wandel des Anwendungsgehalts $\mathrm{nach}$ Inkraftreten der Norm sich ergeben haben. Dies ergibt sich aus dem Gesichtswinkel unserer gegenwärtigen Fragestellung: Es handelt sich hier um die Frage der Geltungsbeendigung ex nunc solcher Gesetze, in deren Zweckwidmung der Gesetzgeber seinerzeit frei w a r, heute aber nicht mehr frei sein würde.

2. Wir kennen nun die Voraussetzungen, unter denen Normen wegen des Obsoletwerdens ihrer Zweckwidmung nach ihrem Inkrafttreten die Geltung abgesprochen werden kann. Damit scheint auf den ersten Blick alles erreicht, was für die an Gesetz und Recht gebundene Rechtsprechung erreichbar ist. Aber das praktische Anwendungsergebnis ist gering: nicht jeder den $Z$ weck wandelnde Verhältniswandel genügt, nicht einmal dann, wenn er den ursprünglichen Widmungszweck der Norm völlig vereitelt; sondern er genügt nur dann, wenn damit zugleich der Anwendungsgehalt der Norm so gewandelt wurde, daß alle 
ihre voraussehbaren Anwendungsfälle gegen ein verfassungsrechtliches $Z$ weckwahrungsverbot verstoßen; nur dann ist die generelle Ungültigerklärung möglich ${ }^{42}$ ).

IV.

Dennoch empfindet man das Bedürfnis, dem Gesetzgeber stärkere Widerstände entgegensetzen zu können; denn selbst unter den seltenen obigen Voraussetzungen kann ja die Rechtsprechung nichts von den Einrichtungen und Rechtslagen beseitigen, die unter der Geltungsdauer des maßnahmeverdächtigen Gesetzes eingetreten sind; was sie erreicht, wird für den Regelfall auf eine neue verwickelte Abwicklungsgesetzgebung hinauslaufen. Eine wirksame Warnung des Gesetzgebers vor weiterer Maßnahmegesetzgebung geht von diesen Möglichkeiten schwerlich aus. Die Ausgangssorge um die Entstörung der rechtsstaatlichen Verwaltung läßt uns Ausschau halten, ob nicht die Rechtsprechung zu Möglichkeiten der Ungültigerklärung von Maßnahmegesetzen ex tunc gelangen kann.

Diese Möglichkeit besteht nur für den Fall, daß ein Wandel außernormativer Verhältnisse die Bedeutung nicht einer einfachen Gesetzesnorm, sondern die einer Verfassungsnorm gewandelt hat.

Auch hier kann Verhältniswandel Möglichkeiten schaffen, die zur Zeit des Inkrafttretens der maßnahmeverdächtigen

42) „Daß Normen nur für normale Situationen gelten, und die vorausgesetzte Normalität der Situation ein positiv-rechtlicher Bestandteil ihres ,Geltens" sei, glaubte Carl Schmitt als "einfache, rechtswissenschaftliche Wahrheit" vertreten zu können "Legalität und Legitimität, 1932. S. 71 f.); indessen verkannte Carl Schmitt nicht, daB die Zulassung eines solchen Geltungsverständnisses (,ratione temporis ac situationis“) „das Legalitätssystem des parlamentarischen Gesetzgebungsstaates zerstören" wünde (aaO. S. 72), und h i er in dürtte die entscheidende rechtswissenschaftliche Wahrheit seiner Aussagen zu finden sein - der Geltungsbegriff unserer Rechtstheorie würde durch diese Voraussetzung aufgelöst werden. Die Entwicklung, die Carl Schmitts Auffassungen später genommen haben, ist nur geeignet, dies zu bestätigen: In den "drei Arten des rechtswissenschaftlichen Denkens" (1934) ist es nicht nur die „als normal unterstellte Lage“, sondern außendem auch „ein als normal unterstellter Menschentypus“, durch dessen Vorliegen die Geltung der Norm bedingt und begrenzt wird (aaO. S. 10; dazu S. 23: „Die Normalität der ... Lage und des ... konkreten Typus ist also ... ein inneres juristisches Wesensmerkmal der Normgeltung, eine normative Bestimmung der Norm selbst"). Uber die auflösende Wirkung, die dieser doppelte Vorbehalt auf das Legalitätssystem jedes - keineswegs nur das des parlamentarischen Gesetzgebungsstaates ausüben muß, flndet sich in dieser späteren Außerung kein Hinweis mehr; Carl Schmitt beschränkt sich hier darauf, "die situationslose und typenlose Norm“ als ein „juristisches Unding“ zu erklären (S. 23). 
Norm noch nicht bestanden; in diesem Falle erhält die Rechtsprechung Gelegenheit, eine Gesetzesnorm ihres Zweckes wegen ex tunc zu vernichten.

Dieser Fall führt uns, wie auf der Hand liegt, zurück in den Bereich der gebundenen Gesetzgebung: Es ist eindeutig ein Fall der Unvereinbarkeit einer einfachen Gesetzesnorm mit einer Verfassungsnorm. Aber der Fall wird modifiziert dadurch, daß erst die Rechtsprechung den an einer Verfassungsnorm eingetretenen Bedeutungswandel freilegt, während sich der Gesetzgeber - aus welchen Gründen auch immer - an den Wortlaut und den Ursprungssinn hält. Es ist also ein Dissensus über den Zweckwandel einer Verfassungsnorm, der zwischen Justiz und Legislative auftritt. In dem Rahmen, in dem die Verfassungauslegung der Justiz zusteht, hat sie auch das letzte Wort über die Beurteilung eines solchen Wandels ${ }^{43}$ ). Für diese Beurteilung gelten die Erfordernisse, die vorhin aufgestellt wurden; es bedarf keiner Darlegung, da $B$ sie sich hinsichtlich einer Verfassungsnorm noch seltener und nur in längeren Zeiträumen ${ }^{44}$ ) erfüllen werden; nichtdestoweniger gehören sie in diesen Zusammenhang hinein. Als Beispiel kann die Schrumpfung der rechtsgeschäftlichen Privatautonomie von der liberalen Vertragsfreiheit zur Eingehungsfreiheit gegenüber den Versorgungsbetrieben der öffentlichen Hand dienen.

\section{SchluB}

Die Möglichkeiten, die die Rechtsprechung hat, sind damit wenigstens skizziert; auf Einzelheiten und Vorbehalte einzugehen, verbot der Zeitmangel.

Umschrieben wurde, was sich der Rechtsprechung an ef f e k t i ve n Möglichkeiten bietet, um gegen die Maßnahmegesetzgebung vorzugehen. Unter diese effektiven Möglichkeiten wurden nur die der allgemeinverbindlichen AuBergeltungsetzung einbezogen; nur diese reduzieren den Bestand an geltenden Normen, und nur von ihnen geht eine Warnung an den Gesetzgeber aus.

43) Vgl. BVerfG im Urteil vom 1. 7. $1953(2,401)$ : „Allendings kann eine Verfassungsbestimmung einen Bedeutungswandel erfahren, wenn in ihrem Bereich nicht vorausgesehene Tatbestände auftauchen oder bekannte Tatbestände durch ihre Einordnung in den Gesamtablauf einer Entwicklung in neuer Beziehung oder Bedeutung erscheinen." Bedenken gegen diese Formulierung, die auch mir zu dehnbar erscheint, macht $\mathrm{K}$ le in aaO., S. 5 (zu Anm.3), geltend.

44) K l e i n spricht aaO., S. 6 der "Verfassungswandlung" "gewohnheitsrechtlichen Charakter" zu - sicherlich nur, um das Erfordernis der längeren Zeitspanne zu unterstreichen. 
Zu fragen bleibt, was von seiten der Verwaltung und des Gesetzgebers selbst geschehen kann. Der Verwaltung steht die Möglichkeit einer Außergeltungsetzung nicht zu Gebote; aber sie kann aufgreifen, was sich der Erörterung und Heilung durch die Rechtsprechung entzieht, nämlich das Häufungsphänomen der Maßnahmegesetzgebung; sie kann sich der gesetzgebungs politischen Seite annehmen, von der her allein das Problem wirksam behandelt werden kann; sie kann damit dasjenige $Z$ weckwahrungsgebot geltend machen, das die Rechtsprechung gegenüber der Maßnahmegesetzgebung nicht durchsetzen kann, das Gewaltenteilungsgebot; und sie kann darüber hinaus ganz allgemein darlegen, daß und inwiefern der Ablauf der exekutiven Staatsfunktion gestört und damit die Verwirklichung des gesetzgeberischen Willens selbst gehindert wird 45 ).

Dies ist in erster Linie freilich Sache der Exekutivspitze, die als Regierung in dieser Frage Rücken an Rücken mit dem Gesetzge ber steht. Für sie beide gilt, daß sie nicht nur mehr tun $k$ ö $n \mathrm{n}$ e $\mathrm{n}$, sondern auch müssen; sie unterliegen den verfassungsrechtlichen Funktionsnormen oder Zweckwahrungsgeboten auch, wo sie dem Zwange ergänzender Kontrollnormen nicht mehr ausgesetzt sind; aber das bedeutet, da $B$ in diesem Bereich nur an ihre Verfassungstreue und Selbstdisziplin appelliert werden kann. Ob sie dem nachkommen wollen und können, ist beides fragwürdig und entzieht sich der Würdigung in einem auf die Rechtsfrage begrenzten Referat. Was das Wollen und die Selbstdisziplin angeht, so genügt es, daran zu erinnern, welches Gewicht in unserem Zusammenhang den Wahlversprechungen der Parteien zukommt; was im Wahlkampf verheißen wird, will nach errungenem Wahlsieg eingelöst sein $\left.^{46}\right)$. Und was das Können angeht, so bleibt es inmitten einer fluktuierenden Weltlage und einer labilen Innenlage begrenzt.

\section{I.}

Hier bleibt noch zusammenzufassen, was das für den B egriff des Maßnahmegesetzes bedeutet. Er wurde hier ein-

45) Vorbildlich und instruktiv in dieser Beziehung die an den Bundestag gerichtete Denkschrift des Bundes Deutscher Steuerbeamten (Paderborn, Michaelstr. 7) vom Juni 1956; dazu Frankfurter Allg. Ztg. Nr, 166 v. 19. 7. 1956, S. 2 u. 9.

46) Montesquieu aaO., VIII 11: Lorsque les principes du gouvernement sont une fois corrompus, les meilleurs lois deviennent mauvaises et se tournent contre l'Etat; lorsque les principes en sont sains, les mauvaises ont l'effet des bonnes: la force du principe entraine tout ... Il y a peu de lois qui ne soient bonnes lorsque l'Etat n'a point perdu ses principes; et, comme disait Epicure en parlant des richesses: Ce n'est point la liqueur qui est corrompu, c'est le vase. 
geführt als ein heuristischer, d.h. auf Hypothesen beruhender Begriff; und die Aufgabe des Referats war insoweit darzulegen, ob etwas diesen Hypothesen an Wirklichkeitsgehalten im Lichte einer wissenschaftlich gesicherten Begrifflichkeit entspricht. Es ist nicht zu leugnen, daß dem hypothetischen Axiom: der Gesetzgeber greift in wachsendem Maße temporäre Zwecke auf, die es nahelegen, die Geltung einer Anzahl seiner Gesetze von ihrer Zweckerreichung abhängig zu machen - es läßt sich nicht leugnen, daß diesem hypothetischen Axiom eine Realität entspricht. Aber es ist eine Realität, die sich nur einer deskriptiven Wissenschaft erschließt. Die Rechtswissenschaft dagegen besitzt, zumindest vorerst, nicht die Begriffe und Axiome, um dieser Realität „Maßnahmegesetzgebung“ Aufnahme unter ihre Grundbegriffe zu gewähren; sie kennt die Begriffe Zweck und Geltung, aber sie unterscheidet temporären Zweck und temporäre Geltung nur empirisch, nicht axiomatisch: a 1 l e gesetzlichen Normen sind Zwecken gewidmet, und alle gesetzlichen Normen gelten bis zu ihrem Außerkrafttreten durch actus contrarius, desuetudo, Ereignisse mit abgeleiteter Rechtssatzwirkung etc.; innerhalb dieser Begrifflichkeit sondern zu wollen, ist vergeblich, weil es eine qualifizierte Geltung für Normen mit qualifizierten Zwecken bislang nicht gibt. Deskriptiv also bleibt, was an Kriterien für das Maßnahmegesetz zusammengetragen wurde; und so kann der Begriff des Maßnahmegesetzes in den soziologischen Disziplinen unseres Fachs, also in der Rechtssoziologie und in der von Jellinek so benannten Soziallehre des Staates einen Platz erhalten; ein juristischer Begriff ist er bis heute nicht ${ }^{47}$ ).

\section{II.}

In der naheliegenden Verlockung, mich über die herkömmliche Schranke zwischen den deskriptiven und den normativen Disziplinen unseres Faches hinwegzusetzen, habe ich eine Versuchung erblickt und demzufolge gemeint, ihr widerstehen $\mathrm{zu}$ müssen. Die Gründe habe ich in dem Exkurs über die beiden Geltungsbegriffe angedeutet. Das Auswechseln der Setzungsgeltung gegen die Geltung kraft Wertteilhabe ist auf dem Papier leicht vollzogen; geschichtliche Entwicklungsergebnisse macht man damit nicht rückgängig, zumal dann nicht, wenn

47) Die Rechtspflege sei - im Gegensatz zur Morallehre - beherrscht von dem Grundsatz „Finis praecepti non cadit sub praeceptum", schreibt Fr. X. Lin sen ma n n, Lehrbuch der Moraltheologie (Freiburg 1878), S. 81. Der diesem Satze zu entnehmende Fingerzeig würde, auf eine allgemeine Formel gebracht, dahin gehen, daß ein Judizieren secundum finem praecepti Intelligibilität des Normzweckes durch den Normadressaten voraussetze, daß dies aber in foro externo nicht vorausgesetzt werden könne. 
sie sich in so großen Zeiträumen vollzogen haben wie die Verankerung des Rechtsdenkens des deutschsprachigen Kulturbereichs auf dem Begriff der Setzungsgeltung.

Und selbst, wenn man meinte, mit diesem Schritt die aktuelle Problematik einer Lösung entgegenführen zu können, so würde man sich denkgesetzlichen, geschichtlichen und rechtspolitischen Einwänden gegenübersehen, die alle miteinander abzutun zumindest solange unratsam ist, als es nur um die Klärung einer Einzelfrage geht. In denkgesetzlicher Hinsicht war es die Warnung, die Nicolai Hartmann in seiner nachgelassenen Schrift über „Teleologisches Denken“49) aufgerichtet hat: „Die Finalität", sagt er hier, „ist im Bewußtsein eine hybride Kategorie. Sie hat die Tendenz, sich überall einzudrängen, wo das Denken auf Determinationsformen stößt, die es einstweilen nicht zu durchschauen vermag." Unser Rechtsdenken ist zwar weithin teleologisches Denken geworden, bedarf aber eben darum des Gegengewichtes in Instituten und Institutionen und, nicht zuletzt, in einer theoretischen Tradition, die der totalen Finalisierung entzogen bleiben müssen $\left.{ }^{4 \theta}\right)$. - Geschichtlich war zu beachten, daß

48) Nicclai Hartma n n, Teieologisches Denken (Berlin 1951), passim. Der zitierte Satz flndet sich $\mathrm{S} .7$. $\mathrm{Zu}$ vergleichen sind jedoch insbesondere S. 79 ff., auch S. 20: „... wenn keine Richtung der Dependenz eindeutig gegeben ist, so läßt jede Ursache sich auch als Mittel, jede Wirkung auch als Zweck auffassen."

49) DaB diese Uberlegung auch Folgerungen hinsichtlich der Verwendung der sog. teleologischen Interpretation bei der Auslegung der Verfassung nach sich zieht, sei angedeutet: Allgemein anerkannt ist, daB teleologische Auslegung Gesetzeslücken zum Verschwinden bringt (vgl. A. M e i e $\mathrm{r}-\mathrm{H}$ a y oz in dem unten zitierten Werk); teleologische Auslegung verfassungsrechtlicher Zweckwahrungsgebote bedeutet mithin regelmäßig Erweiterung der verfassungsrechtlichen Gebundenheit des Gesetzgebers. Unter diesem Gesichitspunkt erscheint mir die einschränkungslose Zulassung der - der gemeinrechtlichen Tradition als solcher unbekannten - teleologischen Methode zur Verfassungsauslegung (vgl. Fr. Kle in, aaO., S. 9: ,... als letztlich entscheidendes, weil eigentlich wertendes Auslegungsmittel ") nicht unbedenklich. Auch hier sind die Grenzen noch nicht geklärt - einerseits zu den gemeinrechitlichen Auslegungsweisen, andererseits zu den jüngeren Auslegungsweisen (hierzu wären zu zählen die "historische Interpretation" neueren Verständnisses - vgl. Fr. K lie in aaO., S. 9, 117 und 119 - andererseits zur „Interpretation im Sinne des vorrechtlichen Gesamtbildes oder der tragenden vorrechtlichen Gesamtidee" - vgl. H. N a w i a s y , Allg. Rechtslehre, Einsiedeln-Zürich-Köln 1948, S. $137 \mathrm{f}$, auch BVerfG oben Anm. 36) sowie schließlich zu den Methoden der Lückenergänzung. Zum Ganzen der teleologischen Methode vgl. A. M e ie r-H a y oz, Der Richter als Gesetzgeber (Zürich 1951), S. 56-59, 68 f., $88 \mathrm{ff}$., 140 ff. (insb. 142, Anm. 9), 146 f., 176 f., 272 f.; auch H. N a w i a s y, aaO., S. 135 ff. und E. Forst h of $f$, VwR I (6. Aufl. 1956), S. 143 ff. 
die Setzungsgeltung in unserer Geschichte zwar durch das Stat pro ratione voluntas des Absolutismus zur Herrschaft gelangt ist, aber seine ethische Weihe empfangen hat, indem es der Selbstvernichtung der europäischen Gesellschaft im Zeitalter der Glaubenskriege ein Ende setzte. Diese ethische Würde ist ihr geblieben; denn - so darf ich hinzufügen - Teleologie würde sich heute wiederum als Ideologie erweisen; sie einem kategorialen Institut wie der Gesetzesgeltung im Verständnis unserer theoretischen Tradition vorzuordnen, würde heißen, diese - und damit Gesetz und Recht in ihrem Fundament - der ideologischen Zersplitterung auszuliefern, die wir allenthalben, auch in den Sozialwissenschaften, am Werke sehen ${ }^{50}$ ). - Politisch schließlich steht man vor der Frage "Wozu"? Es hat sich gezeigt, daß selbst unsere so weit schon gegen den Gesetzgeber vorgeschobenen Justizkontrollen nur zur Korrektur von Randphänomenen der Maßnahmegesetzgebung ausreichen, daß aber das Schwergewicht der Verantwortung selbst dort noch bei ihm bleibt, wo er verfassungsrechtlichen Zweckwahrungsgeboten unterliegt ${ }^{51}$ ). Alles in allem genommen, stand nur zur Wahl, diese Verantwortung durch einen axiomatisch unhaltbaren und in seinen Folgerungen ergebnislosen Schritt zu verschleiern oder sie, im Lichte von Gesetz und Recht, klarzustellen.

30) Treffend E. Forsth off, VwR I (6. Aufl. 1956): „Nur was zweckhaft gestaltet ist, kann auch nach Zweckgesichtspunkten begriffen werden" (S. 145). Jedoch begründet im Verwaltungsrecht „das stark im Vordergrunde stehende . . . Zweckmäßigkeitsmoment der Rechtsanwendung . . . die Gefahr, daß sich ihre Erwägungen in allgemeinen, ungegenständlichen, vielfach in das bloß $\beta$ Weltanschauliche abgleitenden Räsonnements verlaufen. Dem gilt es zu begegnen . . ., um zu verhindern, daB die Weltanschauung zur Ausflucht eines juristischen Unvermögens wird“ (S. 147). Eben dieses Bedenken bringt Nicolai Hartmann gegen das teleologische Denken insgesamt vor: Ihm ,erscheint die Finalisierung im erkennenden Bewußtsein nich't nur als hybride Kategorie, sondern als ein wahres asylum ignorantiae" (S. 83).

51) Für Fälle der administrativen Durchbrechung der ges etz lichen Behördenorganisation hat $\mathbf{E}$. Forsthoff folgenden Satz aufgestellt: „Das ganze System rechtsstaatlicher Mäßigung der Hoheitsfunktionen kommt ins Wanken, wenn die im Behöndenorganisationsrecht geregelte Verteilung der Staatsfunktionen auf die zuständigen Behörden dadurch verändert wird, daß gesetzlich nicht vorgesehene Verbindungen solcher Funktionen hergestellt werden, was eine Potenzierung der Staatlichikeit zur Folge haben muß" (a.a.O., S. 86). Es bestehen keine Bedenken, für die ver fassungs rechtliche Verteilung der Staatsfunktionen und ihre Durchbrechung im Gesetzgebungswege das gleiche Prinzip anzunehmen. Quis autem iudicabit? 


\section{Leitsätze des Mitberichterstatters über: Das Gesetz als Norm und MaBnahme}

$I$.

1.a) Als Maßnahmegesetz wird eine abstrakte Norm bezeichnet, die temporären Zwecken derart gewidmet ist, daß diese Zwecke den Vorrang vor den in der Norm eingesetzen Verwirklichungsmitteln haben (Forsthoff).

b) Der Unterscheidung von Maßnahmegesetzen in diesem Sinne von anderen Gesetzen liegt die Voraussetzung zugrunde, daß die Geltung einer gesetzlichen Norm durch den Zweck, dem sie gewidmet ist, bedingt oder beschränkt werden kann.

2. a) Die Frage der Verwendbarkeit dieses Begriffes durch die Rechtsprechung hängt von der Frage ab, ob und inwieweit die an Gesetz und Recht gebundene Rechtsprechung einer Norm um ihrer gegenwärtigen oder einstigen Zwecke willen die Geltung versagen kann.

b) Der so verstandene Maßnahmecharakter einer Norm kann nur Gegenstand, nicht Ausgangspunkt einer Prüfung durch die Rechtsprechung sein.

II.

3. a) In Rechtsdenken und Rechtsordnung stehen sich zwei Geltungsbegriffe gegenüber: Geltung kraft Setzung und Geltung kraft Wertteilhabe.

b) Die Rechtsordnung des neuzeitlichen Staates beruht auf dem Vorrang der Geltung kraft Setzung.

4. a) In der Vorordnung des Zweckes vor der (Setzungs-) Geltung einer Norm ist der Ubergang vom Boden der Geltung kraft Setzung auf den der Geltung kraft Wertteilhabe $z u$ erblicken.

b) Wegen des Vorranges der Setzungsgeltung ist dieser Ubergang nur zulässig, wenn und soweit ihn die Verfassung gebietet (verfassungsrechtliche Zweckwahrungsgebote = Funktionsnormen i. S. Forsthoffs). 
III.

5. a) Im Hinblick auf ihren Zweck kann einer gesetzlichen Norm die Geltung nur versagt werden, wenn sie gegen ein verfassungsrechtliches Zweckwahrungsgebot verstö $\beta$ t.

b) Außerhalb des Herrschaftsbereiches verfassungsrechtlicher Zweckwahrungsgebote ist der Gesetzgeber in der Zweckwidmung seiner Normen frei und nicht überprüfbar.

6. Ein Versto $\beta$ gegen verfassungsrechtliche Zweckwahrungsgebote kann bereits bei Inkrafttreten der Norm vorliegen, kann sich aber auch als Produkt eines späteren Verhältniswandels ergeben. In diesem Falle unterliegt die Norm der Ungültigerklärung (vorzugsweise im Normenkontrollverfahren), wenn

a) außernormative - d. $h$. im gesetzlichen Tatbestand nicht berücksichtigte - Verhältnisse

b) sich derart gewandelt haben, daß die Anwendung der Norm nach Wortlaut und ursprünglichem Inhalt

c) stets - nicht nur in Einzelfällen -

d) gegen ein verfassungsrechtliches Zweckwahrungsgebot verstoßen würde. 
3. Aussprache über:

\section{Das Gesetz als Norm und Maßnahme}

\section{Kl e in - Münster:}

Meine sehr verehrten Herren Kollegen! Der Herr Erstberichter hat an einer Stelle seines erfreulichen Referates den Artikel 19 Absatz 1 unseres Grundgesetzes angesprochen.

Ich möchte mir erlauben, von dieser Verfassungsbestimmung her einen Diskussionsbeitrag zum Verhandlungsthema zu liefern, weil ich der Meinung bin, daß diese Vorschrift geeignet ist, sachlich zum Thema noch etwas wesentliches beizusteuern.

Der Artikel 19 Absatz 1 Satz 1 verlangt ein ,allgemein und nicht nur für den Einzelfall geltendes" Gesetz. Er fordert also ein allgemein geltendes, nicht dagegen ein allgemeines Gesetz, wie die Verfassung an mehreren Stellen, im Grundrechtsabschnitt im besonderen, bei den von mir sogenannten verfassungsmittelbaren Vorbehaltsschranken formuliert. Der Unterschied zwischen diesen beiden Arten von Gesetzen, von allgemeinen Gesetzen und allgemein geltenden Gesetzen den, nebenbei bemerkt, Hildegard K r üg e $\mathbf{r}$ in ihrem Beitrag zur Verfassungswidrigkeit der lex Schörner im Deutschen Verwaltungsblatt 1955 meines Erachtens übersehen oder nicht beachtet hat - ist der zwischen Geltung und Inhalt. Stellt das allgemeine Gesetz auf den Inhalt und nur auf den Inhalt eines Gesotzes ab, so bestimmt sich der Charakter des allgemein geltenden Gesetzes, wie schon der Ausdruck besagt, nach der Geltling des Gesetzes für alle. Daraus ergibt sich, daß die Formulierung von dem allgemeinen Gelten der Eingriffsgesetze nach Satz 1 des Artikels 19 Absatz 1 bezüglich der allgemeinen Gesetze im Sinne der Formulierung bei verschiedenen verfassungsmittelbaren Vorbehaltsschranken nicht, wie vielfach behauptet worden ist, eine Tautologie darstellt. Vielmehr müssen diese allgemeinen Gesetze genau so wie die den Gegensatz dazu bildenden besonderen Gesetze allgemein gelten.

Ein allgemein geltendes Gesetz ist ein solches, das auf alle Adressaten in gleicher Weise anwendbar ist, soweit diese überhaupt den gesetzlichen Tatbestand erfüllen. Insoweit ist der Satz 1 des Artikels 19 Absatz 1 nur Ausdruck des Gleichheits- 
gedankens in Artikel 3 Absatz 1. Das ist beispielsweise von Herrn G i e s e und von Herrn I p s en hervorgehoben worden.

Das allgemein geltende Gesetz muß also generell sein. Dabei ist aber zu beachten, daß sich die allgemeine Geltung des allgemein geltenden Gesetzes nur auf den angesprochenen Adressatenkreis, nicht dagegen auf den zu regelnden Sachverhalt bezieht. Das bedeutet, daß dieser Satz 1 nur Einzelpersongesetze, das heißt also Individualgesetze, nicht aber Einzelfallgesetze, das heißt also Spezialgesetze, schlechthin verbietet. Demgemäß muß das allgemein geltende Gesetz generell sein. Entgegen Hildegard Kr ü g e $r$ bin ich aber der Meinung, daß es nicht abstrakt zu sein braucht. Einzelfallgesetze sind meines Erachtens nach Satz 1 des Artikels 19 Absatz 1 nur dann unzulässig, wenn sich der gesetzlich zu regelnde „Fall“ nur in einer Person oder in nur so wenigen Personen konkretisiert, daß eine Verletzung des Gleichheitssatzes anzunehmen ist, wenn also - anders ausgedrückt - das Einzelfallgesetz auch und zugleich ein Einzelpersongesetz ist. Die Mehrzahl aller Gesetze, die nach der Kodifikation der großen Rechtsgebiete erlassen werden, sind in dem Sinne Einzelfallgesetze, daß sie zwar nicht der für die Dauer bestimmten, langfristigen Regelung der Rechtsbeziehungen der Einzelnen untereinander und zum Staate dienen, wohl aber für eine größere Zahl von Personen vorübergehend Erscheinungen des täglichen Lebens ordnen, die in mehr oder weniger kurzer Zeit entweder überhaupt nicht mehr der Regelung oder aber einer erneuten anderen Regelung bedürfen, weil sich die tatsächlichen Verhältnisse inzwischen gewandelt haben. In diesem Sinne ist meines Erachtens der größte Teil der von Forsthoff in seinem Beitrag zur Gedächtnisschrift für Walter Jellinek untersuchten sogenannten "Maßnahmegesetze" als auch nach Satz 1 des Artikels 19 Absatz 1 zulässige Einzelfallgesetze anzusehen. Der Satz 1 verbietet nach alledem nicht grundrechtseinschränkende Maßnahmegesetze schlechthin, sondern nur dann, wenn sie Einzelpersongesetze sind.

Darf ich das nun an einigen Beispielen illustrieren. In dem von mir ausgeführten Sinne wäre etwa als zulässiges Einzelfallgesetz ein die Versammlungsfreiheit des Artikels 8 nach dessen Absatz 2 einschränkendes Gesetz denkbar, durch das wegen dauernder schwerster Tumulte Demonstrations- und Propogandazüge am Tage einer Bundestagswahl verboten und die Teilnahme an ihnen unter Strafe gestellt werden würden. Noch konkreter, aber gleichwohl zulässig wäre nach meiner Meinung das folgende Einzelfallgesetz: Die Bundesregierung erwartet, sagen wir, den Staatsbesuch des Ministerpräsidenten 
der Sowjetunion und des Parteisekretärs der KPdSU. Weil sie einerseits auf Grund anonymer Drohungen tumultartige Demonstrationen befürchtet, vielleicht sogar mit Attentaten zu rechnen hat, weil sie anderseits auf Grund der politischen Einstellung derjenigen, die in den zuständigen Behörden der Länder und Gemeinden für die entsprechenden Verwaltungsmaßnahmen zuständig sind, solche Verwaltungsmaßnahmen nicht erreichen kann, wird auf ihre Initiative hin ad hoc ein Bundesgesetz erlassen, das alle Menschenansammlungen unter freiem Himmel am Aufenthaltsort der sowjetischen Gäste verbietet und die Teilnahme an solchen Ansammlungen unter Strafe stellt. Ich würde dies für ein zulässiges Einzelfallgesetz halten. Konkretere Einzelfallgesetze lassen sich wohl kaum denken, es sei denn, daß in den von mir angeführten Beispielsfällen nicht Demonstrationen überhaupt, sondern solche bestimmter bekannter Personen oder politischer Gruppen verboten werden. Dann aber handelt es sich nicht mehr nur um Einzelfallgesetze schlechthin, sondern bereits um Einzelpersongesetze.

Dasselbe dürfte gelten, wenn das Verbot zwar durch die Art und Weise seiner Formulierung den Anschein eines Verbots von Demonstrationen überhaupt erweckt, in Wahrheit aber nur Demonstrationen ganz bestimmter bekannter Personen oder politischer Gruppen treffen will; in den angeführten Beispielsfällen also insbesondere dann, wenn überhaupt nur die Demonstration einer bestimmten politischen Gruppe zu befürchten ist.

Das Gesetz im Sinne des Artikels 19 Absatz 1 Satz 1 muls nicht nur nach seiner Formulierung, sondern auch nach seinen tatsächlichen und gerade beabsichtigten Rechtswirkungen allgemeine Geltung haben. Demgemäß muß es nicht nur seinem Wortlaut nach - weil es hinsichtlich des Adressatenkreises generell gefaßt ist - formal für alle gelten, sondern auch seinem Inhalt nach darauf angelegt sein, daß es nicht von vornherein auf einen bestimmten Personenkreis, bestimmte Personen oder gar nur eine bestimmte Person zugeschnitten ist. Der Satz 1 verbietet außerdem - was bereits in den Referaten angeklungen ist - nicht nur das "offene", sondern auch das von Hildegard Krüger sogenannte "getarnte" Einzelpersongesetz. Das kann garnicht anders und darf nicht anders sein, weil der Gesetzgeber kraft seiner Technik so weit ist, daß jedes Gesetz in der Form eines für alle geltenden Gesetzes ergehen kann, auch wenn es sich ganz bewußt auf die Regelung von Einzelfragen und Einzelfällen beschränken will. Wenn nur eine Person getroffen werden soll, ist die Frage der Zulässig- 
keit eines einschränkenden Gesetzes einfach - im Sinne der Richtigkeit des Gesetzes - zu entscheiden. Wenn dagegen eine Gruppe von Personen getroffen werden soll, erfordert die Entscheidung offenbar sehr viel Takt von dem, der mit der Entscheidung befaBt ist.

Mir möchte es fast so scheinen, als ob sich die Frage in das Gebiet rational nicht mehr recht greifbarer Gerechtigkeitsvorstellungen verflüchtigt. Wenn etwa in Abwandlung meines Beispiels von vorhin - des Beispiels des sowjetischen Staatsbesuches - eine bestimmte Gruppe von anonymen oder auch bekannten Attentätern und Marodeuren, denen auf Grund ihrer ganzen Haltung - ausgewiesen durch Drohbriefe und ähnliches - jedes Mittel recht zu sein scheint, losschlagen will, ist das Gesetz zulässig, weil das entsprechende Handeln der Demonstranten schon nach der sogenannten verfassungsunmittelbaren Vorbehaltsschranke des Artikels 2 Absatz 1 Halbsatz 2 unzulässig ist. Wie aber, wenn irgendeine, wenn auch extreme Gruppe, sagen wir nur demonstrieren will? Ich muß offen bekennen, daB ich in dieser Stunde noch keine rechte Antwort auf diese Frage weiß. Ich meine nur eines mit Sicherheit sagen zu können: So wie Hildegard $\mathrm{K} r$ ü g e $\mathrm{r}$ diese ganze Problematik zu lösen versucht hat, nämlich mit Hilfe der „Lehre von der Vertauschung von Staatsakten", geht es meines Erachtens nicht.

\section{Sche u ner-Bonn:}

Die beiden Referate, die wir heute früh gehört haben, haben uns in einer sowohl sorgfältig absteckenden als auch auf die tieferen Hintergründe eingehenden Weise die Problematik klargemacht, die wir von dem gestellten Thema aus nur gewissermaßen in einem Teilaspekt in unsere Betrachtung einbezogen haben. Es geht heute um die Frage, ob es Möglichkeiten des Maßstabes vom Gesetzbegriff her gibt, um gewisse Gesetze mit vorbeugendem oder sonst allzu konkretisiertem Inhalt, die sich in der neueren Gesetzgebung häufen, entweder als eine Entartungserscheinung der Gesetzgebung oder sogar als eine verfassungswidrige Gegebenheit zu kritisieren. Die Erscheinung, die unter dem Namen Maßnahmengesetze ins Auge gefaßt wird, scheint zwei Erscheinungsbereiche zu umfassen. Auf der einen Seite Gesetze, wie sie Herr Klein soeben im Auge gehabt hat, die man früher als Individualgesetze bezeichnete und heute mit einer moderneren und interessanteren Bezeichnung als Maßnahmengesetze benennt. Zum anderen aber richtet sich die Kritik dagegen, daß der heutige Gesetzgeber in wachsendem Umfange temporär kurzfristige Gesetze 
oder fortlaufende Gesetzesänderungen erläßt, so daß das Erscheinungsbild des Gesetzes sich von jener Vorstellung der Dauer und Beständigkeit entfernt, die noch unser bürgerliches Recht in dem Gedanken kodifikatorischer Zusammenfassungen von Gesetzen vor Augen hält. Das sind aber zwei ganz verschiedene Erscheinungen. Wenn wir die letztere Erscheinung betrachten, so meint - wie Herr Wehrhahn ganz mit Recht gesagt hat - die Kategorie des Maßnahmengesetzes eine soziologische Beobachtung. Sie kann aber in dieser Anwendung keinerlei juristischen Inhalt haben. Ich würde ganz ausdrücklich feststellen, daß es unmöglich wäre, dem Gesetzgeber bei seiner heutigen etwas lockeren Praxis rasch sich wandelnder Gesetze etwa verfassungsrechtliche Schranken auf Grund des geltenden Verfassungsrechts aufzuerlegen. Umgekehrt ist die Frage der Unzulässigkeit des Individualgesetzes oder des Maßnahmengesetzes in jenem technischen Sinne des Einzelpersonen- oder Einzelfallgesetzes, wie es uns Herr Menger klärend vor Augen geführt hat, in der Tat eine verfassungsrechtliche Frage, wobei dann nur das Problem entsteht, woher wir die verfassungsrechtlichen Gesichtspunkte gewinnen, um solche Gesetze verfassungsrechtlich angreifen zu können.

Wenn ich zunächst ein wenig noch auf die Frage des weiteren Hintergrundes eingehe, so scheint mir, daß Herr Wehrhahn uns hier entscheidende Beiträge dadurch geliefert hat, daß er uns darauf aufmerksam machte, der moderne Gesetzesbegriff könne eine inhaltliche Begrenzung vom materiellen Gehalt her kaum mehr ertragen. In der Tat ist die Entwicklung des modernen Gesetzesbegriffes zu einer völligen Verschleißung seiner inhaltlichen Qualitäten vorwärts gegangen. Was wir heute vom Rechtssatz fordern, ist nur die Generalität, die Allgemeinheit. $\mathrm{DaB}$ sich dahinter freilich viel tiefere Probleme verbergen, wird jeder, dem die Geschichte des Gesetzesbegriffes bekannt ist, ohne weiteres erkennen. $\mathrm{DaB}$ lange Jahrhunderte hindurch der Gesetzesbegriff eine inhaltliche Qualität aufwies, brauche ich nicht besonders zu betonen. Das ist für das Mittelalter selbstverständlich gewesen. Es ist das sogar - wie ich vielleicht gegenüber Herrn Wehrhahn betonen möchte - auch für die Zeit des Absolutismus noch gegeben. Man darf nicht Hobbes als einen Normalfall des Absolutismus betrachten, sondern muß sich darüber klar sein, daß auch der absolute Fürst die inhaltliche Bindung seiner Gesetze an das natürliche und göttliche Gesetz bis zur französischen Revolution außer allem Zweifel anerkannt hat. Die Lösung des Gesetzes von göttlichen und natürlichen Gesetzen ist ein Schritt, die vielleicht schon bei Hobbes vorgezeichnet ist, den aber 
im eigentlichen Sinne erst der Positivismus des 19. Jahrhunderts, vielleicht in der Anlage schon die Idee der Volkssouveränität von Rousseau vollzogen hat. Es darf dabei betont werden, daß der moderne Gesetzesbegriff ein voluntaristischer ist, das heißt also mindestens ein gemischter ist in dem Sinne, wie Sie es hier, Herr Wehrhahn, gekennzeichnet haben, daß er also von vornherein als entscheidendes Merkmal den Erlaß durch den Träger der Souveränität enthält, in einer Wendung, die zugleich eine Entscheidung für die nominalistische Gesetzessicht darstellt. Es ist hochinteressant, daß die beiden Autoren, die die Formung des Gesetzesbegriffes für die Moderne stark beeinflußt haben, Locke - wenn wir zurückgehen auf die vor wenigen Jahren veröffentlichte, von ihm selbst zu Lebzeiten nicht veröffentlichte Naturrechtsstudie, die jetzt in England herausgegeben worden ist - und ebenso Pufendorf diesen voluntaristischen Gesetzesbegriff vertreten haben. Mit anderen Morten: In der Entwicklung der Rechtstheorie ist nichts anderes übrig geblieben von den inhaltlichen Qualitäten des Gesetzes als eine abstrakte durch den Kantianismus schließlich zu einem reinen Formalismus abgeschliffene Forderung innerer Gerechtigkeit. Diese Forderung innerer Gerechtigkeit hat auch der Positivismus des 19. Jahrhunderts noch als selbstverständlich empfunden und festgehalten, wenn er freilich infolge seines Formalismus nicht mehr in der Lage gewesen ist, noch eine wirkliche Qualitätsforderung inhaltlicher Art daran zu knüpfen. Heute versucht man diese inhaltliche Forderung durch eine Rückwendung zum Naturrecht wieder einzuführen, über die wir indes hier nicht zu sprechen haben.

Es darf andererseits festgestellt werden, da $\beta$ entscheidende Merkmale des Gesetzes aus verfassungsrechtlichen Zusammenhängen entnommen werden. Der Gesetzesbegriff des 19. Jahrhunderts ist geprägt worden vom Kampfe des Parlamentes um einen möglichst weitreichenden Anteil an der obersten Staatsleitung. Es ist mit Recht hervorgehoben worden, daß das Gesetz einen Doppelcharakter trägt. Es ist sowohl Rechtsetzung wie staatlich-politische Gestaltung. Es ist niemals etwas anderes gewesen, jedenfalls seit dem späteren Mittelalter nicht. Der Staat ist im Gesetze den konkreten Lebensverhältnissen sehr nahe. Ich würde vielleicht Herrn Menger zu bedenken geben, da $B$ seine Forderung, der Gesetzgeber dürfe nicht zu nahe an die konkreten Lebensverhältnisse kommen, diese Notwendigkeit nicht hinreichend berücksichtigt. Sollte der Gesetzgeber etwa bei der Gestaltung des Familienrechtes den Lebensverhältnissen fernstehen? Oder sollte er nicht gerade die 
Lebensverhältnisse unmittelbar in ihrer gegenwärtigen konkreten Bezogenheit im Auge haben? Sollte er nicht dabei auch einen erzieherischen und pädagogischen Zweck verfolgen, um dieses Gesetz nicht nur als Aufzeichnung einer möglicherweise vorliegenden Entartung der tatsächlichen Lebensformen, sondern als eine Wieder-Hebung und Besserung der Lebensverhältnisse durchzusetzen? Mit anderen Worten: Politische, rechtspolitische und rechtliche Festsetzung gehen bei unseren heutigen Gesetzen eine unlösbare Verbindung ein. Der Versuch, diese beiden Dinge auseinander $\mathrm{zu}$ lösen und das eine gegen das andere auszuspielen, ist meiner Ansicht nach unzulässig. Er ist auch philosophisch - das brauche ich eigentlich hier nicht mehr auszuführen - nicht möglich.

Das bedeutet aber ein weiteres. Die Abgrenzung des Gesetzesbereiches ist im 19. Jahrhundert zunächst - jedenfalls in der deutschen und kontinentalen Theorie - an der Formel „Eingriffe in Eigentum und Freiheit" erfolgt. Das ist eine sachliche Umschreibung, die die Zuständigkeit des Parlamentes abgrenzte. Im frühen 19. Jahrhundert fiel alles das, was heute als Maßnahmegesetze bezeichnet wird, in den Bereich der Verordnung, trat also als Problem des Gesetzgebers zum großen Teil gar nicht in Erscheinung. Denn das frühe 19. Jahrhundert kannte noch den barocken, heute noch im angelsächsischen Bereich lebendigen Gesetzesbegriff, der in sich auch den Gedanken der lex specialis, des Privilegiums für einen Einzelfall, enthielt. Denken wir als Beispiel an die im frühen 19. Jahrhundert vorkommenden Gesetze über Änderung der Thronfolge oder über die Rechte einzelner Standesherren. Der monarchische Staat mußte solche Gesetze kennen, weil die Thronfolge nur geändert oder gestaltet werden kann ad personam. Wenn man die Theorie des früheren 19. Jahrhunderts befragt, so kennt sie das Privileg noch immer als einen zugelassenen Bestandteil der Gesetzgebung. Geändert hat sich das erst, als die Formel des Rechtssatzes vom späteren Positivismus ausgestaltet wurde zu dem uns heute beschäftigenden Satze, daß alle generellen Rechtsanordnungen grundsätzlich durch Gesetz erlassen werden müssen. Diese - fast unbegrenzte - Erweiterung des Gesetzes oder Rechtssatzbegriffes hat notwendig auch eine ebenso große Erweiterung der Zuständigkeit des Parlaments gebracht. Sie hat das Parlament überhaupt erst genötigt, für viele vorübergehende Fragen Gesetze zu erlassen, weil man nunmehr nicht mit administrativen Maßnahmen und den bisherigen Verordnungen auskam. Ähnliche Probleme ergeben sich beim Gewaltverhältnis in seiner Beziehung zu diesem weiten Rechtssatzbegriff. Solange man dem Bereich der Gewaltverhältnisse 
einen weiten Umfang gab, konnte man zahlreiche Fragen, etwa des Schulrechtes oder Beamtenrechtes, intern ohne Rechtssatz regeln. Je weiter der Rechtssatzbegriff ausgedehnt wurde, desto mehr flüchtige und vorübergehende Regelungen fielen dem Parlamente zu.

Wir haben uns also an diesem Punkte die Frage vorzulegen: Aus welchem Gesichtspunkt soll eigentlich ein temporäres oder ein singuläres Gesetz des Parlamentes unzulässig sein? Ich stimme ganz mit den beiden Vortragenden überein, daß man hier den Grundsatz der Gewaltenteilung nur mit großer Vorsicht anführen kann, ganz abgesehen davon, daß dieser Grundsatz in den verschiedenen Ländern der Welt einen sehr verschiedenen Inhalt hat. Beispielsweise hindert der Grundsatz der Gewaltenteilung die angelsächsischen Staaten nicht daran, das Einzelgesetz ohne weiteres anzuerkennen. So ist wohl der Grundsatz der Gewaltenteilung in diesem Zusammenhang nur dort anzuführen, wo das Gesetz des Parlaments in die Rechtssphäre einer anderen Gewalt unter Verfassungsverletzung eingreift. Daß das - wie Herr Menger mit Recht hervorgehoben hat - vor allen Dingen bei der Justiz gilt, ist unstreitig. Im Gebiet der Rechtspflege ist es unzulässig, daß das Parlament sich an die Stelle des Richters setzt. Auch hier ging bekanntlich das angelsächsische Recht in älterer Zeit andere Wege, was damit zusammenhängt, da $\beta$ das englische Parlament ein High Court of Parliament ist, also selbst als oberster Gerichtshof fungieren konnte. Es ist bekannt, daß die Supremacy of Parliament in England nicht die Ubertragung der Herrschaft des Königtums auf das Parlament oder eine Eigenschaft des Parlaments als Legislative ist, sondern Supremacy of Parliament folgt im englischen Recht aus der Eigenschaft des Parlaments als oberstes Gericht. Es ist ein Court, dessen Ausspruch kein anderer Court in Frage stellen kann, weil es der höchste Court des Landes ist. Auf dem Kontinent ist hingegen entscheidend: das Parlament darf nicht judizieren. Ein Gesetz, das ein Urteil vorwegnimmt oder ein erlassenes Urteil aufhebt, ist unzulässig. Das können wir aus der Verfassung entnehmen. Dazu brauchen wir gar keine Theorie des Maßnahmengesetzes. Es steht in Artikel 102, daß Ausnahmegerichte unzulässig sind und niemand seinem gesetzlichen Richter entzogen werden kann. Das sind alte Sätze des grundrechtlichen Teils.

Schwieriger ist es bei Ubergriffen des Parlamentes in die Exekutive. Hier berührt sich die Problematik, vor der wir stehen, mit gegenwärtigen politischen Entwicklungen. Die modernen Parlamente werden infolge der schwindenden Gewaltenteilung mehr und mehr die eigentlichen Leiter der Verwaltung. 
Das Parlament leitet die Verwaltung heute folglich weniger durch Einzeleingriffe als durch eine fortlaufende Änderung der Gesetze. Wir sind auf dem Gebiete des Wirtschaftsrechtes daran gewöhnt, daß das Parlament immer von neuem die Gesetze ändert. Das ist in Wahrheit eine mehr administrative als legislatorische Tätigkeit. Dagegen können wir aber nicht von einem Begriff des Gesetzes aus vorgehen. Hier liegt ein Mangel vor, der aus der Verfassungsstruktur heraus berichtigt werden müßte, ein Ziel, das durch eine Selbständigerstellung der Exekutive und durch eine Begrenzung der legislatorischen Tätigkeit erreicht werden müßte. Wenn so die Gewaltenteilung nicht als Maßstab dienen kann, so ist das eigentlich entscheidende Prinzip der egalitäre Zug der Demokratie. Die Demokratie gestattet keine Individualgesetze. Hier ist der eine Ansatz des Verbotes von Individualgesetzen. Der zweite liegt im Rechtsstaatgedanken. Der Rechtsstaatgedanke schließt ebenfalls die Gleichheit ein, freilich eine Rechtsgleichheit, nicht so sehr eine soziale Gleichheit. Auch er verbietet Individualgesetze. Der Erlaß der Steuer für ein großes Industrieunternehmen erscheint sowohl der Demokratie wie dem Rechtsstaat als unzulässig. Ich würde - den Ausführungen des Herrn Kollegen Klein im wesentlichen zustimmend - sagen: der alte Begriff des Individualgesetzes deckte nur den Fall des sogenannten Personengesetzes, nicht des Einzelfallgesetzes, oder jedenfalls dieses nur dann, wenn es ein verhülltes Personengesetz war. Das temporäre Gesetz ist in der Regel überhaupt rechtlich zulässig, wenn es für einen echten vorübergehenden Bedarf erlassen wird. Man sollte sich hüten, durch eine Erweiterung des Begriffes des verfassungsrechtlich unzulässigen Individualgesetzes $\mathrm{zu}$ weit $\mathrm{zu}$ gehen. Ich würde davor warnen, aus der Kritik an der aktuellen Gesetzespraxis heraus zu einer neuen weiteren Kategorie des verfassungsrechtlich unstatthaften Gesetzes, zum Maßnahmengesetz zu kommen. Man mag das Investionshilfegesetz nicht sehr schätzen. Aber die Auffassung, daß es deshalb ungültig sei, weil es ein Gesetz für kurze Zeit war, das in einem besonderen Fall einen Ausgleich zwischen dem einen und anderen Teil der Industrie herbeigeführt hat, das scheint mir aus dem Grundgesetz nicht herauszulesen sein.

Lassen Sie mich nur noch einen Gedanken aussprechen. Der zweite Zusammenhang, über den wir hier gesprochen haben, $\mathrm{da} ß$ allzu viele vorübergehende und oft geänderte Gesetze erlassen werden, ist eine Krankheit aller Länder. Ich habe gerade vor mir hier eine Vortragsreihe, die im letzten Winter in Brüssel über die belgischen Verhältnisse gehalten wurde. Dort 
ist in einer Zusammenstellung erwähnt worden, daß im Jahre 185238 Gesetze, 53 königliche und 5 ministerielle Verordnungen ergingen, im Jahre 1952 - ein Jahrhundert später 148 Gesetze, 489 königliche Verordnungen und 217 ministerielle Verordnungen. Das ist der Tatbestand des heutigen Verwaltungsstaates, der diese Rechtsflut erzeugt, unter der sowohl die Parlamente wie die Verwaltung seufzen. Hiergegen Abhilfe zu treffen, ist keineswegs durch den Gesetzesbegriff möglich. Die Abhilfe liegt hier ausschlieBlich im Parlamentsverfahren, nicht in der Struktur des Verhältnisses von Exekutive und Legislative. Da das über unser Thema hinausführt, will ich nur ganz kurz die Gesichtspunkte andeuten: Muß wirklich das Parlament so viele Einzelheiten regeln? Da diese Einzelheiten notwendig kurzfristig sind und daher immerfort neue $\mathrm{Ge}$ setzesänderungen verlangen, sollte man nicht mehr der Exekutive delegieren? Sollte man nicht Formen schaffen, in denen Exekutivverordnungen die Genehmigung des Parlaments erfordern, aber nicht vom Parlament selbst erlassen werden? Es ist bekannt, daß eine Erweiterung des Verordnungsrechts durch das Grundgesetz (Artikel 80) beschränkt ist und daB die offizielle Auffassung sich sogar noch bemüht hat, den Artikel 80 möglichst starr auszulegen, so da $\beta$ die Verordnungsgewalt der Exekutive allzusehr beschränkt wurde. In anderen Ländern erwägt man schon den Gedanken, den Erlaß mancher Verordnungen dem Parlament beigeordneten Ausschüssen oder Beiräten zu übertragen - wie das auch in den erwähnten belgischen Vorschlägen anklang -, ein Verfahren, gegen das man sehr viele Bedenken anmelden könnte.

Endlich darf in diesem Zusammenhang die Frage aufgeworfen werden, ob nicht überhaupt die Vielgesetzgeberei unserer heutigen Zeit durch eine größere Sammlung des Gesetzesstoffes - also durch eine größere Beschränkung in der gesetzgeberischen Tätigkeit - aufgehalten werden könnte. Das hängt freilich mit Erscheinungen des modernen Wohlfahrtsstaates zusammen, dessen Ruf nach sozialem Ausgleich eine sehr detaillierte Gesetzgebung und häufige Anpassung deren Regeln nötig macht. Weiter darf ich in diesem Zusammenhang noch darauf hinweisen, daB gewisse formelle Maßnahmen des Parlamentes, wie den Haushaltserlaß oder die Zustimmung zu Verträgen, durch Beschluß statt durch Gesetz erlassen werden könnten, wobei man sich freilich darüber klar werden muB, daß sowohl das parlamentarische Verfahren identisch sein muß wie auch die Verkündung im Gesetzesblatt notwendig werden wird. Wir kommen hier auf die Frage, ob nicht ein Souverän, der sehr viele Rechtsätze erläßt, zweck- 
mäßig handelt, wenn er diese Rechtsätze nach ihrer Bedeutung durch die Bezeichnung differenziert. Die Monarchie hat das immer getan. Sie hat gewisse wichtige Erlasse hervorgehoben. Das ist unseren Parlamenten fremd. Nachdem sie aber der Hauptträger der Gesetzgebung geworden sind, ließen sich solche Gedanken vielleicht auch auf sie übertragen.

Abschließend möchte ich feststellen, daß es mir bedenklich erscheint, durch die Verwendung einer so vagen Vorstellung wie der des Maßnahmegesetzes eine Kontrolle der Verfassung und der Art der Gesetzgebung unter Appell an eine Ausdehnung der Rechtssprechung zu suchen. Die Verfassungsrechtssprechung hat ihren guten begründeten Platz. Aber man darf sie nicht überfordern. Ihr Maßstäbe an die Hand zu geben, die mehr oder weniger auf unbestimmte Werturteile hinausliefen, würde ich nicht für einen Gewinn des Verfassungsrechts halten. Kurz und gut: Im ganzen scheint mir der Begriff des Maßnahmegesetzes kaum einen wesentlichen Fortschritt zu bedeuten.

M e r k - Tübingen:

Ich möchte nur zu 4 Punkten das Wort ergreifen. - Zunächst habe ich Bedenken dagegen, daB die Grenzen zwischen sog. „Normgesetzen“ mit an der Gerechtigkeit ausgerichteten Rechtsätzen und sog. „Maßnahmegesetzen“ mit aus Anlaß einer bestimmt gegebenen Sachlage erlassenen, rein zweckbestimmten, Rechtsätzen so scharf gezogen werden, wie es im 1. Vortrage geschehen ist. Mir scheinen die Grenzen in gewissem Grade flüssig zu sein. Einerseits ist das Zweckmerkmal auch bei den sog. Normgesetzen nicht zu übersehen. Denken wir an Zweckmäßigkeitsbestimmungen, wie sie sich vielfach in Verfahrensgesetzen, z. B. hinsichtlich der Rechtsmittelfristen, aber auch im sachlichen Recht, wie z. B. bei den Verjährungsfristen, finden; soll man an diesen Gesetzen eine Aufspaltung vornehmen, je nachdem der Zweckgedanke oder der Gerechtigkeitsgedanke bei den einzelnen Rechtsätzen überwiegt? Freilich stehen doch auch diese Zweckmäßigkeitsbestimmungen im letzten Grunde im Dienste der Gerechtigkeit. Auf der anderen Seite wird nicht in Abrede zu stellen sein, daß auch die sog. Maßnahmegesetze unter dem Gebote der Gerechtigkeit, dem Gleichheitsgrundsatze usw., stehen; daß sie lediglich zweckbestimmt seien, wie gesagt worden ist, möchte ich nicht annehmen, weil es sich auch hier nach den Ausführungen des Herrn 1. Redners um Rechtsätze handelt. Im übrigen werden doch auch die sog. Normgesetze regelmäßig durch einen bestimmten Anlaß ausgelöst und aus ganz bestimmten Gründen 
und zu bestimmten Zwecken erlassen; man denke z. B. an die Sozialversicherungsgesetze, Arbeitsschutzgesetze, Kriegsopferversorgungsgesetze, das KraftwagenfallenG. Sie stehen also auch nicht nur unter dem Gerechtigkeitsgedanken; insofern sind die sog. Normgesetze auch Maßnahmegesetze, wie umgekehrt nach dem vorhin Bemerkten die Maßnahmegesetze auch Normgesetze. Wenn im übrigen bei den Maßnahmegesetzen noch auf die Regelung eines zeitlich oder zahlenmäßig begrenzten Kreises von Sachverhalten als ein weiteres Merkmal abgehoben wurde, so dürfte dies zwar, wie insbesondere der vorübergehende $Z$ weck, für manche Fälle eine gewisse Berechtigung haben, im ganzen aber doch eine willkürliche Einengung des Begriffs der Maßnahme sein, die eine klare Abgrenzung nicht ergibt; auch die in Art. 48, Abs. 2 Weim.RV vorgesehenen „Maßnahmen“, deren Begriff dort auftaucht, wiesen eine derartige Beschränkung nicht auf, wie auch die auf Grund dieser Bestimmung erlassenen gesetzvertretenden Verordnungen z. T. Jahre und Jahrzehnte lang bestanden haben.

Weiter kann man m. E. nicht sagen, wie es der Herr 1. Redner getan hat, daß die sog. Maßnahmegesetze schlechtweg nur als Fälle gestaltender Regierung und Verwaltung zulässig seien (Ziff. III, 2 d. Leits.) oder „dem Bereiche der Regierung und Verwaltung angehören". Das ist mir nicht ganz verständlich, da ja nach Ziff. I, 1 der Leitsätze als Gesetz jeder Rechtsatz gelten soll, der in der verfassungsmäßig für Gesetze vorgeschriebenen Weise zustandegekommen ist, d.h. also doch wohl Gesetz im sachlichen und im förmlichen Sinne ist. Läßt sich das wirklich sagen mit Bezug auf die Rechtsätze - nur von ihnen ist ja die Rede - , die durch solche Maßnahmegesetze erlassen werden, im Hinblick darauf, daß nach dem Grundsatz der Gewaltentrennung (Art. 20, Abs. 2 GG) der Erlaß von Rechtsätzen grundsätzlich dem Träger der gesetzgebenden Gewalt, d.h. der Volksvertretung, vorbehalten, die Regierung und Verwaltung aber ihm grundsätzlich, soweit nichts Besonderes bestimmt ist, entzogen ist? Es scheint doch, als ob hier vor allem, und zwar zu sehr, an die - nicht ausdrücklich erwähnten - gesetzvertretenden Verordnungen der vollziehenden Gewalt gedacht ist, wie sie insb. in der Weimarer Zeit auf Grund der außerordentlichen Gewalt (sog. Diktaturgewalt) vom Reichspräsidenten nach Art. 48, Abs. 2 RV erlassen worden sind. Es ist doch dem Träger der ordentlichen gesetzgebenden Gewalt grundsätzlich nicht verwehrt, auch aus besonderem Anlaß oder für vorübergehende $Z$ wecke Gesetze zu erlassen; man denke an Soforthilfegesetze, Wohnungsbaugesetze, das InvestitionshilfeG usw. Daß infolge des vorwiegenden Zweck- 
gedankens, wenn wir ihn bei gewissen Gesetzen feststellen können, eine gewisse Verwandtschaft mit der weitgehend nach freiem pflichtmäßigen Ermessen erfolgenden Tätigkeit der Regierung und Verwaltung besteht, soll damit nicht in $\mathrm{Ab}-$ rede gestellt werden; aber deshalb von „Fällen gestaltender Regierung und Verwaltung" $z u$ sprechen, erscheint nicht angängig.

$\mathrm{Da}$ durch sog. Maßnahmegesetze bestehendes Recht nicht soll abgeändert werden können, wie unter Ziff. III, 3 der Leitsätze des Herrn 1. Redners schlechthin gesagt ist, möchte jch in dieser Allgemeinheit bezweifeln. Wohl gilt dies ja grundsätzlich für Handlungen der Regierung und Verwaltung, an die wohl hier wieder gedacht ist. Aber es galt nicht für Art. 48 Weim.RV und gilt z. B. auch nicht für die Notstandsgesetze des Art. 81 GG, die nur eine Schranke in den Bestimmungen der Verfassung finden, die nicht geändert noch auch ganz oder teilweise außer Kraft oder außer Anwendung gesetzt werden können. Wie soll das im übrigen mit dem Grundsatze, daß das spätere Gesetz das frühere aufhebt und aufheben kann, in Einklang zu bringen sein? Die unter Ziff. III, 1 der Leitsätze erwähnten Schranken für Maßnahmegesetze, die sich aus dem sachlich-rechtlichen Gefüge des GG ergeben und die Unzulässigkeit von Eingriffen in den grundrechtlich gesicherten Freiheitsbereich oder in die Zuständigkeit des gesetzlichen Richters enthalten, gilt - unbeschadet des Vorbehalts des Gesetzes - m. E. für Gesetze aller Art. Daß weiter die Anwendbarkeit der Maßnahmegesetze unter dem aus dem Völkerrecht bekannten Grundsatze der veränderten Verhältnisse stehe, wird in dieser Weise auch nicht anzuerkennen sein; es wird vielmehr wohl in erster Reihe in Frage kommen, ob sich noch Sachverhalte der bestimmten Art ereignen können, und im übrigen gegebenenfalls sich die Gegenstandslosigkeit wegen $Z$ weckerledigung ergeben oder zur Aufhebung geschritten werden können. Sodann ist unter Ziff. III, 4 der Leitsätze gesagt, daß Maßnahmegesetze dem Grundsatze der Verhältnismäßigkeit von $Z$ weck und Mitteln genügen müßten; aber welche rechtliche Bedeutung das haben soll, insbesondere, welche Rechtsfolgen sich an die Nichtbeachtung knüpfen, ist nicht gesagt - etwa, daß, abgesehen von der gerichtlichen Rechtsatzüberprüfung durch das BVerfG bei Verstößen gegen verfassungsrechtliche Bestimmungen, wegen Ermessensmißbrauchs oder Ermessensüberschreitung die Verfassungsbeschwerde nach $\$ 93$ BVerfGG in Betracht kommt.

Nach alledem scheint mir die ganze Unterscheidung zwischen sog. Normgesetzen und Maßnahmegesetzen, wie sie hier vor- 
genommen worden ist, rechtlich der genügenden Klarheit und Bestimmtheit $z u$ entbehren; es ist doch fraglich, ob sie fruchtbar ist, zumal sie sich auf Gesetze im sachlichen Sinne, Rechtsatzgesetze, beschränkt: es handelt sich allenfalls um Gradesunterschiede, aber nicht um Wesensunterschiede. Demgegenüber erscheint mir bedeutsam einmal bei den Gesetzen im sachlichen Sinne die Unterscheidung zwischen allgemeinen Gesetzen und Einzelfallgesetzen. Darauf ist hier nicht näher einzugehen; es sei nur bemerkt, da $B$ auch die Einzelfallgesetze, die für einen einzelnen bestimmten Sachverhalt bestimmt sind und in deren Regelung sich ihre Geltungskraft erschöpfen soll, nach unserem Recht nicht schlechtweg ausgeschlossen sind, soweit nicht besondere Verfassungsbestimmungen entgegenstehen, wie Art.19, Abs. 2 GG bezüglich des Vorbehalts des Gesetzes bei Grundrechten oder der Gleichheitsgrundsatz nach Art. 3. Gerade das InvestitionshilfeG ist z. B. ein solches Einzelfallgesetz, wie es auch sonst für einmalige Maßnahmen in Betracht kommen kann. Im übrigen dürfen doch auch in diesem Zusammenhang Gesetze im bloß förmlichen Sinne nicht außer Acht gelassen werden. So z. B. sog. Vollzugsgesetze, wo es sich nicht um den Erlaß von Rechtsätzen handelt, sondern um einen bloßen Vollzug von bestehenden Rechtsätzen, d.h. um Verwaltungsverfügungen im sachlichen Sinne, aber in Gesetzesform, die einzelne bestimmte, gegebene, Sachverhalte gestalten, wie z. B. eine Enteignung, wenn sie nach Art. 14, Abs. 3 GG durch Gesetz vorgenommen wird. Ferner sind hier anzuführen Haushaltsgesetze, die Finanzbeihilfen, wie insbesondere verlorene Zuschüsse, für bestimmte Zwecke vorsehen, sowie Gesetze über die Gewährung von Darlehen - wie z. B. für den Wiederaufbau der deutschen Handelsflotte - oder über die Ubernahme von Bürgschaften oder sonstigen Sicherheitsleistungen, die der Form des Gesetzes bedürfen. Warum alle diese Erscheinungen aus dem Begriffe der sog. Maßnahmegesetze ausgeschieden sind (Leitsatz II, 1), ist nicht einzusehen. - Abschließend möchte ich zu diesem Punkte sagen: Maßnahmen des Staates sind m.E. staatliche Willenshandlungen - insbesondere Willenserklärungen - zur Erreichung eines bestimmten Erfolges außerhalb der Rechtsprechung der Gerichte; sie können ergehen als Rechtsatz - allgemeiner Art oder im Einzelfalle - oder als rechtliche oder tatsächliche Gestaltung einzelner bestimmter gegebener Sachverhalte; durch die gesetzgebende Gewalt - als Gesetz im sachlichen oder im bloß förmlichen Sinne - oder durch die vollziehende Gewalt - als Verordnung (insbesondere gesetzvertretende VO), Satzung oder Vereinbarung auf gesetzlicher Grundlage, als Verwaltungsver- 
fügung oder sonstige Verwaltungshandlung, z. B. auch tatsächlicher Art -.

Nun der zweite Punkt. Ich bin der Auffassung, daB an der Unterscheidung zwischen Gesetz im sachlichen und im förmlichen Sinne festgehalten werden sollte, nämlich, ob es sich handelt um den verbindlichen Erlaß von Rechtsätzen, wie dies durch Verfassung, Gesetz, Verordnung, Satzung oder Vereinbarung erfolgen kann, oder aber um eine staatliche Willenserklärung, die im Wege der Gesetzgebung durch den Träger der gesetzgebenden Gewalt erfolgt. So sind Rechtsätze, die durch den Träger der gesetzgebenden Gewalt im Wege der Gesetzgebung erlassen werden, Gesetze im sachlichen und im förmlichen Sinne, während z. B. Haushaltsgesetze, Gesetze über die Aufnahme von Darlehen oder die Ubernahme von Bürgschaften oder sonstigen Sicherheitsleistungen, wie schon bemerkt, Gesetze im bloß förmlichen Sinne sind, weil sie keine Rechtsätze enthalten. Ich sehe nicht ein, warum wir diese Unterscheidung aufgeben sollen.

Der dritte Punkt betrifft den Leitsatz Ziff. II, 3 des 2. Herrn Berichterstatters, daB in Rechtsdenken und Rechtsordnung sich zwei Geltungsbegriffe gegenüberstehen, die "Geltung kraft Setzung " und die "Geltung kraft Wertteilhabe" und die Rechtsordnung des neuzeitlichen Staates auf dem Vorrang der Geltung kraft Setzung beruhe. Dem vermag ich nicht so einfach zuzustimmen. Es sei dazu zunächst daran erinnert, daß schon Platon in seinen "Gesetzen" den Gedanken ausgesprochen hat, da $\beta$ die Gesetze, die nicht um des allgemeinen Besten willen gegeben werden, sondern den Belangen einer Partei dienen, nicht Staatssache, sondern Parteisache seien und dem durch sie bestimmten sog. Recht jeder Anspruch auf diesen Namen abzusprechen sei. Auch im deutschen Mittelalter bestand durchaus der Gedanke, daß das Recht auf der Rechtsüberzeugung des Volkes beruhe. Es sei hingewiesen auf den Krönungseid des deutschen Königs, der nach dem Sachsenspiegel nach seiner Wahl zu schwören hatte, daß er das Recht stärken, das Unrecht kränken und das Reich in seinen Rechten vertreten werde, so gut er könne und möge. Es lag dem die Auffassung zugrunde, daß das Recht nicht künstlich oder gar willkürlich gemacht werden könne, also lediglich auf einem Setzungswillen beruhe, etwa des „Fürsten Wille Gesetz" sei, sondern daß es als eine Ordnung von Natur aus bestehe und gegebenenfalls im Gewissen gefunden werde; nach der Annahme des Christentums wurde es auf Gott zurückgeführt, wie wir denn im Vorwort des Sachsenspiegels lesen können: "Gott ist selber Recht." Demgemäß stand auch der Staat und die Staatsgewalt 
des Herrschers unter, und nicht über, dem Recht. Noch in der Zeit des unbeschränkten Fürstenstaates hat man bei uns in der Aufklärungsphilosophie, insbesondere bei Christian Wolff und Pütter, daran festgehalten, daß die unbeschränkte Gewalt dem Herrscher nur zum allgemeinen Besten durch den Staatsvertrag eingeräumt und eine Abweichung davon rechtswidriger Mißbrauch sei; es konnte deswegen, wie auch wegen Verletzung wohlerworbener Rechte, der Landesherr von den Untertanen bei den obersten Reichsgerichten verklagt werden, solange er nicht ein unbeschränktes Vorrecht des Berufungsausschlusses vom Reiche erlangt hatte. Und wenn auch einzelne Herrscher im unbeschränkten Fürstenstaat betont haben, daß sie Träger unbeschränkter höchster Gewalt seien, so haben sie doch auch z.T. bei uns ausgesprochen, wie z. B. König Friedrich Wilhelm I. von Preußen, daß sie ein Amt von Gott haben, und - wenn auch nicht gegenüber anderen Menschen, so doch - vor ihm und dem eigenen Gewissen hierfür verantwortlich seien; Friedrich der Große hat sich dann bekanntlich nur als den ersten Diener des Staates bezeichnet: das öffentliche Wohl blieb hier als Maßstab für die Herrschertätigkeit anerkannt. Im übrigen kann man doch wohl sagen, daß wir vollends nach der nationalsozialistischen Zeit von der Gegebenheitslehre (dem sog. Positivismus) losgekommen sind. Der Gedanke der Rechtssicherheit hat sicherlich seine Bedeutung; aber er darf nicht einseitig gegenüber dem Rechtsgedanken in den Vordergrund gerückt werden. So bestimmt denn auch das GG in Art. 1 die Unantastbarkeit der Menschenwürde und die Bindung auch der Gesetzgebung an die Grundrechte sowie in Art. 20, daß die vollziehende Gewalt und die Rechtsprechung an Gesetz "und Recht" gebunden sind. Das ist - so kann man doch wohl sagen - in gewisser Hinsicht eine Erneuerung des altdeutschen Rechtsgedankens, daB eben nicht der bloße Wille und die bloße Setzung auch des obersten Machtträgers im Staate „Recht" ist, sondern die Setzung inhaltlich mit Bezug auf die Grundrechte unter dem Rechte steht und im übrigen durch den Rechtsgedanken getragen sein muß, wenn es als Recht im vollen Sinne des Wortes soll angesprochen werden können im Gegensatz zur Willkür eines Gesetzgebers. Danach sollte man m. E. nicht einfach von der Geltung kraft Setzung sprechen und ihr die Geltung „kraft Wertteilhabe" als etwas davon Verschiedenes gegenüberstellen; vielmehr sollte man daran festhalten, daß im Gesetz grundsätzlich die sittliche Vernunft des Volkes zum Ausdruck kommen soll, und nicht der durch eigensüchtige Belange bestimmte Wille eines Einzelnen oder einer Gruppe von Menschen. 
Endlich ein letzter Punkt. Wenn im Leitsatz Ziff. II, 4 des 2. Herrn Berichterstatters gesagt wird, daß in der Vorordnung des Zweckes vor der Setzungsgeltung eines Rechtssatzes der Ubergang vom Boden der Geltung kraft Setzung auf den der Geltung kraft Wertteilhabe zu erblicken sei, so möchte ich doch Bedenken dagegen erheben, daß man in dieser Weise Zweck und Wert - diesen im gegenständlichen Sinne verstanden einfach einander gleichstellt. Ein willkürliches "Gesetz" eines unbeschränkten Machthabers mag wohl einen bestimmten Zweck verfolgen; aber ob ihm Rechtswert zukommt, ist damit noch gar nicht gesagt, vielmehr erst noch und gerade die Frage.

$\mathrm{K}$ a is e - - Freiburg:

Die Begriffsbestimmung der Maßnahme durch den Herrn Erstreferenten enthält ein Element, dem ich nicht voll zustimmen kann. Bedenken habe ich gegen die Auffassung, die die Orientierung an der Idee der Gerechtigkeit als ein Merkmal der Unterscheidung zwischen Maßnahmegesetz und einem Gesetz, das nicht Maßnahme ist, einführt. Es ist zu diesem Element in dem vorausgehenden Diskussionsbeitrag schon einiges gesagt worden. Ich darf mir erlauben, ergänzend dazu noch kurz folgendes zu bemerken.

Ich hoffe, ich habe Herrn Kollegen Menger richtig verstanden. Eine Bestätigung für die Bedeutung, die er der Orientierung an der Gerechtigkeitsidee als Unterscheidungsmerkmal beimißt, finde ich in dem Leitsatz II 3:

„Wenn in einem Maßnahmegesetz der Keim für die Aufrichtung einer gerechten Ordnung schlummert und sich dieser Keim so kräftig entwickelt, daß die Zweckhaftigkeit zurücktritt, kann von einem Maßnahmegesetz nicht mehr gesprochen werden."

Eine noch deutlichere Bestätigung für die Bedeutung jenes Kriteriums im Erstbericht zeigte sich in der mündlichen Begründung des Leitsatzes III 5 letzter Teil: Strafen sollten, wenn ich mich recht erinnere, deshalb nicht angedroht werden, weil Maßnahmegesetze nach der Auffassung des Herrn Erstberichterstatters nicht auf der Rechtsidee gründen.

Demgegenüber bin ich der Meinung, daß die Idee des Rechts oder die Idee der Gerechtigkeit kein Unterscheidungsmerkmal sein kann und auch nicht sein darf. Wie immer man das Verhältnis zwischen Gesetz, Recht und Gerechtigkeit bestimmen mag, für das Maßnahmegesetz gilt nichts besonderes. Es scheint mir auch, daß die Regelung eines konkreten Sachverhalts durch ein Maßnahmegesetz geradezu eine Forderung der Gerechtig- 
keit, etwa des Postulats "suum cuique" sein kann. Ich habe gern den Ausführungen von Herrn Wehrhahn, wenn ich sie richtig verstanden habe, eine gewisse Kritik an der von mir angegriffenen These von Herrn Menger entnommen.

Wenn es erlaubt ist, noch gegen einen zweiten Punkt des Herrn Erstberichterstatters Bedenken vorzutragen, dann gegen die Auffassung, daß eine konkrete Situation, wie sie durch ein Maßnahmegesetz geregelt wird, logisch nicht unbegrenzt andauern könne. Gestatten Sie ein Beispiel: Herr Menger hat in einem anderen Zusammenhang die Subventionierung der Eiererzeugung genannt. Nun ist es doch, wie mir scheint, leicht vorstellbar, daß in einem hochindustrialisierten Staat die Lage der Landwirtschaft andauernd derart ist, daß solchen Maßnahmegesetzen wie anderen Gesetzen Dauer zukommt. Ich glaube, daß die These von der logischen Unmöglichkeit eines unbegrenzt andauernden durch Maßnahmegesetze zu regelnden Zustandes nicht leicht in Ubereinstimmung gebracht werden kann mit dem Leitsatz I 4, in dem von einem zeitlich od e r zahlenmäßig begrenzten Kreis von Sachverhalten gesprochen wird.

\section{Forsth of $f$-Heidelberg:}

Ich habe mich erst im Laufe der Diskussion zum Wort gemeldet, weil das Wort - ich will nicht sagen der Begriff Maßnahmegesetz durch meinen Beitrag zur Gedächtnisschrift für Walter Jellinek mit meinem Namen in gewisser Weise verbunden ist.

Ich möchte zu den Anzweiflungen der begrifflichen Fixierbarkeit des Maßnahmegesetzes bemerken, daß ich den Begriff jederzeit preiszugeben bereit bin, daß ich es aber unter keinen Umständen für zulässig erachte, an dem sachlichen Problem vorbeizugehen oder es auch nur zu bagatellisieren, das mit dem Wort Maßnahmegesetz getroffen werden soll. Damit meine ich folgendes:

Unser Rechtsstaat leistet die Gewähr der gesetzlichen Freiheit in ganz bestimmten Formen und durch deren Beobachtung. Dazu gehört auch die Gewaltenteilung. In Abweichung von dem, was hier mehrfach vorgetragen wurde, wie von Herrn Wehrhahn und Herrn Scheuner, bin ich der Meinung, daß die Gewaltenteilung für die Sache, von der hier die Rede ist - ich lasse das Wort Maßnahmegesetz beiseite sehr erhebliche Bedeutung hat. Die Gewährleistung der gesetzlichen Freiheit beruht nach dem Grundgesetz (Art. 20) auf der Voraussetzung, daß Normsetzung und Normvollziehung in verschiedenen Händen liegen. Die Gewaltenteilung ist nicht 
eine gewöhnliche Kompetenzverteilungsnorm. Sie beruht auf der Einsicht, daß die drei Gewalten qualitativ verschieden sind, daß also auch Normsetzung und Normvollzug qualitativ geschieden werden müssen.

Diese qualitative Unterscheidung beherrscht das rechtsstaatliche System des Rechtsschutzes. Wenn die Gesetze Rechtsmittel grundsätzlich nur gegen Verwaltungsakte zulassen, dann gehen sie davon aus, daß nicht die Gesetze, sondern die Akte der Verwaltung in Freiheit und Eigentum des Einzelnen eingreifen und daß diese Akte in einer gewissen Selbständigkeit von der Verwaltung erlassen werden; denn nur unter dieser Voraussetzung hat es einen Sinn, daß die Verwaltung im Rechtsmittelverfahren für ihre Akte einstehen muß.

Es gehört zu den wesentlichen Merkmalen des Maßnahmegesetzes, daß mit ihm die gesetzgebende Gewalt in den Vollzug übergreift, indem sie selbst zur Aktion schreitet. Das kann in solchem Umfange geschehen, daß der Verwaltung die Möglichkeit selbständiger Entscheidungen nicht mehr verbleibt, da alle Entscheidungen bereits im Gesetz vorweggenommen sind.

Ich habe meine Bedenken gegen eine solche Art von Gesetzgebung, die man sehr wohl aus Art. 20 GG herleiten kann, in der erwähnten Abhandlung angemeldet. Anschaulich und zutreffend hat, wenn ich nicht irre, Herr Wehrhahn ausgeführt, $\mathrm{da} B$ auf diese Weise das Gewaltenteilungsprinzip, also immerhin ein unabänderbares Kernstück des Grundgesetzes, unterwandert wird. Kein verantwortungsbewußter Jurist wird diese Bedenken gegen den Ubergriff der Gesetzgebung in die Verwaltung bagatellisieren können. Wenn man sich überhaupt entschließen will, diese Bedenken angesichts der Realitäten des modernen Staatslebens zurückzustellen, und das habe ich getan, dann halte ich das nur für vertretbar, falls dem besonderen Charakter solcher Gesetze, die in den Bereich der Verwaltung übergreifen, unter dem Gesichtspunkt des Rechtsschutzes Rechnung getragen wird.

Der Rechtsstaat würde zweifach preisgegeben, wenn der Einzelne durch einen Staatshoheitsakt, der zwar als Gesetz firmiert, aber im einzelnen genau festlegt, was für diesen Einzelnen rechtens ist (um an Otto Mayers Definition des Verwaltungsakts zu erinnern) auch noch des Rechtsschutzes beraubt würde, den er gegenüber einem Vollzugsakt der Verwaltung haben würde.

Will man diese zweifache Verleugnung des Rechtsstaats vermeiden, so sieht man sich zu der Annahme genötigt, daß der Gesetzgeber, wenn er schon verwaltet, auch der Rechtskontrolle unterworfen sein muß wie ihr die Verwaltung unterworfen ist. 
Ich verkenne die schwierigen Fragen nicht, die damit aufgeworfen sind. Ich erwähne nur den Begriff des gesetzgeberischen Ermessens, der damit in das Blickfeld tritt und bisher noch nicht im einzelnen untersucht worden ist. Doch will ich dem beileibe nicht weiter nachgehen. Nur dies möchte ich mit aller Schärfe hervorheben: ob man den Begriff des Maßnahmegesetzes anerkennt oder ablehnt, ist von sekundärer Bedeutung. Nicht ausweichen kann man aber der Situation, die entsteht, wenn der Gesetzgeber in den Formen der Gesetzgebung verwaltet. Mit dieser Situation muß man sich unter dem Gesichtspunkt des Rechtsschutzes auseinandersetzen. Darin schlüsselt sich das Thema, das wir behandeln; hier geht es um die praktischen Konsequenzen seiner Problematik.

Ich bin prinzipiell anderer Meinung als Herr Scheuner, der meint, man habe es mit einer allgemeinen Verfassungswandlung zu tun, auf deren Boden man sich stellen müßte. Ich muß ihm auch widersprechen, wenn er meinen Erwägungen zum Rechtsschutz gegenüber Maßnahmegesetzen entgegenhält, man dürfe das Bundesverfassungsgericht und die sonstigen Gerichte nicht überfordern. Von dieser Uberforderung wird seit Jahren viel gesprochen. Ich halte sehr wenig davon, denn ich habe unter den Entscheidungen der Gerichte seit dem Inkrafttreten des Grundgesetzes bisher keine gefunden, die an den Richter Anforderungen gestellt hätte, denen ein qualifizierter Jurist nicht hätte genügen können. Offenbar soll vielfach mit der Feststellung der Ubberforderung ein Zweifel daran geäußert werden, ob man gut daran getan hat, die Kompetenz der Gerichte, vor allem des Bundesverfassungsgerichts wie geschehen zu bemessen. Aber das ist eine Frage für sich, die uns hier nichts angeht.

Das Bundesverfassungsgericht hat in dem Urteil zum Investitionshilfegesetz eine weitergehende Prüfung verweigert, allerdings nur mit dem Satz, es wäre nicht einzusehen, warum solche Gesetze mit anderen Maßstäben gemessen werden sollten als normale Gesetze, die generelle Normen enthalten. Ich halte das nicht für ein Argument, mindestens nicht für ein befriedigendes.

Zum Schlusse möchte ich allgemein noch folgendes sagen: mir scheinen diese Fragen aus folgendem Grunde vordringlich. Wir haben - die Erfahrungen unserer Tage bestätigen es wieder - nach den Jahrzehnten verschiedenartigster Staatsumbrüche kein Staatsbewußtsein mehr. Wir leben insofern in einer gefährdeten Wirklichkeit. In dieser Wirklichkeit sind uns die entscheidenden Hilfen die Formalhilfen, die technischen Hilfen, die sozusagen das technische Gerüst das Han- 
delns sind, die das Grundgesetz enthält. Darum habe ich seinerzeit in Bonn die Formel vom sozialen Rechtsstaat aus dem Verfassungsbereich ausklammern wollen, weil sie mir die Fungibilität der Verfassungstechnik der Freiheitsverbürgung zu gefährden scheint. Darum bin ich beunruhigt über die Maßnahmegesetze oder das, was sachlich darinsteckt, weil ich die Befürchtung habe, daß diese institutionellen Formen der Freiheitsverbürgung, auf denen unsere Ordnung und Freiheit beruhen, ins Gleiten kommen, und wir möglicherweise diesem Prozeß tatenlos und mit leeren Händen zusehen.

Herrfahrd t-Marburg:

Zunächst eine Bemerkung zu Herrn Wehrhahns Gegenüberstellung „Geltung kraft Setzung“ — „Geltung kraft Wertteilhabe". Setzung allein erzeugt doch niemals eine Verbindlicheit, sondern nur insofern, als man in der Setzung einen Wert sieht, nämlich den Wert der Ordnung (vgl. Radbruchs Unterscheidung: Rechtssicherheit als Nahziel, Gerechtigkeit als Fernziel). Setzung einer inhaltlich unvollkommenen Ordnung, durch eine Autorität, die die Macht hat, sie durchzuführen, ist besser als gar keine Ordnung. Geltung kraft Setzung ist also eine besondere Form der Geltung kraft Wertteilhabe.

Zu II 4b) der Thesen von Herrn Wehrhahn, daß der Ubergang vom Boden der Geltung kraft Setzung auf den der Geltung kraft Wertteilhabe nur zulässig sei, wo die Verfassung ihn gebiete, habe ich zu bemerken: Diese Ansicht setzt die Verfassung als die feste Grundlage unserer Staatsordnung voraus. Aber gilt das auch für unsere heutigen Verfassungen? Sind sie nicht gerade extreme Beispiele für das, was hier als „Maßnahmegesetze" bezeichnet worden ist? In der Psychose des $\mathrm{Zu}$ sammenbruches konnten sie sich kein anderes Ziel setzen, als eine vorläufige Ordnung $z u$ schaffen, in einer Situation, wo man nicht voraussehen konnte, was die nächsten Jahre bringen würden. Wir müssen also die Verfassungen selbst daraufhin nachprüfen, inwieweit sie imstande sind, durch die bloße Tatsache der Setzung Ordnung zu verbürgen. Das gilt für alle rein formalen Vorschriften, z. B. daß eine Gesetz nur in Kraft tritt, wenn es vom Bundespräsidenten verkündet ist. Anders z. B. bei den Grundrechten. Hier finden wir meist verschiedene, einander widersprechende Wertungen vor und können mit juristischen oder scheinjuristischen Gründen verschiedene Antworten aus dem Verfassungstext herausholen.

Der Jurist hat eine verständliche Scheu davor, die vermeintlich feste Grundlage der Verfassung in Frage zu stellen und sie an etwas Höherem zu überprüfen. Kelsen würde sagen: 
wir sägen uns den Ast ab, auf dem wir als Juristen sitzen. Ich würde lieber sagen: wir müssen uns klar darüber werden, daß wir keinen Boden unter den Füßen haben und daß deshalb unsere überlieferten juristischen Methoden hier nicht passen. Wir stehen vor einem sehr ernsten Problem, wenn wir darangehen, unsere Verfassungen als bloße „Maßnahmegesetze“ zu überprüfen. Wir haben zu unserem Glück das Bundesverfassungsgericht. Aber dieses müßte dazu etwas anderes sein, als es nach dem Grundgesetz sein soll: nicht ein "echtes Gericht", das nur nach festen Rechtsnormen richtet, sondern ein höchstes politisches Schiedsgericht.

Gegen die Ausweitung der Zuständigkeit des Bundesverfassungsgerichts hat Herr Scheuner mit guten Gründen das Bedenken der Uberforderung geäußert. Aber wenn das Bundesverfassungsgericht vorsichtig, schrittweise seine Zuständigkeit ausdehnt, wäre das doch wohl das kleinere Utbel gegenüber dem, was wir sonst im Falle einer schweren Krise befürchten müßten, eine diktatorische oberste Gewalt. Das Bundesverfassungsgericht ist nach seiner Zusammensetzung die relativ beste Einrichtung, um letzte Fragen, die nicht mehr positivrechtlich beantwortet werden können, zu entscheiden. Wir brauchen einen Hüter der Verfassung, nicht im Sinne einer geschriebenen Verfassung, sondern als Hüter der Ordnung.

M ü n c h - Berlin:

Meine sehr verehrten Herren! Wenn vom Maßnahmegesetz die Rede ist, dann denkt man zuerst an den allgemeinen Begriff der Maßnahme und kommt damit auf das Gebiet der freien Verwaltung.

Da möchte ich sagen, daß der Gesetzgeber dieselbe Aufgabe hat wie die Exekutive, nämlich zum gröBten Wohl aller zu handeln. Ich glaube, der Unterschied zwischen dem Gesetzgeber und der Exekutive in ihrem freien Bereich ist eben nur der: Der Gesetzgeber legt in logisch verfaßten und logisch anzuwendenden Normen fest, was zum Besten aller ist, während der Verwalter in seinem freien Bereich das von Fall zu Fall feststellen muß, ohne an Normen gebunden zu sein in dem Sinn, daß er seine Handlung auf diese Normen begründen oder aus ihnen herleiten müßte. Das Maßnahmegesetz würde dann entsprechen einer generellen Verwaltungsentscheidung. Wir brauchen das Gesetz eben nur deswegen, weil wir in unseren modernen Verfassungen von dem Grundsatz ausgehen: Der Bürger kann nur durch ein Gesetz verpflichtet werden, das heißt durch einen Akt, der von der Legislative erlassen wird. 
Die Exekutive kann das nur, wenn sie von der Legislative die Ermächtigung hat.

Die Rechtsgeschichte hilft uns, glaube ich, hier auch nicht weiter. Es hat das, was wir hier als Maßnahmegesetz bezeichnen, schon im byzantinischen Reich gegeben. Es gibt Novellen, die Devisengesetzgebung und ähnliche Dinge enthalten. Die Satzungen der Städte im Mittelalter enthalten dasselbe. Ich glaube nicht, daß wir aus der Rechtsgeschichte einen idealen Begriff des Gesetzes im Sinne der allgemeinen Norm und des guten alten Rechts herleiten können.

Was wir hier jetzt zu dem Thema hören, ist eigentlich eine Revolte gegen die gegenwärtige Gesetzgebungspraxis. Ich bin durchaus bereit, mich dieser Revolte anzuschließen. Sie zielt auf die Erweiterung der Kompetenz der Verwaltung zum freien Handeln hin, eine Zurückdrängung der Legislative. Allerdings soll die Verwaltung kontrolliert werden können. Weiter dahinter steht auch ein Angriff auf die konkrete Planung durch den Staat; der Staat soll höchstens ein allgemeines Wirtschaftssystem in Normen erlassen können. So verstehe ich diese Diskussion und soweit bin ich damit einverstanden.

Wie verfolgen wir nun diese Linie angesichts des Grundgesetzes? Mit Artikel 19 kommen wir nicht weiter. Wir sind uns darüber klar, daß die Maßnahmegesetze etwas anderes sind und einen größeren Bereich umfassen als die klar verbotenen Individualgesetze. Mit der Gewaltenteilung kommen wir auch nicht weiter. Darüber sind sich bisher alle Redner klar gewesen. Wo wir eigentlich nur anknüpfen können, das ist, daß wir wieder einen neuen - er hat seine Geschichte Normbegriff hervorholen, daß wir das echte Gesetz unterscheiden von der Verwaltungsmaßnahme in der Form eines Gesetzes, also wieder einen ausgesprochenen Wertakzent auf die echte Norm legen.

Verhältnismäßig wenig ist hier gesprochen worden von dem Gleichheitsgrundsatz. Wir sollten doch vielleicht versuchen, das, was wir suchen, am Gleichheitsgrundsatz aufzuhängen. Wenn wir ihn einmal sehr radikal nehmen, dann können wir vielleicht sagen: das Spezialgesetz verstößt gegen den Gleichheitsgrundsatz. Denn ein Gesetz, welches nur für die Apotheker, Viehhändler oder Heilpraktiker gilt, ist eigentlich kein gleiches Gesetz mehr. Es sieht natürlich gleich aus, weil jeder Apotheker und Heilpraktiker darunter fällt, aber es gilt nicht für jeden Bürger. Hier ist eben die Frage, ob man nicht etwa derartige Berufsordnungen, die in Form eines Gesetzes ergehen, einem 
anderen Schema unterwerfen und als Verordnungen erlassen sollte. Sehr viel schärfer tritt der Konflikt mit dem Gleichheitssatz hervor in dem berühmten Platowparagraphen des Amnestiegesetzes. Es ist also tatsächlich zu fragen, ob wir nicht auf die Dauer - nicht von heute auf morgen - durch eine Verfeinerung und Entwicklung des Gleichheitssatzes dahin kommen, wohin wir kommen wollen. Dann lösen sich vielleicht auch so schwierige Fragen, wie der Fortfall von temporären Gesetzen, die nicht unter die Kategorie des verbotenen Individualgesetzes gebracht werden können.

Jetzt möchte ich noch einen etwas banalen Punkt anbringen, nämlich die Frage stellen: Wie kommt es denn in der Praxis zu so vielen Maßnahmegesetzen und bloßen Organisationsakten? Warum findet man in vielen Gesetzen die Einrichtung von Behörden? Einesteils liegt es natürlich an den föderalistischen Einschlägen unserer Verfassung. Nicht der Bund soll alle möglichen Behörden einrichten, sondern die Länder sollen überwiegen. Aber liegt es nicht zum anderen Teil daran, daß die Bürokratie eine Grundlage für die Etatgestaltung haben will? Ist es nicht so - ich bitte mich darüber zu belehren -, daß, wenn eine Behörde durch Gesetz eingerichtet wird, ihre Ausgaben gesetzlich sind, die vom Parlament bewilligt werden müssen?

Ich denke an einen Fall, den ich selbst erlebt habe. Es wurde ein Entwurf fertiggestellt zur Reinhaltung der Wasserstraßen - ich weiß nicht, ob die Vorlage inzwischen Gesetz geworden ist. $D a$ hie $B$ es zunächst, daß jede Hafenverwaltung verpflichtet ist, jeden Morgen um $7 \frac{1}{2}$ Uhr eine Wasserprobe aus dem Fluß zu entnehmen, sie auf Verschmutzung zu untersuchen und den Verschmutzungsgrad festzustellen. In der Besprechung habe ich erklärt, daß so etwas in ein Gesetz nicht gehöre. Selbst wenn wir heute den Begriff der Heiligkeit des Gesetzes nicht mehr kennen, so komme mir das sehr seltsam vor. Es genüge vollkommen, wenn der Minister eine Verwaltungsanweisung an die Behörden schickt, damit sie diese Maßnahme vornehmen. Man hat mich in dieser Besprechung absolut nicht verstanden und nicht begriffen, worauf ich hinaus wollte. Wenn also dergleichen in ein Gesetz hereingeschrieben wird, liegt es etwa daran, daß die Bürokratie sich sichern will, daß die Kosten für diese Maßnahmen ein für allemal als notwendige gesetzliche Ausgaben in den Etat hereinkommen müssen?

\section{Hans Schneider-Heidelberg:}

Ich ziehe es vor, nicht von Maßnahmegesetzen zu sprechen, sondern von Einzelfallgesetzen und zwar deswegen, weil ich 
einmal das Wort „Maßnahme" schon vorbelastet finde durch den Streit um die Auslegung des Artikels 48 der Weimarer Verfassung. "Einzelfallgesetz" scheint mir auch deswegen glücklicher zu sein, weil es die Einzigartigkeit des Falles bezeichnet, der hier gelöst werden soll, die Unwiederholbarkeit des Tatbestandes, den der Gesetzgeber aufgreift. Gerade weil das Einzelfallgesetz einen unwiederholbaren Tatbestand betrifft, scheinen mir die Erörterungen über die Frage seiner Geltung und dem Vorbehalt der clausula rebus sic stantibus gegenstandslos, weil das Einzelfallgesetz sich erschöpft mit dem Eintritt des einen konkreten Tatbestandes, an den das Gesetz eine Rechtsfolge knüpft.

Einzelfallgesetze betreffen eine bestimmte Person oder Personengruppe oder einen bestimmten, vorgegebenen Sachverhalt. Inhaltlich sind die Fälle, die sich in der Praxis ereignet haben, von zweierlei Art. Einmal handelt es sich um Anordnungen, die getroffen werden innerhalb eines Bereiches, der bis dahin nicht gesetzlich geregelt ist. Dahin gehören Organisationsgesetze, Gesetzesbeschlüsse über eine Schenkung an einen verdienten Staatsmann, eine Ehrung usw. Das sind Fälle von Privilegierungen. Zum anderen sind es inhaltlich Fälle, in denen innerhalb eines gesetzlich schon geordneten Bereiches ein Dispens erteilt wird. Zum Beispiel: die Altersgrenze für gewisse amtierende Richter wird verlängert; eine Wahlperiode des Landtages oder des Reichspräsidenten wird verlängert, ein anhängiges Strafverfahren wird niedergeschlagen; oder der Artikel 142 a GG, der, wie wir jetzt in der Rückschau wohl deutlicher sehen, doch den Einzelfallcharakter (hier sogar ein Einzelfall-Verfassungsartikel!) deutlich auf die Stirn geschrieben trägt. Ich möchte also sagen, daß man inhaltlich einerseits Privilegierungen und andererseits Dispense in den Einzelfallgesetzen erkennt.

Daß man Schranken gegenüber dieser Erscheinung ziehen muß, dürfte sicher sein. In dem Anliegen, welches Herr Forsthoff hier so wirkungsvoll vorgetragen hat, also in dem Bestreben, daß man die Möglichkeit der richterlichen Kontrolle erhalten muB, sind wir uns einig. Es fragt sich nur, von welcher Ecke her man gegen die Erscheinung angehen kann.

Sicher ist es der Artikel 19 Abs. 1, der einem etwas hilft. Der Gleichheitsgrundsatz - von dem Herr Münch eben sprach wird einem dagegen wenig weiterhelfen, weil erfahrungsgemäß immer die Einzigartigkeit und Unvergleichbarkeit des Falles, der getroffen werden soll, gegenüber allen anderen Lagen hervorgehoben wird. Dann wird im Strafrecht der Artikel 
"nulla poena sine lege“ Schutz bieten. Daß „lex" nur eine generelle Regel sein darf, ist ja unzweifelhaft. Dann wird es der Anspruch auf den gesetzlichen Richter sein, der die $\mathrm{Zu}$ lässigkeit von Einzelfallgesetzen einschränkt. Dann wird es sein die verfassungsmäßig festgelegte Zuständigkeitsverteilung, die es verbietet, daß der Gesetzgeber eine Zuständigkeit in Anspruch nimmt, die einem anderen Organ vorbehalten ist zum Beispiel dem Bundespräsidenten das Begnadigungsrecht für den Bund.

SchlieBlich werden noch weitere Fälle übrigbleiben, bei denen es sich um die Alternative handelt, da $B$ entweder überhaupt nichts geschieht oder daß, weil keine andere Stelle etwas tun kann und die Regierung und Verwaltung auf Grund der vorhandenen Gesetze nichts unternehmen dürfen, dann eben der Gesetzgeber im Wege eines Einzelfallgesetzes eine Entscheidung trifft, zum Beispiel bei der Verlängerung der Wahlperiode eines Parlamentes, oder Amtszeit von Beamten oder des Präsidenten. In diesen Fällen - ich kann die Grenze noch nicht näher beschreiben - empfinde ich doch eine Unausweichlichkeit, daß einer solchen anomalen Lage auch mit einem atypischen Mittel begegnet wird.

Ich habe bedauert, daß der Erstreferent, indem er von dem förmlichen Gesetzesbegriff ausgegangen ist, sich den Weg verbaut hat, noch eine Erscheinung in sein Blickfeld einzubeziehen, nämlich die Einzelfallverordnung. Die Einzelfallverordnung weist ja ganz entsprechende Probleme auf. Gerade im Bereich der Landesgesetzgebung gibt es eine ganze Reihe von Einzelfallverordnungen: Enteignungsverordnung, Polizeiverordnung für einen bestimmten Fall, auch die Frage des Bauplanes, der nur ein bestimmtes Grundstück betrifft. Der letzte Punkt, den das Bundesverwaltungsgericht entschieden hat, betrifft ja eine recht problematische Angelegenheit. Sicher wird man nur sagen können, daß die Delegation zum Erlaß von Verordnungen die Ermächtigung zum Erlaß von Einzelfallverordnungen nicht in sich begreift.

Schließlich - das hat die Zeit für den Herrn Erstreferenten verboten und für den zweiten Referenten die Art, wie er das Thema bewältigt hat - bleibt es doch bedauerlich, da $\beta$ wir die Frage der private laws und private bills in den Vereinigten Staaten und England nicht näher behandeln konnten. Auch in Frankreich sind eine Reihe von Gesetzen und Dekreten ergangen, die ohne Zweifel Einzelfallcharakter haben. Vielleicht könnte man in einer späteren Untersuchung diese Punkte nachholen. 
R u m p f - Heidelberg:

Die Aussprache hat sich auf die interessante Frage zugespitzt, ob der Begriff der Maßnahmegesetze eine juristisch greifbare und rechtsbegrifflich gesicherte Kategorie ist oder werden kann. Schon das Korreferat hat in seinen wesentliche Punkte treffenden Einwendungen diese Frage aufgeworfen und negativ beantwortet. Trotzdem will mir scheinen, daß in diesen Phänomenen, die mit dem Begriff des Maßnahmegesetzes hier erfaßt werden sollen, Erscheinungen der modernen Gesetzgebungspraxis vorliegen, die auch für den Juristen beachtlich sind.

Obwohl man zweifellos im bisherigen Stand der Diskussion sagen muß, es handele sich hier nur um "soziologische Beobachtungen“ und es bedürfe eines "Sprunges über das Gehege" zwischen juristisch-normativer und teleologisch-soziologischer Betrachtung, um diese Erscheinungen zu erfassen, sollte man trotzdem versuchen, in Weiterführung etwa der Gedanken von Forsthoff und Menger diese Phänomene auch für den Juristen greifbar und nutzbar zu machen. Nicht nur aus dem Rechtsschutzbedürfnis heraus, das Herr Forsthoff in den Vordergrund stellte, sondern auch im rein akademischen, theoretischen und wissenschaftlichen Interesse der systematischen Klärung.

Allerdings scheint auch mir - insofern stimme ich den kritischen Stimmen weitgehend zu - die bisherige Abgrenzung des Begriffs der Maßnahmegesetze noch nicht ganz überzeugend zu sein. Wenn Forsthoff vorhin in seinem Diskussionsbeitrag darauf abgestellt hat, daß es sich hier um Akte der Verwaltung im Kleide des Gesetzes und von der Urheberschaft des Gesetzgebers handele, so glaube ich, wenn ich seinen Beitrag in der Jellinek-Festschrift recht in Erinnerung habe, darin eine gewisse Fortentwicklung oder auch Änderung seiner Unterscheidung in diesem Beitrag $\mathrm{zu}$ sehen, die auch im wesentlichen wieder bei Menger in seinem Referat zu finden ist. In der bisherigen Unterscheidung Mengers und auch Forsthoffs wurde abgestellt auf die Gerechtigkeitsvorstellung einerseits und die bloße Zweckhaftigkeit auf der anderen Seite. Es tauchte also im Hintergrund der Unterscheidung zwischen Rechtsnormen im engeren Sinne und Maßnahmegesetzen eine rechtspilosophische Vorstellung auf, die zwischen einem Gerechtigkeitsdenken und Gerechtigkeitsstreben und einem bloßen Zweckmäßigkeitsdenken und Zweckstreben unterscheidet.

In seinem Diskussionsbeitrag hier hat Forsthoff diese Linie, ich will nicht sagen verlassen, er hat sie nicht erwähnt und hat jedenfalls eine andere Stütze für seine Begrifflichkeit gebaut, 
die mir eigentlich weniger tragfähig erscheint als die Gedanken, die hier zunächst angeklungen sind, wenn diese auch noch keineswegs, wie das bei dem jungen Lebensalter dieses Problemstandes nicht anders sein kann, zu Ende durchgedacht sind. Wenn wir das Maßnahmegesetz nur auf den Eingriff in die Verwaltungsfunktionen abstellen, dann verengen wir den Kreis der Gesetze, die überhaupt noch als Maßnahmegesetz anzusprechen sind, in starker Weise. Denn die meisten, der, wie Herr Schneider es vorzieht zu sagen, Einzelfallgesetze bedürfen ja doch immer noch einiger Verwaltungsakte, um sie für die Einzelnen und für den Einzelfall anwendbar zu machen, um eben hier dem Einzelnen zu sagen, was für ihn „rechtens ist".

Das scheint mir eine Verschiebung der Argumentation zu sein gegenüber der Argumentation, die in dem Menger'schen Referat und auch in dem Forsthoff'schen Beitrag zur JellinekGedächtnisschrift angewandt wird. Nun zu dieser Argumentation, die ich für sehr interessant halte. Man könnte mit ihr in der Tat versuchen, hier eine auch für den Juristen - wenn er, das muß man dazu sagen, sich nicht auf formal-rechtliches, positivistisches Denken beschränkt, - interessante und maßgebliche Unterscheidung zu finden. Diese Unterscheidung jedoch darf nicht dabei stehenbleiben, daß man Rechtsnormen als solche bezeichnet, die am Maßstabe der Gerechtigkeit orientiert sind, und ferner feststellt, es könne Normen geben, bei denen noch nicht ganz sicher ist, ob in ihnen nicht der "Keim zur Aufrichtung einer gerechten Ordnung schlummert", und ähnliche Dinge.

Dabei handelt es sich um so abstrakte und unverbindliche Begriffe und Vorstellungen, da $B$ wir damit die Abgrenzung nicht erfolgreich bewältigen können. Mir scheint es vielmehr so, daß man nur dann zu einer gültigen Einteilung in Maßnahmegesetze und Rechtsnormgesetze kommen kann, wenn man voraussetzt, daß es eine materiale Wertordnung gibt, die eben diesen Begriff der Gerechtigkeit ausfüllt. Dann kann man allerdings behaupten, da $B$ Rechtsnormen, die diese materiale Wertordnung - man hat sie früher mit dem Begriff des Naturrechts bezeichnet, der nach dem Kriege eine etwas überhitzte Konjunktur erlebte und heute wieder im Begriff ist, der Skepsis allmählich zum Opfer zu fallen - aufnehmen und verwirklichen, sich von bloßen Maßnahme- oder Zweckgesetzen unterscheiden. Das ist dann allerdings eine ganz andere Unterscheidung als die zwischen allgemein-abstrakten Normen oder Gesetzen und Einzelfallgesetzen. Die Unterscheidung der Normen in allgemeine und individuelle, abstrakte 
und konkrete ist eine andere als die zwischen an der Wertordnung orientierten und reinen Zweckgesetzen.

Es ist ja die große Frage, ob wir heute noch übergeordnete Maßstäbe haben und anerkennen. Ich bekenne mich $\mathrm{zu}$ solchen übergeordneten Maßstäben. In der einen oder anderen Form tut es heute jeder Rechtspraktiker und Rechtsgelehrte. Aber wenn man dann an die konkreten Anwendungen, ja auch nur an die Bestimmung der Postulate und einzelne Werte herantritt, dann beginnt die große Wertdiskussion, dann beginnt der Streit.

Hinter dieser Unterscheidung von Rechtsnormen und Maßnahmegesetzen öffnet sich das ganze Kampffeld der weltanschaulich-politischen Ideologien, hier wird der Marxist andere Maßstäbe und Vorstellungen haben als etwa der auf dem Boden fines liberalen oder christlichen Naturrechts stehende Rechtsdenker. Das sind die metajuristischen Probleme, die sich hier auftun, und ohne sie in irgendeiner Weise zu beantworten, werden wir meines Erachtens auch das Problem der Maßnahmegesetze nicht vollgültig beantworten können.

Forst h of $f$ - Heidelberg:

Ich erbitte das Wort zu einer kurzen Bemerkung, die lediglich der Klarstellung dienen soll. Wenn auf Grund meiner Ausführungen der Eindruck entstanden sein sollte, daß ich die grundsätzlichen Positionen meines Beitrages zur JellinekGedächtnisschrift aufgegeben hätte, so wäre das ein Mißverständnis. Ich habe mich heute auf einen bestimmten Aspekt des Themas beschränkt und deshalb den Begriff des Maßnahmegesetzes, an dem ich festhalte, keineswegs erschöpfend kennzeichnen wollen.

S ch ät z e l-Bonn:

Meine Herren! Wenn das Thema auf die heutige Tagesordnung gestellt ist und wenn wir die Referate und die in der Diskussion geäußerten Meinungen überblicken, dann werden wir allgemein das Empfinden haben: hier ist irgend etwas Neues aufgetreten, was uns nicht so ganz paßt und von dem wir irgendwelche Gefahren für den Rechtsstaat fürchten.

Wir haben die theoretischen Grundlagen von den verschiedensten Seiten erörtert und gesehen, daß das außerordentlich schwer faßbar ist. Ich möchte zu diesen Fragen nichts mehr beitragen, sondern Sie werden es mir gestatten, daß ich als ein Mann, der ein Menschenalter Richter gewesen ist, versuche, ein Fazit zu ziehen: Kommen wir schon zu irgendwelchen Ergebnissen, und können wir irgend etwas praktisch machen? 
Ich glaube, die Einteilung der Maßnahmegesetze - bleiben wir bei diesem Ausdruck - als Personen-, Einzelfall- und als Zeitgesetze gibt uns einen gewissen Anhaltspunkt. Wir sind uns meines Erachtens darüber einig, da $B$ die Personengesetze unzulässig sind. Das kann man aus unserer Verfassung herauslesen. Ebenso besteht wohl kein Zweifel darüber, daß Zeitgesetze notwendig sind. Nehmen Sie an, die Banken zahlten nicht mehr. Dann wird der Gesetzgeber etwa die Verjährungsfristen ausdehnen müssen. Was zweifelhaft bleibt, das sind die Einzelfallgesetze. Gerade diese beschäftigen uns, weil sie zunehmen. Ich habe das Empfinden, daß die Mehrzahl meiner Kollegen das mißbilligt. Man sucht nach irgendwelchen Grenzen und fragt sich, ob man vielleicht einen Teil dieser Maßnahme - also der Einzelfallgesetze - mit verfassungsrechtlichen Gründen zu Fall bringen könnte. Ich glaube, daß dieses ganze Bestreben nicht allzuviel Erfolg haben wird. Wir stehen hier vor einem Phänomen, das aus verschiedenen Gründen wahrscheinlich noch seinen Fortgang nehmen muß. Den einen Grund sehe ich in folgendem: in der internationalen Verknüpfung. Eine ganze Reihe von diesen Einzelfallgesetzen beruht darauf, daß internationale Verpflichtungen, Konjunkturlagen oder etwas ähnliches entstanden sind. Dann bleibt dem Gesetzgeber nichts anderes übrig, als irgendwie einzugreifen. Dann muß er sogar einzeln eingreifen. Da spielt der nationale Gesetzgeber gewissermaßen die Rolle, die im Staat selbst die Verwaltung spielt. Im Staat gibt der Gesetzgeber normalerweise eine allgemeine Norm, und die Verwaltung führt aus. Jetzt tritt häufig der Fall ein, daß international irgend etwas bestimmt wird, oder daB eine gewisse weltpolitische Lage etwas erfordert. Dann müssen wir das entsprechend ausführen. Wenn jetzt der Gesetzgeber sich damit begnügte, eine allgemeine Norm zu erlassen und er der Verwaltung die Ausführung überließe, dann könnte er fürchten, daß die Verwaltung dies vielleicht nicht so macht, wie er will, und er internationale Schwierigkeiten bekommt. Infolgedessen setzt sich in diesen Fällen der nationale Gesetzgeber einfach in die Rolle der Verwaltung. Ich glaube, das ist eine Entwicklung, die nun einmal in der zunehmenden internationalen Verknüpfung liegt und gegen die überhaupt nichts zu machen ist.

Der zweite Grund, warum der Gesetzgeber dazu neigt, um - wie wir empfinden - etwas zu sehr in die Verwaltung einzugreifen, liegt vielleicht am parlamentarischen Staat. Wenn der Gesetzgeber ein allgemeines Gesetz macht und die Ausführung der Verwaltung überläßt, dann ist er natürlich nicht ganz sicher, in welchem Sinne die Verwaltung das machen 
wird. Die Verwaltung bemüht sich im parlamentarischen Staat eine gewisse neutrale Haltung einzunehmen. Das paßt aber nicht unbedingt der parlamentarischen Mehrheit. Gerade einer parlamentarischen Mehrheit, die fürchten muß, daß etwa bei den nächsten Wahlen eine anders geartete Mehrheit mit anderen wirtschaftlichen und politischen Zielen kommt, wird daran liegen, ihren Willen möglichst rasch und bestimmt durchzusetzen, damit die Verwaltung nicht lawieren kann und kostbare Zeit nicht vergeht. Denn wartet man ab, bis die Verwaltung in sämtlichen Instanzen tätig geworden ist, dann können die 4 Jahre der Legislaturperiode vergehen. Käme dann eine andere Parlamentsmehrheit, so wäre die Sache verpaßt.

Mir scheinen diese beiden Gründe, die internationale Verknüpfung, die den Gesetzgeber dazu zwingt, die Sache so auszuführen, wie es international nötig ist, und die parlamentarische Lage, dazu beizutragen, daß die Maßnahmegesetze beliebt sind und daß sie wahrscheinlich noch zunehmen werden. Wenn wir das als ein gegebenes Faktum hinnehmen - Sie mögen es lieben oder nicht -, dann werden wir uns natürlich fragen müssen: Wie schützen wir den Einzelnen dagegen? Unsere ganze Verwaltung ist darauf aufgebaut, daß wir ihm einen möglichst weitgehenden Gerichtsschutz mit vielen Instanzen geben. Wenn einer enteignet werden soll, dann kann er normalerweise bei einem Verwaltungsakt die ganzen Verwaltungsgerichtsinstanzen durchlaufen. Er hat nachher noch die Möglichkeit der Einreichung einer Entschädigungsklage usw. Das wird ihm evtl. abgeschnitten, wenn die Sache durch einen Gesetzgebungsakt gemacht wird. Daher wurde die Frage aufgeworfen: Was kann man nun machen? Herr Forsthoff hat ganz richtig die Frage gestellt, ob man ihm dann irgendeinen gleichwertigen Gerichtsschutz geben muß. Es wurde darauf hingewiesen, daß wir bei uns eine sehr ausgeprägte Verfassungsgerichtsbarkeit haben. Der eine hat das gelobt. Kollege Scheuner war bedenklicher und meinte, dann könnte man die Verfassungsgerichtsbarkeit überfordern. Das eine scheint mir allerdings sicher: Wenn es zunimmt, daß man alle möglichen wirtschaftlichen Maßnahmen, Enteignungen usw., durch Einzelgesetze macht und wenn man regelmäßig nur auf die Verfassungsgerichtsbarkeit verweist, dann bekommen wir eine ganz neue Art der Gerichtsbarkeit. Wir können aus dem Verfassungsgericht kein falsches Amtsgericht machen. Das liegt nicht in den Zielen der Verfassungsgerichtsbarkeit. Wenn wir hier einen gleichwertigen Gerichtsschutz geben wollen, müßten wir ernstlich daran denken, ob wir diese Maßnahmegesetze nicht wie die einzelnen Verwaltungsmaßnahmen unter die 
Verwaltungsgerichtsbarkeit stellen müssen. Ich weiß, das geht augenblicklich nicht. Das ist aber ein Problem, das wir allen Ernstes erörtern müssen. Wollen wir den anderen Weg gehen und etwa sagen, es könne die Normenkontrollklage oder die Verfassungsbeschwerde erhoben werden, dann besteht noch folgende Schwierigkeit:

Es gibt keine gemeinsame oberste Instanz zwischen dem Bundesverfassungsgericht und den anderen obersten Bundesgerichten. Ich habe es als Spezialist für Staatsangehörigkeitsfragen gesehen, daß die streitigen Fragen vielfach verschieden entschieden sind und diametral entgegengesetzte Entscheidungen in konkreten Staatsangehörigkeitsfragen vom Bundesverfassungsgericht und anderen Gerichten erlassen sind. Verfahren wir nun so, daß wir den ganzen Rechtsschutz gegenüber den Maßnahmegesetzen auf das Bundesverfassungsgericht abschieben, dann werden wir vielfach Parallelfälle bekommen: der eine geht vor das Bundesverfassungsgericht, ein anderes Mal ist ein ganz ähnlicher Tatbestand durch eine Verwaltungsmaßnahme ergriffen worden, und die Sache läuft den Instanzenweg hinauf bis zum Bundesverwaltungsgericht. Dann sitzen wir eines Tages wieder da mit widersprechenden Entscheidungen des Bundesverfassungsgerichtes und des Bundesverwaltungsgerichts.

Wir müssen das Problem und die Aufgabe, die vor uns auftaucht, deutlich sehen. Es ist meiner Ansicht nach unsere Aufgabe als Juristen, daß wir rechtzeitig uns überlegen, was gegenüber diesen zu erwartenden Schwierigkeiten geschehen kann.

M e r k l - Wien:

Ich gestatte mir, von meinem heutigen engsțen Interessenbereich aus an den zweiten Leitsatz des Herrn Menzel anzuknüpfen. Er lautet: „Rechtsnorm ist das aus einer festgefügten, am Maßstabe der Gerechtigkeit orientierten Ordnung fließende Verhaltensgebot."

Durch diesen Leitsatz wird unser Thema mit einem weiteren Problem belastet, nämlich mit dem Verhältnis von Recht und Gerechtigkeit, und damit der nicht nur möglichen, sondern allzu oft auch wirklichen Spannung zwischen Recht und Gerechtigkeit, die nicht wegzureden, ja vielleicht nicht einmal aus der Welt der Tatsachen wegzudenken ist. Wir stehen meines Erachtens vor der Unmöglichkeit, das Recht etwa im Sinne einer sanktionierten Verhaltensregel von Menschen mit der Gerechtigkeit gleichzusetzen. In dieser Hinsicht gibt es 
meines Erachtens keinen Unterschied zwischen Gesetz im engeren Sinne des Wortes und einer "Maßnahme".

Gewiß erhebt der Gesetzgeber meistens - nicht ausnahmslos - den Anspruch für seine Gesetze und auch für die heute sogenannten Maßnahmen und sonstigen Staatshandlungen, die Gerechtigkeit zu verwirklichen. Aber er kümmert sich in der Regel nicht um den Nachweis dieser Ubereinstimmung, sondern behauptet ohne Prüfung und oft auch ohne Zulassung einer Kritik eine solche Ubereinstimmung von Recht und Gerechtigkeit.

Der grundsätzliche Unterschied von Recht und Gerechtigkeit zeigt sich namentlich bei der Beurteilung der Rechtmäßigkeit und Gerechtigkeit eines Krieges. Mein augenblickliches besonderes schriftstellerisches Anliegen ist die Nutzanwendung der Idee der Gerechtigkeit, im besonderen des gerechten

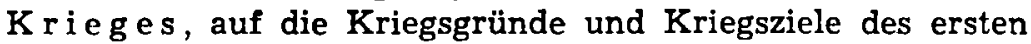
und des zweiten Weltkrieges. Beide Kriegsparteien haben bekanntlich für sich den Anspruch erhoben, einen gerechten Krieg zu führen, mindestens eine Kriegspartei offensichtlich zu Unrecht. Ich möchte auch auf das umfangreiche Buch von Johannes $\mathrm{H}$ öf $\mathrm{n}$ er "Christentum und Menschenwürde. Das Anliegen der spanischen Kolonialethik" hinweisen. Dieser katholische Theologe ist so ehrlich und um die Wahrheit beflissen gewesen, einen weitgehenden Widerspruch zwischen dem Gerechtigkeitsanspruch der spanischen Staatspraxis, namentlich des 16. Jahrhunderts, der Konquista, und der tatsächlichen Handlungsweise dieser Pioniere und Eroberer aufzuweisen.

Für die Willensäußerungen des Staates kann man also bestenfalls den Anspruch der Gerechtigkeit behaupten. Doch allzu oft verzichtet. Jer ethisch skrupellose Staat auch auf diesen Anspruch, wie als der Erfahrung der toislitären Staaten der jüngsten Zeit unc wohl auch der Gegenwart genügend bekannt ist. Also wollen auch wir darauf verzichten, den Begriff des Gesetzes oder irgendeiner Maßnahme und Handlung des Staates mit einer solchen psychologischen Vorfrage, etwa mit der Frage nach dem Willen zur Gerechtigkeit, zu belasten.

Es ist aber hiermit erwiesen, daß Recht im Sinne des durch den staatlichen Erfüllungsstab gestützten Willens mit Gerechtigkeit wesenhaft nicht übereinstimmt. Halten wir daran fest, daß die Gerechtigkeit - oder auch nur der gewollte Versuch der Gerechtigkeit - nicht Bedingung, sondern eine unendliche ethische Aufgabe des Rechtes ist, die bloß vom moralgebundenen Staat erfüllt, aber von anderen Staaten leider nur zu oft nicht erfüllt, ja nicht einmal angestrebt wird. 
$\mathrm{B}$ a c h of - Tübingen:

Meine Herren Kollegen! Aus Herrn Forsthoffs Ausführungen ist sehr deutlich geworden, daß das Problem der Maßnahmegesetze für die Rechtspraxis vor allem ein Problem des Rechtsschutzes ist; oder, wie Herr Schneider es ausgedrückt hat: es dreht sich darum, in welcher Weise man an die Maßnahme- oder Einzelfallgesetze ",herankommt". Herr Schätzel schließlich hat die Frage aufgeworfen, ob man nicht die Einzelfallgesetze der Verwaltungsgerichts b a r ke i t unterstellen müsse.

Wenn ich Sie nach dem Höhenflug rechtsgrundsätzlicher Erörterungen einmal in die Niederungen der Praxis führen darf, so möchte ich Sie auf eine Entscheidung aufmerksam machen, die jene Rechtsschutzfragen betrifft und in die von Herrn Schätzel aufgezeigte Richtung weist; es handelt sich dabei um den Rechtsschutz gegenüber einer Organisationsmaßnahme, die zwar nicht in Form eines Gesetzes, wohl aber einer Rechtsverordnung ergangen war. Im bayerischen Recht besteht eine merkwürdige Regelung für das Verfahren bei Umgemeindungen. Sie erfolgen entweder durch Verwaltungsakt; oder aber durch Rechtsverordnung, die wieder in gewissen Fällen der Zustimmung des Landtages bedarf, in anderen Fällen einer solchen Zustimmung nicht bedarf; oder schließlich durch formelles Gesetz. Welche Form Anwendung findet, hängt davon $a b$, ob mit der Umgemeindung eine Auflösung oder Neubildung von Gemeinden verbunden ist, ob gleichzeitig Kreisoder Regierungsbezirksgrenzen geändert werden usw.; im einzelnen ist das teils in der Gemeindeordnung, teils in der Verfassung festgelegt. Der Bayer. VGH hatte nun über einen Fall $\mathrm{zu}$ entscheiden, in dem eine Umgemeindung durch Verordnung der Staatsregierung mit Zustimmung des Landtags erfolgt war. Er hat sich auf den Standpunkt gestellt, daß es sich, unbeschadet der Form, der Sache nach um eine Einzelmaßnahme, einen Verwaltungsakt, handele und daß deshalb das Anfechtungsverfahren und nicht etwa das Normenprüfungsverfahren Anwendung zu finden habe (Beschluß vom 31.3.1953, Nr. 76 IV 52 und 77 IV 52; Urteil vom 20.1.1956, Bayer. VBl. 1956 S. $121 \mathrm{ff}$.); auch der Bayer. VerfGH ist dieser Auffassung beigetreten (Bayer. VGH Band 7 II 113 ff., 120).

Ich bekenne, daß ich Bedenken gegen diese Entscheidungen habe. Ich habe mir die Frage vorgelegt, wie der VGH wohl entscheiden würde, wenn einmal ein förmliches Umgemeindungs ge set $z$ angefochten würde. Der VGH würde ja, wenn er an der Logik seiner Entscheidung festhält, gar nicht anders können, als nun auch dieses formelle Gesetz als Verwaltungs- 
akt $\mathrm{zu}$ behandeln und möglicherweise aufheben! Das wäre in der Tat ein Novum. Aber es war ja schon ein Novum, daß eine Rechtsverordnung nicht etwa im Normenkontrollverfahren, sondern im Anfechtungsverfahren überprüft wurde. Ich habe Bedenken gegen diese Rechtsprechung, weil ich meine: wenn der Gesetzgeber - und gar erst der Verfassungsgesetzgeber - sich ausdrücklich für eine bestimmte Form entscheidet, dann ist darin wohl auch die Entscheidung mit enthalten, daß alle üblicherweise aus dieser Form folgenden Konsequenzen gezogen werden sollen, und zwar auch im Hinblick auf den Rechtsschutz. Ich glaube, daß man allenfalls im Falle eines eklatanten und offenbaren Formen miBbrauchs in der Weise, wie der Verwaltungsgerichtshof das getan hat, die Form außer acht lassen und allein auf den Inhalt abstellen könnte.

Aber ich will diese Frage hier nicht vertiefen. Mir lag nur daran, darauf hinzuweisen, daß es in der Praxis schon ein Beispiel dafür gibt, daB die Verwaltungsrechtsprechung sich über die Form einer Maßnahme hinwegsetzt und allein auf deren materiellen Gehalt abstellt. Sollte dieser Weg weiter beschritten werden, so könnte die Entwicklung möglicherweise in der von Herrn S chät $\mathrm{z}$ el aufgezeigten Richtung verlaufen, Maßnahmegesetze der Uberprüfung der Verwaltungsgerichte zu unterstellen. Persönlich stehe ich einer solchen Möglichkeit skeptisch gegenüber.

\section{U le - Speyer:}

Ich möchte nur insofern in die Diskussion eingreifen, als ich durch einige Fragen den Versuch machen will, die beiden Herren Referenten noch in gewissen Punkten zu einer Konkretisierung ihres Standpunktes zu veranlassen.

Ich habe es heute nach den beiden Referaten bedauert, da $B$ in manchen Dingen nicht konkreter gesprochen worden ist. Ich begebe mich jetzt vielleicht mit Herrn Bachof in gewisse Niederungen der Verwaltungspraxis. Aber mir scheint, daß wir hier über diese Dinge doch nicht sprechen können wie die Blinden von der Farbe.

Manchmal ist es mir heute nachmittag, offen gestanden, so vorgekommen. Ich habe mir, als ich vor einem Jahr den Beitrag von Herrn Kollegen Forsthoff in der JellinekGedächtnisschrift gelesen habe, die Frage vorgelegt, wie es wohl mit diesen Maßnahmegesetzen im Laufe der geschichtlichen Entwicklung gewesen sei. Ich habe bei der Gelegenheit einmal die alten Gesetzblätter aus dem 19. Jahrhundert durchgesehen. Ich weiß nicht, ob wir darüber einig sind, daß das 
Problem des Maßnahmegesetzes ein Problem des Verwaltungsrechts ist. Ich möchte das annehmen. Denn es wird doch gerade die Behauptung aufgestellt - und ich glaube mit Recht hier greife der Gesetzgeber unmittelbar in die Verwaltung ein. Das Bürgerliche Gesetzbuch z. B. wäre doch wohl der typische Fall eines Gesetzes als Inbegriff von Rechtsnormen im strengen Sinne. Wenn man sich nun die Entwicklung der Verwaltungsgesetzgebung im letzten Jahrhundert ansieht, dann kann man feststellen, daß die Zahl der Gesetze, in der der Gesetzgeber irgendwie in die Verwaltung eingreift, zunimmt. Man kann das mit einem sehr äußerlichen Beispiel belegen. Wenn Sie etwa die Entwicklung des Werkes von M. von Brauchitsch "Verwaltungsgesetze in Preußen" durch die Jahrzehnte hin beobachten, dann finden Sie, daß dieses Werk zunächst im wesentlichen nichts anderes enthielt als Organisations-, Zuständigkeits- und Verfahrensgesetze. Damit fing es an. Das ist die pr. Gesetzgebung von 1872, 1875, 1883 usw. Dann war es im Grunde schon zu Ende. Dazu kam noch die Gewerbeordnung. Mit diesem Band über die Gewerbeordnung schloB das Werk im wesentlichen ab. Da war also von irgendwelchen Maßnahmegesetzen ganz gewiß nicht die Rede. Denn diese Gesetze, also Organisations-, Zuständigkeits- und Verfahrensgesetze, haben wohl mit dem Begriff der Maßnahmegesetze nichts zu tun.

Wenn man nun in der geschichtlichen Betrachtung weiter fortschreitet, dann möchte ich Ihnen ein sehr prägnantes Beispiel vorführen: das preußische Wohnungsgesetz vom 28 . März 1918, überhaupt die ganze Wohnungsmangelgesetzgebung der Zeit nach dem ersten Weltkriege. Diese Gesetze (Reichsmietengesetz, Mieterschutzgesetz, Wohnungsmangelgesetz) sind doch sicher in einem soziologischen Sinne Maßnahmegesetze, hervorgerufen durch die Wohnungsnot jener Zeit. Diese Gesetze hatten aber einen sehr langen Bestand, sie gelten teilweise, wenn auch in geänderter Fassung, noch heute. Nach 1933 entstand im Zuge der Rüstungswirtschaft eine umfangreiche Wirtschaftsverwaltungsgesetzgebung. Es ist heute schon der Name von Otto Haussleiter gefallen, der sich kürzlich gerade mit „Maßnahmerecht und Dauerrecht auf dem Gebiet der wirtschaftspolitischen Verordnungs- und Gesetzgebung" beschäftigt hat (DÖV 1956 S. 143 ff.). Was ist etwa die ganze Preisgesetzgebung seit 1936? Sie ist nichts anderes als eine Maßnahmegesetzgebung, bei der neuerdings die interessante Lage eingetreten ist, daß die Rechtsprechung gesagt hat: Die Verwaltung hat hier überhaupt nichts mehr mitzureden; die Preise werden unmittelbar durch das Gesetz oder die Verordnung 
für die Parteien festgesetzt; wenn sie sich darüber streiten, können sie sich an die ordentlichen Gerichte wenden. Ich darf an die bekannten Entscheidungen des Bundesverwaltungsgerichts zur Untermietpreisanordnung erinnern (v. 27.9.1955 Amtl. Samml. Bd. 2 S. 208 ff. u. v. 15.11. 1955 DÖv 1956 S. 507).

Das sind doch wohl alles in diesem weiten Sinne Maßnahmegesetze. Ich glaube nicht, daß man an ihrer verfassungsrechtlichen Zulässigkeit irgendwelche Zweifel hegen wollte oder könnte. Hier liegt auch nicht das Problem; so habe ich das jedenfalls in der Aussprache empfunden. Andererseits liegt das Problem wohl auch nicht bei den Individualgesetzen, auf die ja erst im Laufe der Debatte hingewiesen worden ist. Das ist eine Frage, die im Grunde genommen außerhalb des heutigen Themas liegt.

Das für mich Unbefriedigende - und darum bin ich eigentlich nur im letzten Augenblick hierher gekommen - ist die Frage, die ich gern stellen möchte, und, wenn es möglich ist, auch gern beantwortet hätte: Wo sind denn nun eigentlich die Maßnahmegesetze, von denen Herr Forsthoff $h$ eute - ich will mich jetzt nicht zum Interpreten seiner $\mathrm{Ab}$ handlung und seiner eigenen Auffassung machen - gesprochen hat und die offenbar auch Herrn Schätzel in seinem Diskussionsbeitrag vorgeschwebt haben, also die Gesetze, die der Erfüllung völkerrechtlicher Verpflichtungen usw. dienen sollen, und die Gesetze, die - ich kann die Formulierung von Herrn Schätzel nicht wörtlich wiedergeben - irgendwie unmittelbare Verwaltungsmaßnahmen in Gesetzesform darstellen. Ich muß ganz offen gestehen: Mir fehlt die Anschauung, denn ich weiß nicht, was für Gesetze damit gemeint sind. Ich wäre dankbar, wenn gesagt würde, an welche konkreten Fälle man hier denkt. Wenn ich es richtig in der Erinnerung habe, hat Herr Forsthoff in seinem Beitrag in der Gedächtnisschrift für Walter Jellinek im wesentlichen drei Fälle herausgegriffen, von denen das Investitionshilfegesetz wohl der wichtigste war; die beiden anderen (Art. 142a GG und die lex Platow) sind von geringerer Bedeutung. Ich glaube, ein sehr breites Erfahrungsbild ist da auch nicht gezeigt worden. Uber das Investitionshilfegesetz kann man übrigens auch noch verschiedener Meinung sein. Ich bezweifle sehr, ob es sich bei ihm um den Standardfall eines solchen Maßnahmegesetzes in diesem strengen Sinne handelt, daß durch das Gesetz unmittelbar verwaltet würde, so daß also für einen Gesetzesvollzug durch Verwaltungsbehörden überhaupt kein Raum mehr bliebe.

Art. 41 der hessischen Verfassung kann hier vielleicht noch als Paradepferd dienen. Der heute von Herrn Forsthoff her- 
ausgestellte Gesichtspunkt ist $\mathrm{ja}$ auch bei dem Streit um die hessische Sozialisierung herangezogen worden. Wenn ich mich recht erinnere, hat Carl Schmitt gerade sein Gutachten im wesentlichen auf diesen eben erörterten Gesichtspunkt gestützt.

Am Schluß meines Diskussionsbeitrages - wenn Sie ihn so nennen wollen - möchte ich nochmals die Bitte aussprechen, da $B$ die beiden Herren Referenten das, was sie in sehr eindringlicher Weise heute morgen theoretisch und abstrakt dargelegt haben, in ihrem Schlußwort etwas konkretisieren möchten, damit für diejenigen, die, wie ich, weniger abstrakten Uberlegungen, sondern mehr konkreten Anschauungen zugänglich sind, die Problematik ein etwas anschaulicheres Bild gewinnt, als sie es bisher gehabt hat.

Wehrhahn - Tübingen (Schlußwort):

Meine Herren!

Ich habe den Eindruck, daß ich in erster Linie zu danken habe, und ich bin mir darüber klar, daß ich nicht allen Hoffnungen auf mein Schlußwort gerecht werden kann.

Dies gilt vor allem für den Beitrag von Herrn Ule! Ich verstehe, daß der Wunsch nach Anschauungsmaterial unbefriedigt geblieben ist - ich habe im Referat selber einem Gefühl des Unbefriedigtseins Ausdruck gegeben - -; aber Herr Forsthoff hat genau mein Anliegen getroffen: daß wir nämlich in eịner Entwicklung stehen, die entweder die Legislative zum Leiter der Administration macht, oder die uns nur die Hoffnung auf den Juristen läßt, „,er mit allem fertig wird“ - auch mit dem Gesetz - und der die Legislative aller ihrer Funktionen entsetzt. Beides sind generelle Phänomene, so generell, daß man sie, ohne ihnen Gewalt anzutun, generalisierend und also in allgemeinen Begriffen ansprechen darf.

Beides ist bedrückend. Der Legislative als Leiterin der Exekutive würden keine Grenzen gesetzt sein; sie unterwürfe sich die Exekutive zu jedem $Z$ wecke mit dem Instrument des Gesetzes, das ihr die Regierungsjuristen darbieten. Führen wir die Justiz als Kontrollinstanz gegen die entfesselte Legislative vor, so können wir zwar sicher sein, daß dem fixen Juristen zu jedem Legislativakt etwas Kritisches einfallen wird - zu welchem Ende aber? M.E. mit dem Ende eines Katze- und Maus-Spieles zwischen den die Legislative steuernden Regierungsjuristen und den Justizjuristen, zu einem Zustande also, den wir im Frankreich des 17. und 18. Jahrhunderts vorgebildet finden, in dem einem durch nichts beschränkten Gesetz- 
geber eine durch nichts beschränkte Justiz gegenübersteht. Die Lage einer Justiz, die eine so umfassende Kontrolle über die Legislative üben soll, wie sie die richterliche Kontrolle der $\mathrm{Maßnahmegesetzgebung} \mathrm{bedingt} \mathrm{und} \mathrm{erfordert,} \mathrm{ist} \mathrm{eine} \mathrm{grund-}$ sätzlich andere als die einer Justiz, die exekutive Funktionen zu überprüfen hat: Der Gesetzgeber ist nicht nur vom Gesetze frei, sondern auch von der theoretischen Tradition; er kann - und wird - nach Belieben neue Grundvorstellungen und Begriffe kreieren. Die Justiz mag dem entgegentreten wollen. Aber dazu muß sie ihr überkommenes Vorstellungsund Begriffsgefüge erweitern, ergänzen, auswechseln, muß - nolens volens - neue Begriffe und Vorstellungen rezipieren. So zieht die Entfesselung des Gesetzgebers eine Auflösung des axiomatischen Gefüges zumindest der praktischen Jurisprudenz nach sich - abyssus abyssum clamat - und zahlreiche Urteile, die wir lesen, zeigen uns, daß diese Entwicklung in vollem Gange ist. Hält sie an, so wird sich auch eine traditionsgefestigte theoretische Jurisprudenz ihr gegenüber nicht behaupten können - ich weiß m. a. W. nicht, wie alsdann Jura als Handwerk noch methodisch studiert und dargestellt werden sollen - Dies war einer der Gründe, um deretwillen ich mir soviel begriffliche Abstinenz in meinem Referat auferlegt und - als ersten Vollzug eines allgemeinen Grundsatzes - anempfohlen habe, dem Begriff "Maßnahmegesetz" die Aufnahme in die exakte Jurisprudenz zu verweigern: ich fürchte, daß mit der Einsetzung der Justiz als Kontrolleurin der zur Administrationsleitung denaturierten Legislative das juristische Denken und die juristische Begrifflichkeit ihre Handwerksmäßigkeit, Elernbarkeit und damit ihre Sicherheit und Präzision einbüßen.

Ich habe zunächst dem Bedürfnis nachgegeben, die Identität der düsteren Aspekte klarzustellen, die ich mit Herrn Forsthoff teile. Ich sehe mich auch einig mit ihm hinsichtlich der Aushilfen. Ich habe mir Ihren Satz gemerkt: Die Zuversicht muß man auf formale Aushilfen setzen.

Dies ist nun - ich darf damit zugleich zu dem Beitrag Scheuner überleiten - ein Grundgesetz neuzeitlichen Rechtsdenkens. Es gibt nicht mehr - wie im mittelalterlichen und noch im absoluten Staate - die Bindung der Souveränitätsakte an Natur- und göttliches Recht als Prinzip; wir haben an seiner Stelle die - wie Herr Forsthoff sagte und wie ich bekräftigen möchte - die Teilung von Normsetzung und Normanwendung. Eben dies aber droht - und jegliches sonstige Minimum an formaler Axiomatik dazu - verloren zu gehen, droht uns in einen vorneuzeitlichen und nun aber völlig bin- 
dungslosen Gewaltenmonismus zurückzustürzen, wenn wir die Justiz mit der umfassenden Gesetzgebungskontrolle überfordern und sie damit des Haltes in Theorie und Tradition berauben. Gerade weil ich die Zuversicht allein noch in formalen Aushilfen und allein noch in der Verwendung solcher formaler Aushilfen durch die Justiz sehen kann, spreche ich mich gegen ihre Maßnahmekontrollkompetenz gegenüber dem Gesetzgeber aus.

$\mathrm{DaB}$ man vor anderen Fragen steht, wenn man den Fall setzt, daß eine Norm der Verf as sung sich als Maßnahmenorm erweist, versteht sich. Ich neige dazu, daran festzuhaiten, da $B$ die verfassunggebende Gewalt die Natura naturans der Staatsordnung ist, und daß darum ihre Maßnahmekompetenz jedenfalls anders zu beurteilen ist als die des einfachen Gesetzgebers. Aber ich gestehe $\mathrm{zu}$, daß hier so viele allgemeine rechts- und ideengeschichtliche und auch ideologische Faktoren zu erörtern wären, daß ich diese Ihre Frage, Herr Professor Herrfahrdt, hier nur flüchtig berühren kann.

Einzuräumen habe ich Herrn Professor Merk, daß zwischen Wert und Zweck unterschieden werden müsse. Nicht jeder Zweck ist "Wert" im Verständnis unserer Wertabwägung. Indessen: was hülfe es dem Wert, kein Zweck zu sein? Unter dem Gesichtspunkt und für die Phase seiner Verwirklichung muß er Zweck werden - innerhalb dieser Begrenzung dürften diese beiden Begriffe auswechselbar sein. -

Hiermit bitte ich schließen zu dürfen; ich danke sehr herzlich für alle Anregung.

\section{Menge r - Speyer (Schlußwort):}

Meine sehr verehrten Herren Kollegen, die Diskussion hat eine solche Fülle von Anregungen gebracht, daß ich nun das Gefühl habe, als Berichterstatter der Beschenkte zu sein. Aber eben wegen der großen Zahl der dabei hervorgetretenen Gesichtspunkte wird es mir in einem kurzen SchluBwort nicht möglich sein, auf alles Gesagte einzugehen.

Erlauben Sie mir, zunächst einige Mißverständnisse aufzuklären, die wahrscheinlich auf mein zu leises Sprechen zurückzuführen sind. Ich glaube, Herr Kollege Scheuner hat mich mißverstanden, als er meinte, ich mißbilligte die Forderung, Sachverhalt und Tatbestand eng zu verknüpfen. Ich wollte lediglich als reine Beschreibung eines Phänomens feststellen, da $B$ speziell das Individualgesetz, in eingeschränktem $\mathrm{Maße}$ auch das Zeitgesetz ihren Tatbestand aus einem relativ eng begrenzten Kreis von Fällen bzw. aus einem zeitlich begrenzten Bereich entnehmen; mit dieser Feststellung wollte ich 
eine Abgrenzung vom normalen Gesetz erreichen, dessen Tatbestand regelmäßig viel weiter gespannt ist. Ebenso hat mich auch Herr Kollege Merk mißverstanden. Ich habe nicht die Absicht, die Unterscheidung: Gesetz im formellen und Gesetz im materiellen Sinne aufzugeben; das, was ich in meinem Bericht anregen wollte, war lediglich, das sogenannte rein formelle Gesetz - also eine Maßnahme des Legislativorgans in der äußeren Form des Gesetzes, die kein anwendbares Recht schafft - des Namens "Gesetz" zu entkleiden, weil ich glaube, daß die überkommene Terminologie insoweit irreführend ist.

Eine grundsätzliche Frage ist, ob Abhängigkeit von einem konkreten Zweck und Orientiertheit an der Idee der Gerechtigkeit brauchbare Kriterien für die Unterscheidung zwischen Maßnahmegesetz und Norm abzugeben vermögen. Dabei darf ich in Paranthese hinzufügen, daß gegen den Terminus „Maßnahmegesetz" gewiß Bedenken geltend gemacht werden können, daß ich aber doch glaube, daß damit ein politisches Phänomen unserer Zeit in etwa deutlich gemacht wird, so daß ich es nicht für richtig hielt, von diesem mir in der Themenstellung vorgezeichneten Wort abzugehen. Ich verkenne nicht - das habe ich, glaube ich, auch mehrfach gesagt -, daß jedes heutige Gesetz einen gewollten Zweck verfolgt. Gleichwohl glaube ich nicht, daß jene Unterscheidungsmerkmale ganz unbrauchbar sind. Die Erfüllung bestimmter Zwecke durch ein Gesetz kann ausgerichtet sein auf eine höhere Vorstellung, die Vorstellung nämlich, durch die Verwirklichung der angestrebten Ziele ein nach dem Maßstabe der Gerechtigkeit geordnetes, friedliches Zusammenleben der Bürger im Geltungsbereich des Gesetzes herbeizuführen oder zu erhalten. In einem solchen Falle spreche ich von Rechtsnorm. Nur dann, wenn es sich um eine rein "technische" Regelung handelt - technisch im Sinne der Bewältigung einer konkreten Schwierigkeit mit rein situationsgebundenen Mitteln - spreche ich von Maßnahmegesetz. Schon daraus folgt, daß ich den Umfang der Maßnahmegesetzgebung rein faktisch für wesentlich geringer halte, als das in der Diskussion zum Teil angenommen worden ist. Die Wohnraumbewirtschaftung der zwanziger Jahre z. B. würde ich nicht als Maßnahmegesetzgebung ansehen. Hier stand der Gesetzgeber vor einer ungerechten Lage, gegen die er angehen mußte. Ob die einzelnen Akte dieses Gesetzgebungswerks nun durchweg dem Maßstabe der Gerechtigkeit genügen können, das mag hier dahingestellt bleiben. Ich glaube aber, daß die Gesamtkonzeption der Wohnraumbewirtschaftung nicht nur darin gesehen werden darf, nach Art der Obdachlosenpolizei einer konkreten Notlage Herr zu werden, 
die entstanden war, weil infolge des Stilliegens der Bautätigkeit während des ersten Weltkrieges Wohnraummangel bestand, der durch das Einströmen zahlreicher Menschen aus den abgetretenen Provinzen in das Reichsgebiet noch verschärft wurde. Ich bin vielmehr der Ansicht, daß dabei der höhere Gesichtspunkt obwaltete, nach einem gerechten Ausgleich zwischen den Opfern jener Entwicklung und den unbeeinträchtigt Gebliebenen zu suchen. Deshalb kann man, glaube ich, von mindestens dem Versuch des gerechten Ordnens eines Lebensbereiches sprechen und demgemäß der Wohnraumbewirtschaftungsgesetzgebung die Anerkennung als Rechtsnorm nicht versagen. Andererseits dürfen wir, wie ich meine, nicht verkennen, daß der Gesetzgeber - damals wie heute - Verwaltungsmaßnahmen in Gesetzesform traf und trifft; ich erinnere nochmals an $\S 8$ des Straffreiheitsgesetzes 1954 und an das Bundesgesetz über die Getreidepreise von 1951. In solchen Fällen kann von einem Streben des Gesetzgebers, eine gerechte Ordnung aufzurichten, wohl kaum die Rede sein.

Herr Kollege Merkl hat es für verfehlt angesehen, wenn man im Zusammenhange mit der staatlichen Gesetzgebung überhaupt den Maßstab der Gerechtigkeitsidee anlegt. Ich darf dazu nochmals unterstreichen, daß ich in meinem Referat bewußt nur auf die Rechtslage in der Bundesrepublik Deutschland abgestellt habe, schon weil ich sonst mit der Zeit nicht hätte auskommen können. Der Uberzeugung bin ich allerdings, daß unsere Rechtsordnung, speziell das Grundgesetz, davon ausgeht, daß Unrecht in Gesetzesform nicht gelten kann. Der alte Streit aus dem Anfang dieses Jahrhunderts, ob ein formal gültig zustande gekommenes Gesetz Geltung haben kann. obwohl es inhaltlich ungerecht ist, ist vom Grundgesetz entschieden und die Frage für den Geltungsbereich unserer Verfassung verneint worden. Dem Grundgesetz selbst liegt eine - sicherlich nicht ganz leicht greifbare - Gerechtigkeitsvorstellung zugrunde, die sich etwa aus dem Grundrechtskatalog und dem Bekenntnis zum sozialen Rechtsstaat erschließen läßt. Daran ist auch unsere Gesetzgebung zu messen, und deshalb kann ich auf das Kriterium der Gerechtigkeit für den $\mathrm{Zu}-$ sammenhang des heutigen Themas nicht verzichten.

Ich habe mich - wenn ich das zum Abschluß sagen darf in meinem, bewußt sehr nüchtern formulierten, Referat bemüht, den Begriff der Maßnahmegesetzgebung nicht ausufern $\mathrm{zu}$ lassen. Ich habe nicht jedes Individualgesetz und schon gar nicht jedes Zeitgesetz für ein Maßnahmegesetz erklärt, sondern lediglich gesagt, daß in diesen Fällen eine gewisse Vermutung dafür besteht, daß der Gesetzgeber damit 
einen Akt gestaltender Regierung bzw. Verwaltung vollzieht. Ich bin durchaus der Meinung, da B die "inhaltlich a-typischen" Gesetze - vielleicht sogar Einzelpersonengesetze - Rechtsnorm sein können. Ich bin aber andererseits der Meinung, daß wir nun auch nicht in uferlosem Skeptizismus die rechtsstaatliche Konzeption, innerhalb deren das Maßnahmegesetz immer ein Fremdkörper bleiben wird, überhaupt aufgeben dürfen. Denn der Rechtsstaat ist einer der Werte, auf denen unser Leben in der Bundesrepublik heute maßgeblich basiert. 